\title{
ipeen
}

AUTARQUIA ASSOCIADA À UNIVERSIDADE DE SÃO PAULO

\section{UTILIZAÇÃO DE ZEÓLITAS SINTETIZADAS A PARTIR DE CINZAS DE CARVÃO NA REMOÇÃO DE CORANTE EM ÁGUA}

\author{
MARIZA BRUNO
}

Dissertação apresentada como parte dos requisitos para obtenção do Grau de Mestre em Ciências na Área de Tecnologia Nuclear - Materiais

Orientadora:

Dra. Denise Alves Fungaro

São Paulo

2008 



\section{$((1-3))$ \\ ipen}

INSTITUTO DE PESQUISAS ENERGÉTICAS E NUCLEARES AUTARQUIA ASSOCIADA À UNIVERSIDADE DE SÃO PAULO

\section{UTILIZAÇÃO DE ZEÓLITAS SINTETIZADAS A PARTIR DE CINZẢS DE CARVÃO NA REMOÇÃO DE CORANTE EM ÁGUA}

MARIZA BRUNO

Dissertação apresentada como parte dos requisitos para obtenção do Grau de Mestre em Ciências na Área de Tecnologia Nuclear - Materiais

Orientadora:

Dra. Denise Alves Fungaro

São Paulo

2008 


\section{DEDICATÓRIA}

Dedicar é mais do que agradecer. ̀̀ dizer para uma pessoa o quanto ela foi especial durante o período que passamos juntas $e$ o afeto $e$ a amizade que ela nos deu. Suas palavras sempre foram as melhores possíveis.Para mim, vocês valem muito mais que Ouro, valem Platina.

Ivan Santos: você virou parente. Sabe aquele primo que é ao mesmo tempo um grande amigo e que divide tudo com a gente? Você é assim.

Afonso Rodrigues de Aquino: quero ser sua aluna e amiga eternamente.

Denise Alves Fungaro, minha orientadora e amiga. Um presente de Natal que chegou atrasado e que só me deu alegrias.

Com carinho

MARIZA 


\section{AGRADECIMENTOS}

Agradecer é o ato de reconhecer o que uma pessoa fêz ou faz por nós. Seja um mínimo gesto ou uma atitude grandiosa.

Em primeiro lugar, a DEUS por ter me dado saúde, luz e equilíbrio para seguir na minha caminhada.

À Carbonífera do Cambuí por ter nos cedido as amostras.

Ao CNPq pelo incentivo financeiro, através da bolsa de estudos.

À minha família que sempre se faz presente em todos os momentos: meu falecido pai, Antonio Bruno, que estaria presente neste dia com muita alegria e orgulho; minha mãe Victória, meus irmãos Rosa e Roberto, meus cunhados e os meus sobrinhos que já cresceram, dois estão casados e um é o pai do João Pedro, uma criança linda. Seja bem vindo! E os meus primos queridos.

Aos amigos que caminharam comigo ao longo da vida, estudando no Colégio "Brasílio Machado" na Faculdade "Oswaldo Cruz", na Faculdade de Saúde Pública da USP: Tatá, Padula, Wagner, Paulo, Maria Pedrina, Reginaldo, Valmir, Fatiminha e Lobão, Rosinha e Serginho, Cláudia, Roberta, Valéria, Vera, Hilda, Cíntia e toda galera que me falta á memória.

Àqueles que ao longo de mais de 20 anos dividiram comigo as tarefas na CEF com dedicação e profissionalismo. Às vezes, as pessoas perdem o contato devido ao dia a dia que nos impede de estarmos sempre juntos, o que não quer dizer que esse laço tenha se perdido e nem se rompido. Apenas, nos afasta: Claudenete, Miriam, Villanova, Cláudio, Ana Maria, Cida, Elizabete Prado, Kátia...

Aos que cuidam da nossa saúde com dedicação, atenção e preocupação: Muito Obrigada. Divido esta alegria com vocês.

Aos professores: Fausto, Lembo e Haroldo do curso Anglo-latino que me fizeram perder o medo da Química, a ponto de tomar a decisão de cursar uma faculdade de Química.

Aos professores da FOC: Thaís Vitória, Victor Nehmi, Nereu e Tereza que sempre se mostraram altamente conhecedores de sua tarefa e me ensinaram muito do que sei hoje.

Aos professores da Faculdade de Saúde Pública que me deram os primeiros princípios de meio ambiente e preservação.

À doutora Sueli Ivone Borrely, minha primeira orientadora. 
À doutora Denise Alves Fungaro que me orientou durante esta dissertação de mestrado com muito profissionalismo.

Aos colegas e professores do IPEN: Ivan, Afonso, Elaine, Wagner, Mai, Dionísio, André Luis, Guilherme, Hélio, Elide, Juliana, Lucas, José Eduardo, Roseli, Celso, Rita, Elaine, Penha, Sílvia, Ivanildo, Claudia, Ricardo, Francisco Carlos, Luciana.

Aos funcionários do IPEN, pela atenção no atendimento.

Aos amigos que estão sempre comigo nas horas de samba e festa e também no dia a dia, torcendo pelo meu sucesso e realização: Maria da Penha, uma segunda mãe; Maria Odécia, Verona, Wagner, André, Leandro, Vanessa, Gláucia, Claudinei, Laura, Guaraci, Regina, Betinha, Marlene, Paula, Eduardo, Fernando, Eulália, Silvana, Regina. Vocês são verdadeiras testemunhas da minha vida.

Vocês representam muito para mim. São o maior patrimônio que alguém possa ter: a verdadeira amizade. 


\title{
UTILIZAÇÃo DE ZEÓLITAS SINTETIZADAS A PARTIR DE CINZAS LEVES DE CARVÃO NA REMOÇÃO DE CORANTE EM ÁGUA
}

\author{
Mariza Bruno
}

\section{RESUMO}

Os experimentos de adsorção descontínuos foram realizados para remover azul de metileno de solução aquosa usando zeólitas sintetizadas a partir de cinza leve de carvão como adsorvente. Os estudos foram conduzidos para avaliar os efeitos do tempo de contato, concentração inicial do corante, parâmetros de ativação hidrotérmica, composição da cinza leve, quantidade do adsorvente, $\mathrm{pH}$ e temperatura sobre a adsorção.

Um tempo de contato de aproximadamente 10 minutos foi suficiente para a adsorção do corante alcançar o equilíbrio. Os dados de equilíbrio foram analisados usando as isotermas de Langmuir e Freundlich e os resultados se ajustaram melhor à equação da isoterma de Freundlich. A eficiência de adsorção estava entre 72 a 98\% sob as condições estudadas. $\mathrm{O}$ valor da constante de Freundlich para a capacidade de adsorção $\left(\mathrm{K}_{\mathrm{F}}\right)$ do azul de metileno no adsorvente foi $0,738(\mathrm{mg} / \mathrm{g})(\mathrm{L} / \mathrm{mg})^{1 / \mathrm{n}}$.

Os dados de adsorção foram ajustados aos modelos cinéticos de pseudoprimeira-ordem de Lagergren e pseudo-segunda-ordem e seguiram as cinéticas de pseudosegunda-ordem. As constantes de velocidade foram estimadas em diferentes concentrações iniciais. O mecanismo do processo de adsorção encontrado mostrou-se complexo, consistindo de adsorção superficial e difusão intrapartícula. Os parâmetros termodinâmicos foram avaliados indicando que o processo de adsorção do azul de metileno sobre a zeólita é espontâneo e exotérmico. 


\title{
UTILIZATION OF ZEOLITES SYNTHETIZED FROM FLY ASH ON THE REMOVAL OF DYE FROM AQUEOUS SOULTION
}

\author{
Mariza Bruno
}

\begin{abstract}
Batch sorption experiments were carried out to remove methylene blue from its aqueous solutions using zeolites synthesized from coal fly ash as an adsorbent. The studies were conducted to evaluate the effects of contact time, initial dye concentration, hydrothermal activation parameters, composition of fly ash, quantity of adsorbent, $\mathrm{pH}$ and temperature on adsorption. Nearly $10 \mathrm{~min}$ of contact time are found to be sufficient for the adsorption of dye to reach equilibrium. Equilibrium data have been analyzed using Langmuir and Freundlich isotherms and the results were found to be well represented by the Freundlich isotherm equation. The adsorption efficiency was between 72 and $98 \%$ under the conditions studied. The value of the Freundlich constant for adsorption capacity $\left(\mathrm{K}_{\mathrm{F}}\right)$ of methylene blue on the adsorbent was $0.738(\mathrm{mg} / \mathrm{g})(\mathrm{L} / \mathrm{mg})^{1 / \mathrm{n}}$.

Adsorption data were fitted to both Lagergren first-order and pseudo-secondorder kinetic models and the data were found to follow pseudo-second-order kinetics. Rate constants at different initial concentrations were estimated. The adsorption process mechanism was found to be complex, consisting of both surface adsorption and intraparticle diffusion. Thermodynamic parameters were evaluated indicating that adsorption process for methylene blue onto zeolite is spontaneous and exothermic.
\end{abstract}




\section{SUMÁRIO}

1. INTRODUÇÃO 15

$\begin{array}{lr}\text { 2.OBJETIVOS } & 18\end{array}$

2.1.Objetivos específicos 18

3. REVISÃO DA LITERATURA

3.1. Corantes utilizados na indústria têxtil 20

3.2. Tipos de tratamentos de efluente têxtil 21

3.2.1. Tratamento físico químico 22

3.2.2. Tratamento biológico 25

3.2.3. Tratamentos combinados 25

3.3. Processo de Adsorção 26

3.4. Zeólitas sintetizadas a partir de cinzas de carvão 28

3.4.1. Cinzas de carvão 28

3.4.2. Zeólitas 29

3.4.3. Síntese Hidrotérmica 31

3.5. Adsorção de Azul de Metileno sobre cinzas de carvão e zeólitas 34

3.5.1. Azul de Metileno 34

3.5.2. Adsorventes de Baixo Custo 36

3.6. Modelagem de Adsorção 37

3.6.1. Modelos Cinéticos 37

3.6.1.1. Modelo de pseudo-primeira-ordem de Lagergren 39

3.6.1.2. Modelo de peseudo-segunda-ordem de Ho e Mckay 39

3.6.1.3. Modelo de Difusão Intrapartícula 40

3.6.2. Isotermas de Adsorção 40

3.6.3. Termodinâmica de Adsorção 44

4. MATERIAIS E MÉTODOS 46

4.1. Área de Estudo 46

4.2. Amostras de cinzas de carvão 48

4.3. Reagentes e Soluções 48

4.4. Preparação das zeólitas por síntese hidrotérmica 48

4.5. Estudos sobre a remoção do corante 48

5. RESULTADOS E DISCUSSÃO 50 
5.1. Caracterização Química das cinzas de carvão

5.2. Estudo da Influência das amostras de cinzas de carvão 52

5.2.1. Efeito do tempo de contato

5.2.2. Modelos Cinéticos de Adsorção 54

5.2.3. Isotermas de Adsorção

5.3. Estudo da influência dos parâmetros de ativação na síntese das zeólitas $\quad 68$

5.3.1. Efeito do tempo de contato

5.3.2. Modelos Cinéticos de Adsorção 73

$\begin{array}{ll}\text { 5.3.3. Isotermas de Adsorção } & 75\end{array}$

5.3.4. Influência do $\mathrm{pH}$ inicial $\quad 79$

5.3.5. Influência da dose de zeólita 80

5.3.6. Influência da temperatura 81

5.3.7. Análise espectrofotométrica da degradação do azul de metileno comparada $\begin{array}{ll}\text { a um padrão permitido } & 83\end{array}$

6. CONCLUSÕES

$\begin{array}{ll}\text { APÊNDICES } & 87\end{array}$

Apêndice A - Massa Específica e Área Superficial Específica das Zeólitas

$\begin{array}{ll}\text { Sintetizadas a partir de cinzas de carvão } & 88\end{array}$

Apêndice B - Capacidade de Troca Iônica (CTC) das zeólitas sintetizadas a

Partir de cinzas de carvão $\quad 89$

Apêndice C - Microfotografias das zeólitas sintetizadas a partir de cinzas de $\begin{array}{ll}\text { de carvão por microscopia } & 90\end{array}$

Apêndice D - Difratogramas das zeólitas sintetizadas a partir de cinzas de Carvão: (a) ZM5, (b)Z1, (c) Q = quartzo, (d) M = Mulita. $\quad 91$

REFERÊNCIAS BIBLIOGRÁFICAS 92 


\section{LISTA DE TABELAS}

TABELA 1 - Relação entre o valor de $\mathrm{R}_{\mathrm{L}}$ e o processo de adsorção.

TABELA 2 - Valores característicos de variação de entalpia $\left(\Delta \mathrm{H}^{0}\right)$, de entropia $\left(\Delta \mathrm{S}^{0}\right)$ e de energia livre de Gibbs $\left(\Delta \mathrm{G}^{0}\right)$ para processos de adsorção espontâneos e não-espontâneos (Shaw, 1975).

TABELA 3 - Composição química das cinzas de carvão de diferentes amostragens

TABELA 4 - Concentrações dos elementos traço das cinzas de carvão de diferentes amostragens

TABELA 5 - Parâmetros cinéticos para a remoção do azul de metileno pela zeólita ZM1

TABELA 6 - Parâmetros cinéticos para a remoção do azul de metileno pela zeólita ZM2

TABELA 7 - Parâmetros cinéticos para a remoção do azul de metileno pela zeólita ZM3

TABELA 8 - Parâmetros cinéticos para a remoção do azul de metileno pela zeólita ZM4

TABELA 9 - Parâmetros cinéticos para a remoção do azul de metileno pela zeólita ZM5

TABELA 10 - Parâmetros dos modelos de Freundlich para azul de metileno com as zeólitas.

TABELA 11 - Condições experimentais para a síntese dos produtos zeolíticos a partir da cinza de carvão.

TABELA 12 - Capacidades de adsorção do azul de metileno com as zeólitas obtidas com diferentes condições de tratamento hidrotérmico.

TABELA 13 - Parâmetros cinéticos para a remoção do azul de metileno pela zeólita Z1

TABELA 14 - Parâmetros dos modelos de Freundlich para azul de metileno com a zeólita $\mathrm{Z1}$.

TABELA 15 - Comparação da capacidade de adsorção (segundo Freundlich) do azul de metileno em vários adsorventes. 
TABELA 16 - Parâmetros cinéticos da adsorção do azul de metileno sobre a zeólita Z1 em diferentes temperaturas.

TABELA 17 - Parâmetros termodinâmicos para a adsorção do azul de metileno sobre a zeólita Z1 em diferentes temperaturas. 


\section{LISTA DE FIGURAS}

FIGURA 1 - Estrutura molecular do azul de metileno

FIGURA 2 - Isotermas de Adsorção (McCabe et al., 1993).

FIGURA 3 - Localização da Usina Termelétrica de Figueira - PR

FIGURA 4 - Efeito do tempo de agitação e da concentração do azul de metileno sobre a capacidade de adsorção das zeólitas ZM1 a ZM5.

FIGURA 5 - Comparação dos modelos cinéticos da adsorção do azul de metileno sobre ZM1: (a) cinética de pseudo-primeira-ordem; (b) cinética de pseudo-segunda-ordem; (c) difusão intrapartícula.

FIGURA 6 - Comparação dos modelos cinéticos da adsorção do azul de metileno sobre ZM2: (a) cinética de pseudo-primeira-ordem; (b) cinética de pseudo-segunda-ordem; (c) difusão intrapartícula.

FIGURA 7 - Comparação dos modelos cinéticos da adsorção do azul de metileno sobre ZM3: (a) cinética de pseudo-primeira-ordem; (b) cinética de pseudo-segunda-ordem; (c) difusão intrapartícula.

FIGURA 8 - Comparação dos modelos cinéticos da adsorção do azul de metileno sobre ZM4: (a) cinética de pseudo-primeira-ordem; (b) cinética de pseudo-segunda-ordem; (c) difusão intrapartícula.

FIGURA 9 - Comparação dos modelos cinéticos da adsorção do azul de metileno sobre ZM5: (a) cinética de pseudo-primeira-ordem; (b) cinética de pseudo-segunda-ordem; (c) difusão intrapartícula.

FIGURA 10 - Isotermas de adsorção do azul de metileno com diferentes zeólitas. 
FIGURA 11 - Isotermas de Freundlich para adsorção do azul de metileno com diferentes zeólitas.

FIGURA 12 - Efeito do tempo de agitação e da concentração do azul de metileno sobre a capacidade de adsorção da zeólita Z1.

FIGURA 13 - Comparação dos modelos cinéticos da adsorção do azul de metileno sobre ZM1: (a) cinética de pseudo-primeira-ordem; (b) cinética de pseudo-segunda-ordem; (c) difusão intrapartícula.

FIGURA 14 - Isoterma de adsorção da zeólita Z1 para o azul de metileno.

FIGURA 15 - Isoterma de Freundlich para adsorção do azul de metileno com zeólita Z1.

FIGURA 16 - Influência do pH na adsorção do azul de metileno na zeólita Z1.

FIGURA 17 - Influência da dose de zeólita Z1na adsorção do azul de metileno.

FIGURA 18 - Efeito da temperatura na dinâmica de adsorção do azul de metileno sobre zeólita Z1.

FIGURA 19 - Análise espectrofotométrica da degradação do azul de metileno após tratamento com zeólita Z1 comparada a um padrão definido. 


\section{LISTA DE EQUAÇÕES E FÓRMULAS}

$\mathrm{M}^{\mathrm{n}+} \mathrm{x} / \mathrm{n}\left[\left(\mathrm{AlO}_{2}\right) \mathrm{x}\left(\mathrm{SiO}_{2}\right) \mathrm{y}\right] \cdot \mathrm{m} \mathrm{H}_{2} \mathrm{O}$

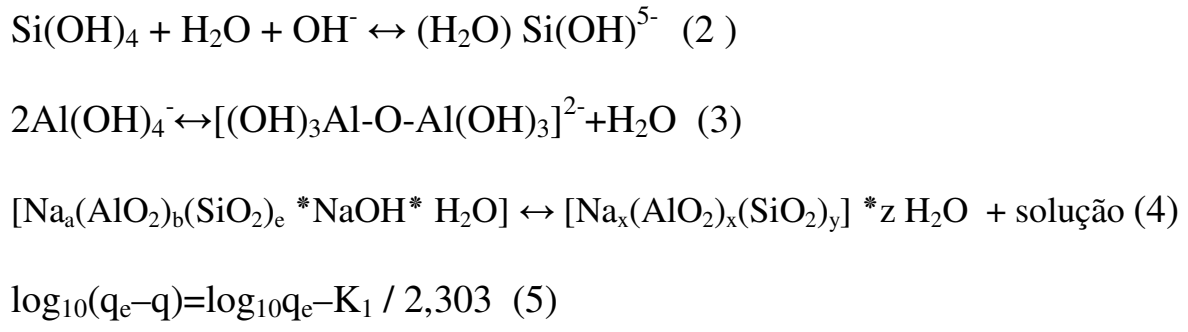

$\log \mathrm{q}_{\mathrm{e}}=\log \mathrm{K}_{\mathrm{f}}+\frac{1}{n} \log C_{e}$

$\mathrm{K}=\frac{C_{A}}{C_{s}}$

$\Delta \mathrm{G}^{\mathrm{o}}=-2,303 R T \log \mathrm{K}_{\mathrm{c}}(15)$

$\Delta \mathrm{H}^{\mathrm{o}}=2,303 \mathrm{R}\left(\frac{T_{1} T_{2}}{T_{2}-T_{1}}\right) \log \frac{K_{C_{2}}}{K c_{1}}$

$\Delta \mathrm{S}^{\mathrm{o}}=\frac{\Delta H^{o}-\Delta G^{o}}{T}$

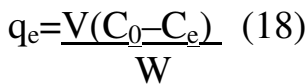




\section{INTRODUÇÃO}

Algumas usinas termelétricas utilizam a queima de carvão para gerar energia elétrica e como em todos os processos de produção geram resíduos, no caso, sólidos: cinzas de carvão. De acordo com a granulometria, as cinzas são carreadas para uma parte do queimador. As cinzas que caem na base da chaminé são consideradas pesadas, devido ao tamanho dos seus grãos (granulometria $>100 \mu \mathrm{m}$ ). As cinzas de grãos menores são consideradas cinzas leves (granulometria compreendida entre 0,01 a $100 \mu \mathrm{m}$ ) e são arrastadas pelos gases através do queimador, sendo uma parte delas retida no filtro ciclone e as partículas ainda menores pelo filtro manga. Durante o processo de queima do carvão $80 \%$ das cinzas geradas são leves.

A forma de disposição e acumulação destas cinzas se dá numa decisão puramente econômica, sem considerar as relações com o meio ambiente, sendo dispostas de forma inadequada dentro do perímetro urbano e nas zonas rurais. A disposição das cinzas em aterros oferece perigos potenciais aos mananciais hídricos, pois contaminam as águas superficiais e subterrâneas.

Anualmente, mais de 3,5 milhões de toneladas de carvão são usadas no Brasil em usinas termelétricas, o que faz com que a quantidade de cinzas geradas chegue a 1,7 milhões de toneladas. Como é previsto um aumento de mais de $100 \%$ no consumo de carvão até 2010, a geração de cinzas deverá atingir 4 milhões de toneladas por ano.

As principais aplicações das cinzas são na fabricação e incorporação ao cimento e uso como material fertilizante, mas isto ainda ocorre em pequena escala ( 30\%). O pequeno consumo das cinzas de carvão na indústria de cimento e como fertilizante é inevitável devido á combinação de alto custo de transporte com um produto de valor relativamente baixo no mercado. Uma das maneiras de reduzir os impactos ambientais decorrentes da disposição destes resíduos no meio ambiente consiste na ampliação das potencialidades de sua utilização. Uma alternativa de aproveitamento destes resíduos é a transformação das cinzas de carvão em um adsorvente de baixo custo. As cinzas de carvão mineral são constituídas basicamente de sílica e alumina, sendo possível convertê-las em material zeolítico após tratamento hidrotérmico em meio alcalino. O material zeolítico é caracterizado por alta capacidade de troca catiônica e boa adsorção possibilitando inúmeras aplicações potenciais. A sintetização da zeólita a partir das cinzas leves de carvão é uma 
tecnologia que oferece consideráveis vantagens em termos econômicos, técnicos e de desempenho ambiental. A saber:

(1) A zeólita é sintetizada a partir da reciclagem de resíduo abundante e poluente;

(2) O reagente usado na síntese é de baixo custo e pode ser reaproveitado;

(3) A zeólita após uso pode ser regenerada;

(4) Os poluentes removidos da água podem ser recuperados com soluções regenerantes;

(5) A estrutura da zeólita confere seletividade de moléculas por tamanho, forma e carga;

(6) Além da utilização do material zeolítico em processo de leito móvel o adsorvente poderá ser empregado em processos de leito fixo; como barreira permeável reativa; no polimento de efluente de outro sistema passivo; colocado dentro de sacos permeáveis que podem ser removidos após o tratamento;

(7) A zeólita apresenta estabilidade térmica e resistência à radiação ionizante;

(8) A utilização da zeólita sintetizada a partir da cinza leve de carvão tem um amplo mercado, podendo substituir as zeólitas naturais e as resinas trocadoras comerciais, dado que o custo de produção é de 25 a $30 \%$ mais baixo do que a zeólita comercial e apresenta o mesmo preço de venda da zeólita natural;

(9) A exploração dos depósitos de zeólitas naturais causa impacto ambiental;

(10) A mitigação dos impactos ambientais e dos prejuízos à saúde humana causados pela atividade de usinas termelétricas a carvão;

(11) Os efluentes líquidos gerados na usina e o solo contaminado ao redor poderão ser tratados com zeólita;

(12) As zeólitas sintetizadas a partir das cinzas leves de carvão representam uma contribuição ao sistema de gestão ambiental da usina termelétrica;

(13) A geração de empregos pela implantação da produção de zeólita junto à usina e a posterior comercialização.

O Centro de Química e Meio Ambiente do Instituto de Pesquisas Energéticas e Nucleares vem contribuindo com a gestão ambiental da Usina Termelétrica de Figueira, localizada no Paraná, desde 1996 com diferentes projetos de pesquisas enfocando: (a) avaliação de elementos poluidores do carvão, das cinzas, do solo, das águas de chuva e águas subterrâneas; (b) estudos sobre a reciclagem das cinzas de carvão.

Por outro lado, a indústria têxtil desempenha um papel importante na economia do Brasil, se destacando entre os 8 setores mais importantes da atividade industrial. $\mathrm{O}$ grande centro têxtil do Brasil se concentra nas regiões Sul e Sudeste com cerca de $80 \%$ das 
indústrias instaladas, destacando-se o Estado de São Paulo, onde se situa cerca de $30 \%$ desse parque industrial, conforme diagnóstico realizado pelo Ministério do Desenvolvimento, Indústria e Comércio Exterior - MDICE (2006).

Do ponto de vista ambiental, a remoção da cor dos efluentes é um dos grandes problemas enfrentados pelo setor têxtil. Em face deste panorama, a adsorção pode se constituir numa alternativa tecnológica extremamente importante, principalmente pela possibilidade do uso de adsorventes de baixo custo em processos de controle da poluição, visando além do abatimento da carga poluidora, a remoção de cor dos efluentes.

Este estudo poderá contribuir com os sistemas de gestão ambiental, tanto do setor têxtil quanto de usinas termelétricas por meio da simbiose industrial, de tal forma que: as cinzas de carvão, um resíduo sólido poluidor de grande impacto ambiental, serão transformadas em um produto que poderá ser aplicado no tratamento de efluente têxtil. 


\section{OBJETIVOS}

O objetivo geral deste projeto foi contribuir com a gestão ambiental de usinas termelétricas realizando o estudo da transformação das cinzas de carvão, um resíduo sólido poluidor de grande impacto ambiental, em um produto de alto valor agregado.

\subsection{Objetivos específicos}

1. Sintetizar as zeólitas a partir de amostragens de tipos de cinzas de carvão geradas na Usina Termelétrica de Figueira. Verificar a influência da composição química das cinzas de carvão no processo de zeolitização.

2. Sintetizar as zeólitas com a mesma matéria-prima e diferentes parâmetros de tratamento hidrotérmico.

3. Estudar os principais parâmetros do processo de adsorção de corante usando as zeólitas sintetizadas: cinética, isoterma de equilíbrio e capacidade máxima de adsorção; dose do adsorvente; $\mathrm{pH}$ e temperatura.

4. Avaliação da eficiência das zeólitas de cinzas de carvão como material adsorvente de baixo custo na remoção de corante. 


\section{REVISÃO DA LITERATURA}

A origem dos corantes têxteis é incerta, mas há indicações de seu uso pelo homem desde os primórdios das civilizações. No Egito, muitos dos tecidos encontrados em múmias eram coloridos. No Brasil, desde seu descobrimento, sua história tem estado relacionada à produção de corantes. A começar pelo seu nome, uma vez que este é proveniente da madeira "Pau Brasil", da qual era extraído um pigmento capaz de tingir tecidos com cores fortes, como vermelho, rosa ou marrom.

Segundo Conchon (1999), a indústria têxtil desempenha um papel importante na economia de muitos países. No Brasil, esta indústria se destaca entre os oito setores mais importantes da atividade industrial, ocupando os primeiros lugares em empregos diretos e em faturamento.

Atualmente, aproximadamente 10.000 corantes são produzidos em escala industrial. Destes, cerca de 2.000 encontram-se disponíveis para a indústria têxtil. No Brasil, das aproximadamente 20 t/ano de corantes consumidos pela indústria têxtil, cerca de $20 \%$ são descartados como efluentes. A principal fonte desta perda corresponde à fixação incompleta dos corantes à fibra durante o processo de tingimento (Weber et al., 1993; Acântora e Daltin, 1996; Guaratini e Zanoni, 2000; Zanoni e Carneiro, 2001).

Do ponto de vista ambiental, a remoção da cor dos efluentes é um dos grandes problemas enfrentados pelo setor têxtil. Embora as diferenças tecnológicas entre as pequenas e grandes indústrias sejam bastante significativas, todas têm em comum a particularidade de utilizar grandes quantidades de água. Este fato, associado ao baixo aproveitamento dos insumos (corantes, detergentes, engomantes, amaciantes, etc.), faz com que a indústria têxtil seja responsável pela geração de grandes volumes de resíduos, com elevada carga orgânica e forte coloração (Kunz et al., 2002). O potencial poluidor de uma indústria têxtil de pequeno/médio porte equivale ao volume de resíduos gerados por aproximadamente 7.000 pessoas ou, ainda, ao de 20.000 pessoas considerando-se o teor de material orgânico (Moraes et al., 2000).

Os corantes, mesmo presentes em pequenas quantidades, são visualmente detectáveis e causam sérios problemas de natureza estética nos corpos d'água receptores. Além dos efeitos estéticos, a maioria dos corantes comercialmente usados é resistente à biodegradação, à fotodegradação e à ação de agentes oxidantes (Houk, 1992; Knapp et al., 1997; Kapdan et al., 2000; Zanoni e Carneiro, 2001; Bertazzoli e Pelegrini, 2002). Outros 
problemas causados comumente pelos corantes são: afetam significativamente a atividade fotossintética pela redução da penetração da luz solar, podem ser tóxicos a certas formas da vida aquática devido à presença de metais substituintes e cloreto, alguns são carcinogênicos e mutagênicos (azocorantes) (Nam et al., 2001) e a interferência em certos tratamentos operacionais de água residuária municipal como a desinfecção ultravioleta e o sistema de lodos ativados. É importante ressaltar que os azocorantes representam cerca de $60 \%$ dos corantes atualmente utilizados no mundo.

\subsection{Corantes utilizados na indústria têxtil}

No processo de tingimento de tecidos, utilizam-se vários corantes, que são compostos de moléculas que compreendem dois componentes-chave: o grupo cromóforo, responsável pela cor e o grupo funcional, que se liga às fibras do tecido. Existem centenas de corantes conhecidos na literatura, que são classificados por sua natureza química ou em termos de sua aplicação ao tipo de fibra.

Deve-se caracterizar a diferença entre corantes e pigmentos. Os pigmentos são caracterizados por serem praticamente insolúveis no meio no qual são aplicados. Os corantes são aplicados em vários substratos (materiais têxteis, papel, couro, etc.) e são provenientes de um líquido, onde são completamente ou parcialmente solúveis (Zollinger, 1991).

Os corantes têxteis são classificados nas categorias:

a) Corantes básicos: Também conhecidos como corantes catiônicos. São solúveis em água. Os corantes básicos dividem-se em diversas classes químicas, azo, antraquinona, triarilmetano, triazina, oxima, acridina e quinolina (Trotman, 1975).

b) Corantes ácidos: São também chamados de corantes aniônicos. Muitos dos corantes ácidos são sais de ácido sulfônico. Quimicamente, os corantes ácidos são classificados em azo, antraquinona, trimetilmetano, xanteno, nitro, quinolina e ftalocianina (Trotman, 1975).

c) Corantes diretos: Também chamados de corantes substantivos. São corantes aniônicos solúveis em água e diferem dos corantes ácidos e básicos por apresentarem alta afinidade por fibras celulósicas. A maioria é representada por azo-compostos, similares a constituição dos corantes ácidos, não existindo uma clara delimitação entre as duas classes (Trotman, 1975). São aplicados em fibras celulósicas, viscose e polinósica. 
d) Mordentes: Neste grupo estão incluídos muitos corantes naturais e sintéticos. O corante mordente se liga à fibra têxtil por meio de um mordente, que pode ser uma substância orgânica ou inorgânica. O mordente inorgânico mais comumente utilizado é o cromo, na forma de óxido de cromo. O mordente orgânico é o ácido tânico. São aplicados no tingimento de fibras celulósicas, protéicas e poliamida (Trotman, 1975).

e) Corantes ao enxofre: São corantes cuja característica principal é a presença de enxofre na molécula. São insolúveis em água, mas se dissolvem numa solução de sulfito de sódio ou hidrossulfito de sódio que atua como um agente redutor (Trotman, 1975).

f) Corantes de cuba: São corantes insolúveis em água e podem ser convertidos em compostos leuco-solúveis por ação de um meio alcalino $(\mathrm{NaOH})$ e agente redutor, como o hidrossulfito de sódio. Esses corantes têm afinidade com a celulose, são absorvidos pela fibra e subsequentemente oxidados em presença de ar, em um pigmento insolúvel no interior da fibra (Trotman, 1975).

g) Corantes azóicos: São obtidos no interior das fibras, no momento da reação de tingimento, a partir da aplicação de dois componentes, um de cada vez: naftol e uma base. Esses corantes podem ser aplicados em fibras celulósicas, seda, viscose e poliamida (Trotman, 1975).

h) Corantes dispersos: São denominados corantes não-iônicos. São suspensões de compostos orgânicos finamente insolúveis em água. São aplicados em fibras sintéticas, como poliéster, nylon, diacetato de celulose e fibras acrílicas.

i) Corantes reativos: São compostos que contêm um ou mais grupos reativos capazes de formar ligações covalentes com um átomo de oxigênio, nitrogênio ou enxofre, de substratos como fibras celulósicas, fibras protêicas e poliamidas (Trotman, 1975).

\subsection{Tipos de tratamento de efluentes da indústria têxtil}

Ainda não existe um método geral para a descoloração de efluentes aquosos da indústria têxtil. A maior parte dessas indústrias realiza processos de tratamentos fundamentados na operação de precipitação-coagulação, seguida de oxidação biológica, principalmente lodos ativados. 
Os métodos mais utilizados para o tratamento de efluentes contendo corantes podem ser agrupados nas três categorias: químicos, físicos e biológicos. A utilização destes métodos combinados também é possível. A seguir alguns são descritos.

\subsubsection{Métodos físico-químicos}

Nas águas de despejo têxtil, particularmente de empresas que utilizam algodão, emprega-se o processo que consiste em duas etapas básicas: a coagulação e a floculação (Nunes, 1993). O tratamento preliminar consiste na remoção de materiais sólidos grosseiros, como restos de tecidos e fibras, bem como a equalização dos despejos dos diferentes processos de beneficiamento com correção de $\mathrm{pH}$ e de temperatura. O processo de coagulação consiste na mistura do coagulante com o efluente, o qual provoca a hidrolização e a polimerização.

Em meio alcalino, formam-se hidróxidos que produzem na solução íons positivos, em reação extremamente rápida. Estes íons desestabilizam as cargas negativas dos colóides e sólidos em suspensão, permitindo a aglomeração das partículas e a conseqüente formação dos coágulos. $\mathrm{Na}$ etapa da floculação, conhecida como mistura lenta, os coágulos tornam-se mais densos e estáveis formando os flóculos, facilitando a sua sedimentação formando uma mistura de duas fases. Na primeira fase, o efluente tratado após filtração pode ser re-circulado no processo industrial. A outra fase formada pelo lodo decantado é encaminhada para secagem a fim de receber o destino final adequado.

O processo de flotação consiste na adição de sulfato de alumínio em solução de $10 \%$, coadjuvado por um polieletrólito e ar. Forma-se um sistema com três fases: na parte superior obtêm-se uma camada consistente de espuma, na fase intermediária, uma camada de produto químico coagulado e na parte inferior, a água tratada. A adição de ar tem várias funções, tais como: o floco, ao ser formado, se associa a uma ou menores bolhas, permitindo sua rápida ascensão à superfície; promove a formação de espuma consistente e abundante, contribuindo desta forma para a remoção de tensoativos e supre a deficiência de oxigênio dissolvido, elevando-se de praticamente zero a valores próximos de $3 \mathrm{mg} / \mathrm{L}$. $\mathrm{Na}$ câmara de flotação, ocorre um sistema de forças que tem a principal componente dirigida para a saída do equipamento obtendo-se a auto-eliminação de sobrenadantes e com isto evita-se a deposição de flocos no fundo da estação e gasto de energia para o deslocamento do lodo e da espuma (Nunes, 1993).

O princípio da osmose reversa consiste em aplicar uma força bem superior à pressão osmótica no compartimento da solução concentrada, o qual em função da inversão 
do fluxo devido à pressão exercida força-se a passagem do solvente por uma membrana, retendo o soluto. Entretanto, apresentam algumas limitações que devem ser consideradas para o seu uso destacando-se: sólidos em suspensão que saturam rapidamente a membrana provocando entupimento; cloro livre e outros agentes oxidantes que corroem a membrana; a sua sensibilidade pode ser destruída pela concentração por polarização de agentes incrustantes na sua superfície; necessidade de implantar um sistema de pré-tratamento, geralmente do tipo físico-químico por flotação; recomendação quanto ao uso de filtro de carvão ativado para reter gases oxidantes e, finalmente necessidade de execução de um programa de monitoramento para avaliar a taxa de rejeição de sais e variações nas pressões de trabalho. (Mishra e Tripathy, 1993).

A coagulação eletrocinética é um método economicamente viável e têm sido publicados alguns trabalhos mostrando que sulfato ferroso e cloreto férrico dão bons resultados na remoção de corantes diretos, mas não é um método adequado para remover corantes ácidos (Jida e Endo, 1968; Kamel et al., 1991). Outra desvantagem da eletrocinética consiste na geração e na dificuldade de remover o lodo inorgânico produzido, que até então, era permitido ser enviado para os aterros públicos ou incorretamente incinerado, pois, sobraria um resíduo inorgânico não-biodegradável.

No processo de troca iônica, o efluente líquido passa através de um leito de resina de troca iônica. $\mathrm{O}$ processo pode remover tanto corantes aniônicos como corantes catiônicos dos efluentes. Segundo Rock e Stevens (1975), um processo combinado envolvendo adsorção sobre polímeros e troca iônica foi testado com sucesso na remoção de corantes ácidos, básicos, reativos e diretos de efluentes aquosos, sendo o polímero regenerado com metanol. Entretanto, o processo é pouco efetivo na remoção de corantes dispersos, além do fato da regeneração do polímero com metanol produzir um efluente que deverá também ser tratado.

Alguns processos baseiam-se no emprego de agentes oxidantes destinados a acelerar a degradação dos corantes.

O reativo de Fenton $\left(\mathrm{H}_{2} \mathrm{O}_{2}\right.$-Fe II) é um agente bastante efetivo no tratamento de efluentes contendo compostos resistentes ao tratamento biológico. A principal desvantagem deste método é a geração de lodo através da floculação do reativo com as moléculas do corante. Este lodo que contém contaminantes concentrados, ainda tem que ser disposto adequadamente para proteção do meio ambiente. Normalmente são incinerados para produção de energia (ROBINSON et al., 2001). 
O ozônio é um agente oxidante extremamente forte, o que possibilita reações rápidas e completas, com uma grande variedade de compostos. Entre as principais vantagens da utilização do ozônio, em relação a outros oxidantes que contêm cloro, está a não formação de compostos organoclorados como os trihalometanos. Esta forma triatômica de oxigênio se decompõe em oxigênio e em espécies radicalares, em solução aquosa, funcionando como um poderoso oxidante quando comparado a outros como $\mathrm{H}_{2} \mathrm{O}_{2}$. No tratamento de efluentes, além de propiciar a remoção de cor, melhora a qualidade final por meio da oxidação de substâncias indesejáveis, tais como: fenol, cianetos, íons metálicos e orgânicos. É aplicado ao efluente sob a forma de gás, não aumentando o volume final de resíduo.

Segundo Perkins (1998), todos os corantes têxteis podem ser descoloridos por ozônio. Os solúveis em água como os reativos e diretos reagem rapidamente, enquanto que os insolúveis como os dispersos à tina reagem mais lentamente. A grande desvantagem do sistema é a toxicidade dos produtos formados. As moléculas de corantes possuem $\mathrm{N}, \mathrm{Cl}$ e/ou S e a oxidação destas moléculas pode gerar novas moléculas de toxicidade superior àquela original (Moran, 1998; Höhn, 1997 e Cooper, 1993). As outras desvantagens dessa técnica são a baixa estabilidade do ozônio (cerca de 20 minutos) e o custo elevado de implantação (Guaratini e Zanoni, 2000; Kunz et al., 2002; Robinson et al., 2001).

$\mathrm{O}$ método fotoquímico decompõe as moléculas de corante em $\mathrm{CO}_{2}$ e $\mathrm{H}_{2} \mathrm{O}$ por irradiação de luz ultravioleta em presença de $\mathrm{H}_{2} \mathrm{O}_{2}$. Dependendo do material inicial, produtos de transformação, tais como metais, ácidos inorgânicos e orgânicos e aldeídos podem ser formados. Este método não gera lodo e os odores são drasticamente reduzidos. A luz ultravioleta ativa a decomposição da $\mathrm{H}_{2} \mathrm{O}_{2}$ em dois radicais que oxidam o material orgânico (Robinson et al., 2001). As principais limitações estão vinculadas ás fontes artificiais de radiação, á dificuldade de sua penetração no meio reacional e à remoção dos fotocatalisadores empregados.

Recentemente foi desenvolvido o processo de destruição eletroquímica das moléculas de corante, no qual praticamente não se utiliza reagentes químicos e não gera lodo. Os produtos de degradação formados não são tóxicos e podem ser lançados em corpos d'água sem impacto na qualidade da água (Carneiro et al., 2004; Robinson et al., 2001). 


\subsubsection{Método biológico}

Os diversos processos biológicos disponíveis para tratamento de efluentes têxteis apresentam elevada eficiência voltada para a redução de sólidos e carga orgânica, principalmente medida em DBO/DQO, chegando a valores de $98 \%$ de redução, quando se adota um sistema do tipo Lodo Ativado. Porém, quando se trata de remoção de cor, esta eficiência não atinge a ordem de $20 \%$, verificando-se assim que embora o tratamento biológico atenda aos parâmetros de lançamento preconizados pelo CONAMA (No. 357/2005), em termos de remoção de cor se faz "mister" o uso de técnicas complementares, que atuam como o chamado tratamento terciário ou de polimento.

O estudo experimental realizado através de um teste de DBO de 21 dias de Singer e Little (1975) utilizando efluentes têxteis indicou que a remoção de cor é em geral menor do que $50 \%$.

A tratabilidade de seis corantes têxteis mostrou que os corantes são lentamente degradados, numa extensão muito pequena e o mecanismo de remoção é a adsorção sobre microorganismos. Neste estudo, foi observado que o tempo de contato não tem influência na remoção da cor e a capacidade de adsorção tem um limite (Tunay et al., 1996). Esta limitação na remoção de cor no tratamento biológico tem sido atribuída principalmente à floculação e adsorção sobre os sólidos suspensos (Porter e Snider, 1976).

Alguns autores (Pagga e Brown, 1986; Grau, 1991), propõem a partir dos resultados de biodegradação aeróbia, que é improvável que os corantes sejam biodegradados e a remoção da cor observada tem sido atribuída à adsorção.

Davis et al. (1982), estudaram o tratamento biológico de vários efluentes coloridos da indústria têxtil e observaram que há uma tendência de maior remoção de cor à medida que aumenta a carga orgânica, que é provavelmente devido à maior taxa de crescimento celular.

\subsubsection{Métodos Combinados}

Os métodos combinados de tratamento dos efluentes da indústria têxtil têm sido utilizados unindo vantagens e desvantagens dos diferentes processos, como por exemplo, a combinação do tratamento biológico por lodos ativados e métodos químicos (Lin e Chen, 1997). A combinação dos processos vai depender dos objetivos que queremos 
atingir no tratamento. Outros métodos de tratamento combinando precipitação química, oxidação química e adsorção também têm sido propostos (Tunay et al., 1996).

\subsection{Processos de Adsorção}

O processo de adsorção se baseia na separação de componentes de uma mistura através do fenômeno físico de transferência de massa. Na mistura há um componente diluído na fase líquida, que pode estar na forma gasosa ou líquida denominado adsorbato e um sólido, denominado adsorvente. Quando as duas fases entram em contato, o componente diluído na mistura se difunde, transferindo-se do seio da fase líquida para a superfície do adsorvente. A força motriz desta difusão é determinada pela diferença entre a concentração no seio da solução e a superfície do material sólido. No caso de um sistema de leito fixo ou um sistema agitado, existe uma componente de difusão forçada originada pelo fluxo da fase fluida.

Quando o processo de adsorção consiste na troca ou compartilhamento de elétrons entre o adsorvente e o adsorbato é conhecido como quimissorção. No caso em que o processo envolve forças de Van der Walls, o processo é chamado de fisissorção. A fisissorção é um processo reversível, devido à magnitude das forças de Van der Walls. Por outro lado, a quimissorção é um processo praticamente irreversível, devido à alteração da natureza química do adsorbato. A separação entre substâncias ocorre porque diferenças no peso molecular ou na polaridade do componente a ser adsorvido fazem com que algumas moléculas sejam presas mais fortemente na superfície do que outras ou devido aos poros serem muito pequenos para admitirem moléculas maiores. Em muitos casos, o adsorbato (componente adsorvido) está fortemente e suficientemente ligado para permitir a remoção completa de um determinado composto da fase fluida com pequena adsorção de outros (McCabe et al., 1993).

Os tratamentos por processos de adsorção encontram maior aplicação industrial do que outras técnicas, pois associam baixo custo e elevadas taxas de remoção. Além disto, em alguns casos, por não se tratar de um método destrutivo, possibilita a recuperação do corante sem perda de sua identidade química. Outras vantagens encontradas são um menor tempo de processamento e poucas variáveis a serem controladas comparando-se com os outros processos físico-químicos, como a degradação biológica mixta aeróbia-anaeróbia (Banat et al., 1996) entre outros processos.

Atualmente, o material que apresenta maior capacidade de adsorção, sendo amplamente utilizado para o tratamento de efluentes, é o carvão ativado. Entretanto, devido 
às perdas durante o processo de recuperação do adsorvente, sua utilização torna-se onerosa. Além disso, em função de sua superfície ser quimicamente positiva, a adsorção de corantes de caráter catiônico é limitada.

Neste sentido, existe um crescente interesse pela busca de materiais alternativos de baixo custo que possam ser utilizados como adsorventes, em substituição ao carvão ativado, bem como para a eliminação de corantes têxteis, tais como argilas, bagaço de cana, madeira e outros resíduos celulósicos. Sanghi et al., 2002, relataram uma revisão sobre a descolorização de corantes em soluções aquosas usando-se adsorventes de baixo custo.

A habilidade da madeira para adsorver corantes aniônicos foi investigada por Poots et al., em 1976 e os resultados mostraram que a adsorção de corantes ácidos é bastante eficiente, embora seja necessário um grande tempo de contato para atingir o equilíbrio. A adsorção do corante sobre a madeira se restringe à superfície externa das partículas da madeira. O custo da madeira é relativamente pequeno quando comparado à maioria dos adsorventes comerciais, como o carvão ativado comercial e o adsorvente saturado pode ser queimado e utilizado na geração de vapor.

Segundo Kamel et al. (1991), derivados da celulose como carbamato de celulose também têm sido usados com sucesso na remoção de corantes diretos. A velocidade de adsorção depende da concentração inicial do corante, da quantidade de adsorvente, do tempo de contato, da temperatura e da adição de eletrólitos.

$\mathrm{O}$ uso de argilas naturais, bagaço de cana e espiga de milho como adsorventes foi estudado (Nassar e El-Geundi, 1991) e mostraram-se economicamente atraentes para a remoção de cor de soluções aquosas. Estes adsorventes naturais foram recomendados como efetivos e de baixo custo e, portanto, a regeneração do adsorvente após a saturação não seria assim tão necessária.

Sílica gel (McKay e Alexander, 1977), foi empregada para a remoção de corantes básicos, porém alguns problemas foram apontados como, reações paralelas de oxidação e a colmatação da coluna de adsorção devido ao material particulado.

A maior parte dos adsorventes naturais usados com sucesso para a adsorção de corantes dos efluentes é constituída de compostos orgânicos com grupos polares reativos, responsáveis pela ligação com os corantes iônicos.

Os adsorventes derivados da madeira ou derivados da celulose têm a vantagem de apresentar baixo custo, portanto, não seria necessária a regeneração e o adsorvente saturado pode ser queimado para a geração de energia. Entretanto, apresenta o problema da 
hidrólise e/ou solubilização da celulose, o que acabaria por aumentar a DQO do efluente (Sun e Xiangjing, 1997; Namasivayam et al., 1996).

A quitosana derivada do bipolímero quitina presente nas cascas de camarão também pode ser uma fonte de matéria-prima altamente renovável podendo ser utilizada na remoção de corantes de efluentes industriais (Maghami e Roberts, 1988; Smith et al., 1993). Mas, existe um inconveniente, pois a quitosana na forma de flocos ou pó incha e não se comporta idealmente numa coluna empacotada, pois apresenta propriedades de intumescimento e retração, sendo necessário assim um beneficiamento melhor elaborado (Rorrer e Hsien, 1993).

Além dos resíduos orgânicos e materiais naturais aplicados como adsorventes de baixo custo para a remoção de corantes em água, resíduos industriais poderão também ser testados para tal fim.

\subsection{Zeólitas sintetizadas a partir de cinzas de carvão}

\subsubsection{Cinzas de Carvão}

As unidades termoelétricas no Brasil são do tipo convencional, ou seja, carvão pulverizado, onde a combustão do carvão se dá a temperaturas superiores a $1400{ }^{\circ} \mathrm{C}$. As cinzas oriundas deste tipo de combustor são de dois tipos: as volantes ou leves (fração granulométrica $<100 \mu \mathrm{m}$ ), que são emitidas com os gases e abatidas em sistema de limpeza do tipo precipitadores eletrostáticos e as de fundo ou pesadas (fração granulométrica mais grossa), que saem pelo fundo do equipamento, normalmente na forma de lama. Em torno de $80 \%$ das cinzas geradas são cinzas leves e o restante é cinza de fundo.

As características físicas, químicas e mineralógicas das cinzas leves de carvão dependem de uma variedade de fatores, incluindo: a composição do carvão que lhes deu origem (precursor), as condições de combustão, do tipo e eficiência do sistema de controle de emissões e os métodos de disposição utilizados (Adriano et al. 1980). Conseqüentemente, é difícil generalizar sobre a composição das cinzas ou sobre o seu comportamento no ambiente. Contudo, certas características são bastante uniformes para a maioria das cinzas.

As cinzas leves são consideradas como mineral aluminosilicato ferroso, com $\mathrm{Al}, \mathrm{Si}, \mathrm{Fe}, \mathrm{Ca}, \mathrm{K}$ e $\mathrm{Na}$ como elementos predominantes. Em geral, são compostas predominantemente de partículas pequenas, vítreas e ocas, com granulometria de 0,01 a $100 \mu \mathrm{m}$. O material é heterogêneo e complexo, constituído de ambas as fases, amorfa e 
cristalina (El-Mogazi et al., 1988; Page et al., 1979; Mattigod et al., 1990). O pH das cinzas varia de 4,5 a 12 dependendo das características geoquímicas do carvão precursor.

As cinzas leves contêm todos os elementos de ocorrência natural e são substancialmente enriquecidas em elementos traços se comparadas com o carvão precursor. Estudos têm demonstrado que muitos elementos traços estão adsorvidos nas partículas menores e entre os elementos que estão enriquecidos nas cinzas podem ser citados: As, B, Ca, Mo, S, Se e Si.

A análise mineralógica das cinzas leves mostrou que de 70 a $90 \%$ das partículas são esferas vítreas, o restante é constituído de quartzo $\left(\mathrm{SiO}_{2}\right)$, mulita $\left(3 \mathrm{Al}_{2} \mathrm{O}_{3} \cdot 2 \mathrm{SiO}_{2}\right)$, hematita $\left(\mathrm{Fe}_{2} \mathrm{O}_{3}\right)$ e magnetita $\left(\mathrm{Fe}_{3} \mathrm{O}_{4}\right)$ e uma pequena porção de carbono não queimado (1 a 2\%). Em adição a estes minerais, podem ainda conter gesso $\left(\mathrm{CaSO}_{4} \cdot 2 \mathrm{H}_{2} \mathrm{O}\right)$ e anidrita $\left(\mathrm{CaSO}_{4}\right)$, (Umaña, 2002).

Entre as principais aplicações das cinzas leves estabelecidas e que são prática comum em todo mundo encontram-se: aditivos em cimento e cerâmicas, fabricação de blocos e tijolos (Calarge et al., 2000; Chies, et al., 2003), ladrilhos e refratários (Silva et al., 1999), pavimentação e preenchimento de cava de mina de carvão (Queralt et al., 1997; Vassilev et al., 2001; Hall e Livingston, 2002). Porém estas aplicações ainda ocorrem em pequena escala ( 30\%) e sem aumento de uso previsto. O pequeno nível de consumo das cinzas de carvão é inevitável devido á combinação de custos altos de transporte com produto de valor relativamente baixo no mercado.

O principal esforço no sentido de mitigar os impactos ambientais decorrentes da disposição destes resíduos no meio ambiente deve ser dirigido no sentido de ampliar as potencialidades de utilização, em particular, com a transformação das cinzas de carvão em um produto de alto valor agregado.

A similaridade de composição da cinza leve com alguns materiais vulcânicos precursores das zeólitas naturais foi a principal razão para o experimento realizado por Höller e Wirsching, 1985, que sintetizaram zeólita a partir desse subproduto da combustão do carvão.

\subsubsection{Zeólitas}

O termo zeólita foi utilizado inicialmente para designar uma família de minerais naturais que apresentavam como propriedade particular o intercâmbio de íons e a dessorção reversível de água. Esta última propriedade deu origem ao nome genérico de 
zeólita, o qual deriva das palavras gregas: zeo - que ferve e lithos - pedra, ou seja, pedra que ferve (Gianneto, 1990).

As zeólitas são aluminosilicatos hidratados de metais alcalinos e alcalinoterrosos (principalmente $\mathrm{Na}, \mathrm{K}, \mathrm{Mg}$, e $\mathrm{Ca}$ ), estruturados em redes cristalinas tridimensionais, compostas de tetraedros do tipo $\mathrm{TO}_{4}(\mathrm{~T}=\mathrm{Si}, \mathrm{Al}, \mathrm{Ga}, \mathrm{Ge}, \mathrm{Fe}, \mathrm{B}, \mathrm{P}$, Ti, etc. $)$ unidos nos vértices através de átomos de oxigênio e podem ser representados para tetraedros de alumina e sílica pela seguinte fórmula química por célula unitária (Deer et al. 1966; Breck, 1984; Gianetto; 1990, Luz, 1994).

$$
\mathrm{M}^{\mathrm{n}+}{ }_{\mathrm{x} / \mathrm{n}}\left[\left(\mathrm{AlO}_{2}\right)_{\mathrm{x}}\left(\mathrm{SiO}_{2}\right)_{\mathrm{y}}\right] \cdot \mathrm{mH}_{2} \mathrm{O}
$$

onde: $\mathrm{M}$ é o cátion intercambiável ou de compensação de valência $\mathrm{n}$; $\mathrm{m}$ é o número de moléculas de água e $\mathrm{x}+\mathrm{y}$ é o número de tetraedros por célula unitária.

A estrutura da zeólita apresenta canais e cavidades interconectadas de dimensões moleculares, nas quais se encontram íons de compensação, moléculas de água ou outros adsorbatos e sais. Este tipo de estrutura microporosa confere á zeólita uma superfície interna extremamente grande em relação á sua superfície externa. A microporosidade destes sólidos é aberta e a estrutura permite a transferência de matéria entre os espaços intercristalinos. Essa transferência, porém, é limitada pelo diâmetro dos poros da zeólita, onde só poderão entrar ou sair do espaço intercristalino moléculas com dimensões inferiores a certo valor crítico, o qual varia de uma zeólita a outra (Gianneto, 1990; Luz, 1994). O que dá a variedade de zeólitas existentes é a maneira como os tetraedros se unem associado á possível substituição de silício por vários outros elementos, e o tipo de íon presente nos poros.

As zeólitas com importância comercial devem seu valor a pelo menos uma de três importantes propriedades: adsorção, capacidade de troca catiônica e catálise (Luz, 1994). A grande capacidade de adsorção das zeólitas está relacionada à sua estrutura microporosa formada por poros de dimensões definidas, que funcionam como peneiras moleculares, permitindo a entrada de moléculas menores e barrando a entrada das maiores. A estrutura microporosa é responsável pela seletividade de forma.

A capacidade de troca catiônica de uma zeólita está intrinsecamente relacionada com sua relação $\mathrm{Si} / \mathrm{Al}$, já que para cada $\mathrm{Si}$ que foi substituído por um $\mathrm{Al}$ é gerada uma carga negativa, a qual é compensada por um cátion. Os cátions estão livres para migrarem para dentro e para fora das estruturas zeolíticas, característica esta que 
permite que estes materiais possam ser usados para trocar seus cátions com os cátions de líquidos no qual elas estejam imersas. A preferência da zeólita por um determinado cátion é própria de sua capacidade como peneira molecular ou da competição entre a zeólita e a fase aquosa, para os cátions presentes. Esta função pode ser observada na presença de zeólita em formulações de detergentes, ou seja, trocar seus cátions pelos $\mathrm{Ca}^{2+}$ presentes nas águas (remoção da dureza da água).

As propriedades catalíticas das zeólitas estão relacionadas à substituição do $\mathrm{Si}$ pelo Al nas suas estruturas cristalinas com a conseqüente formação de sítios ácidos, bem como à seletividade de forma de suas estruturas necessárias ao seu uso principalmente em catálise e troca catiônica. Assim, pesquisadores começaram a estudar o processo de síntese de zeólitas artificiais. O único método comercial, necessárias ao seu uso principalmente em catálise e troca catiônica.

\subsubsection{Síntese hidrotérmica}

As zeólitas naturais ocorrem de modo característico, em vesículas e fendas, principalmente em rochas vulcânicas básicas e encontram-se também em filões e outros ambientes da fase hidrotermal tardia. As zeólitas de ocorrência natural, normalmente possuem um teor elevado de impurezas e/ouão possuem as propriedades para a obtenção de zeólitas artificiais é por reação hidrotérmica em processo semelhante ao que ocorre na natureza, podendo ser realizada por meio de hidrogel ou pela conversão de materiais sólidos naturais ou resíduos. No processo hidrogel, as zeólitas puras são sintetizadas a partir de soluções supersaturadas de aluminatos e silicatos (géis) em condições operacionais bastante rígidas (Barrer, 1982). Em muitos casos, a variação de poucos graus na temperatura leva a formação de estrutura zeolítica bastante diferente da desejada. No segundo caso, materiais sólidos naturais ou resíduos do tipo aluminosilicatos amorfos são usados como fontes de $\mathrm{Si}$ e $\mathrm{Al}$, incluindo aqui as cinzas de carvão.

Desde os estudos iniciais por Höller e Wirsching (1985), muitos patentes e artigos técnicos têm proposto diferentes métodos de ativação hidrotérmica para sintetizar diferentes zeólitas a partir de cinza leve (Henmi, 1987; Mondragon et al., 1990; Shigemoto et al., 1992, 1993, 1995; Kolousek et al., 1993; Bang-Sup et al., 1995; Chang e Shih, 1995; Park e Choi, 1995; Querol et al., 1997, 2001; Singer e Bekgaut, 1995; Amrhein et al., 1996). 
Todas as metodologias desenvolvidas estão baseadas na dissolução das fases de cinza leve sustentadas por Si e Al com soluções alcalinas (principalmente soluções de $\mathrm{NaOH}$ e $\mathrm{KOH})$ e a subseqüente precipitação do material zeolítico.

O mecanismo de reação envolve as seguintes etapas (Murayama et al, 2002):

a) dissolução da cinza entre $20-120^{\circ} \mathrm{C}$ : a velocidade é bastante dependente da concentração de $\mathrm{OH}^{-}$.

b) condensação ou gelatinização: reação entre os íons aluminato e silicato com a formação de gel aluminossilicato.

c) cristalização: o gel aluminossilicato se transforma em um cristal de zeólita. A velocidade de reação é dependente da quantidade de $\mathrm{Na}^{+}$.

No processo de ativação, os complexos monoméricos de sílica e alumina são formados em $\mathrm{pH}>10$ pela solubilidade da sílica amorfa e a reação se processa por meio de íons complexos carregados negativamente (Czurda e Haus, 2002):

$$
\mathrm{Si}(\mathrm{OH})_{4}+\mathrm{H}_{2} \mathrm{O}+\mathrm{OH}^{-} \leftrightarrow\left(\mathrm{H}_{2} \mathrm{O}\right) \mathrm{Si}(\mathrm{OH})_{5}(2)
$$

Os complexos $\mathrm{Al}(\mathrm{OH})_{4}{ }^{-}$são sujeitos à etapas de desidratação:

$$
2 \mathrm{Al}(\mathrm{OH})_{4}{ }^{-} \leftrightarrow\left[(\mathrm{OH})_{3} \mathrm{Al}-\mathrm{O}-\mathrm{Al}(\mathrm{OH})_{3}\right]^{2-}+\mathrm{H}_{2} \mathrm{O}
$$

A zeolitização seguinte a partir da cinza de carvão representa um equilíbrio de reação entre a solução e a fase sólida. Pela elevação da temperatura, a solubilidade dos íons de sílica e alumina aumenta e reações de condensação pelas neoformações de núcleos de cristais são iniciadas. $\mathrm{O}$ crescimento de cristais leva a uma completa solução de material original amorfo pela formação de diferentes fases de zeólita, como mostra a reação (4):

$$
\begin{array}{cc}
{\left[\mathrm{Na}_{\mathrm{a}}\left(\mathrm{AlO}_{2}\right)_{\mathrm{b}}\left(\mathrm{SiO}_{2}\right)_{\mathrm{e}}{ }^{*} \mathrm{NaOH}^{*} \mathrm{H}_{2} \mathrm{O}\right] \leftrightarrow\left[\mathrm{Na}_{\mathrm{x}}\left(\mathrm{AlO}_{2}\right)_{\mathrm{x}}\left(\mathrm{SiO}_{2}\right)_{\mathrm{y}}\right] \text { " } \mathrm{z} \mathrm{H} \mathrm{H}_{2} \mathrm{O}+\text { solução (4) }} \\
\text { íon complexo } & \text { zeólita }
\end{array}
$$

A cristalização em um estágio resulta, geralmente, em um material zeolítico que contém 20 - 75\% de zeólita, dependendo das condições da reação de ativação, e cinza de carvão não-convertida. As substâncias tóxicas que a cinza contém são removidas na solução básica que é encaminhada para tratamento e/ou re-aproveitamento posterior. 
Os principais fatores que influenciam a síntese de zeólitas a partir de cinzas de carvão são: tipo e composição das cinzas; tipo e concentração do meio reacional; pressão, temperatura; tempo de reação; relação solução/cinzas; uso de promotores (sementes, direcionadores).

A conversão clássica alcalina das cinzas de carvão utiliza geralmente solução de hidróxido de sódio ou potássio com diferentes concentrações, temperatura de 80 a $200{ }^{\circ} \mathrm{C}$, tempo de reação de 3 a 48 h e uma variação nos outros parâmetros. Pelo menos 15 tipos diferentes de zeólitas poderão ser produzidos a partir de uma cinza pela variação dos parâmetros de ativação (Querol et al., 2001; Moreno et al., 2001a, 2001b). As condições de ativação poderão ser otimizadas para maximizar a capacidade de adsorção dos produtos zeolíticos obtidos, tendo em vista também aspectos econômicos.

A maioria dos estudos demonstrou que as soluções de $\mathrm{NaOH}$ têm uma eficiência de conversão mais alta que as soluções de $\mathrm{KOH}$ sob a mesma temperatura. As eficiências de conversão são também dependentes dos conteúdos das fases não reativas componentes das cinzas (principalmente hematita e magnetita) e da fase resistente de aluminosilicato, tais como mulita e quartzo, e a distribuição de tamanho de grãos.

Uma das principais aplicações da zeólita de cinzas de carvão tem sido na remoção de íons metálicos e amônio em água devido a sua excelente propriedade de material trocador catiônico. No entanto, há poucos estudos empregando-se cinzas de carvão geradas no Brasil. O carvão brasileiro apresenta uma proporção maior de matéria mineral do que os carvões europeus e norte-americanos e um alto teor de cinzas (45 - 60\% $\mathrm{m} / \mathrm{m}$ ). A composição química e a composição mineralógica associadas à morfologia irão influenciar as propriedades das cinzas e das suas respectivas zeólitas e, conseqüentemente, a capacidade de adsorção do produto sintetizado.

Os trabalhos referentes á sintetização de zeólitas a partir de cinzas de carvão brasileiro são examinados a seguir.

A zeólita preparada a partir de cinza leve do filtro manga da Usina Termelétrica de Figueira (PR) foi usada para descontaminar o efluente de um processo de zincagem de uma indústria de galvanoplastia $\left(\mathrm{Zn}^{2+} 17 \mathrm{mg}\right.$. $\left.\mathrm{L}^{-1} ; \mathrm{pH} 4,6\right)$. No processo de leito móvel, alcançou-se uma remoção de $88 \%$ do poluente. A quantidade do íon metálico e o pH no efluente, após o tratamento, estavam dentro dos limites permitidos pela legislação para descarte no meio ambiente (Resolução CONAMA No. 357 - artigo 34). O material pode ser empregado também em colunas de percolação, em sistemas similares aos empregados para resina de troca catiônica e carvão ativado por indústrias de 
galvanoplastia. $\mathrm{O} \mathrm{Zn}^{2+}$ adsorvido na zeólita foi recuperado (85\%) usando-se $\mathrm{NaCl} 2$ mol.L ${ }^{-1}$ como solução regenerante (Fungaro, 2004, 2006; Fungaro e Izidoro, 2006).

O tratamento em efluente de galvanoplastia foi igualmente eficaz com o uso de zeólita da cinza pesada da base da chaminé. Uma eficiência de remoção acima de $77 \%$ foi obtida para os íons cádmio, zinco, cobre e chumbo após contato do sistema zeólitaefluente. $\mathrm{O}$ efluente tratado estava adequado para ser lançado em corpos receptores conforme as regulamentações em vigor (Fungaro e Silva, 2002).

As amostras do horizonte A de solo foram coletadas a uma distância de $1 \mathrm{~km}$ da Usina Termelétrica de Figueira na direção predominante dos ventos (noroeste). A concentração parcial do zinco obtida por digestão ácida foi de $83 \mathrm{mg} \mathrm{kg}^{-1}$, que está acima do valor de referência de qualidade do solo $\left(60 \mathrm{mg} \mathrm{kg}^{-1}\right)$ segundo a Companhia de Tecnologia e Saneamento Ambiental (CETESB). O solo é considerado poluído e a contaminação é proveniente das cinzas de carvão geradas pela usina termelétrica por deposição atmosférica. As zeólitas sintetizadas a partir de cinzas de carvão adicionadas ao solo mostraram alta capacidade para reduzir a mobilidade e a biodisponibilidade do $\mathrm{Zn}^{2+}$. A lixiviação do $\mathrm{Zn}^{2+}$ foi reduzida para mais de $80 \%$ usando um mínimo de $10 \%$ de aditivo. (Fungaro et al., 2004).

O processo hidrotérmico em meio alcalino foi estudado para a síntese de zeólitas a partir de cinzas do carvão geradas na usina termelétrica de Candiota (RS). As variáveis estudadas foram: tipo e composição das cinzas de carvão (dezessete tipos), tipo e concentração do meio reacional alcalino $(\mathrm{NaOH}$ e $\mathrm{KOH})$, temperatura de reação, tempo de reação e relação solução alcalina/cinzas de carvão. Para o meio reacional com $\mathrm{NaOH}$, foram gerados sete tipos diferentes de zeólitas: A, P, X, sodalita, cancrinita, noselita e chabazita. Para o meio reacional com KOH foram gerados quatro tipos de zeólitas: F, L, W e chabazita. A utilização das zeólitas não foi considerada promissora na remoção de íons metálicos em água sob o ponto de vista técnico e econômico. Por outro lado, os produtos zeolíticos potássicos foram utilizados com sucesso como fonte de $\mathrm{K}$ e, complementar ou total de N no cultivo de plantas de aveia (Ferret, 2004).

A gama de aplicações das zeólitas naturais é muito grande e podem ser previstas as mesmas aplicações para as zeólitas de cinzas de carvão agregando maior valor ao produto.

A eficiência de adsorção alcançada com o uso de material zeolítico preparado com as cinzas de carvão da usina termelétrica Figueira indicou perspectivas promissoras 
para que este material seja favoravelmente aplicado também na remoção de corantes em água.

\subsection{Adsorção de azul de metileno sobre cinzas de carvão e zeólitas}

\subsubsection{Azul de Metileno}

O azul de metileno é o corante mais usado em testes de adsorção porque serve como um composto modelo para o estudo da remoção de contaminantes orgânicos e corantes de solução aquosa (Aygun et al., 2003; Yenisoy-Karakas et al., 2004). É um corante importante por ser muito utilizado para propósitos de impressão, na indústria têxtil e na medicina. A molécula do azul de metileno tem um diâmetro mínimo de 0,8 nm e é acessível a poros com diâmetros maiores que 1,3 nm (Yenisoy-Karakas et al., 2004).

O azul de metileno é um corante catiônico ou básico, com número de classificação CI 52015. A fórmula química é $\mathrm{C}_{16} \mathrm{H}_{18} \mathrm{~N}_{3} \mathrm{SCl}$, massa molar $319,8513 \mathrm{~g} / \mathrm{mol}$ e estrutura molecular ilustrada na FIG.1:

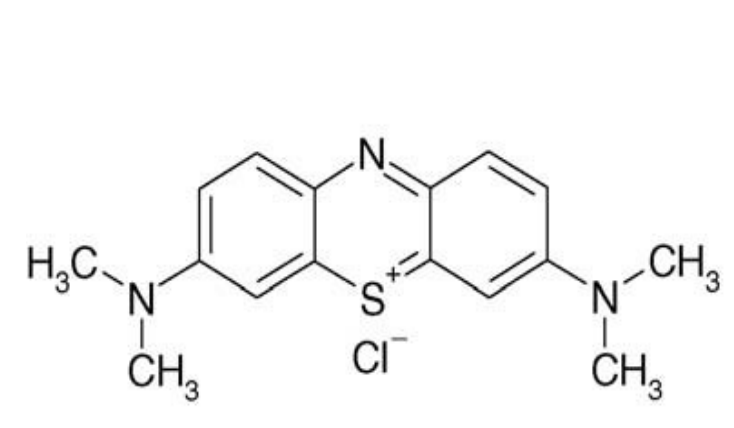

FIGURA 1 - Estrutura molecular do azul de metileno

Embora não seja fortemente venenoso, o azul de metileno pode causar vários efeitos prejudiciais á saúde humana. Observam-se períodos rápidos de dificuldade de respiração por inalação, enquanto a ingestão pela boca produz uma sensação de queima e provoca náuseas, vomito diarréia e gastrite. A ingestão de altas doses provocará dores do abdômen e tórax, dor de cabeça severa, transpiração abundante, confusão mental, 
menstruação dolorosa e metahemoglobinemia (Ghosh e Bhattacharyya, 2000; Karaca et al., 2003).

Muitos pesquisadores têm usado vários tipos de materiais de baixo custo para a remoção de azul de metileno de solução aquosa, como por exemplo: carvão de casca de pêra, casca de arroz, cabelo, restos de algodão, casca de árvore, rocha vulcânica vítrea, caulim cru e puro, caulim calcinado, caulim tratado com $\mathrm{NaOH}$, argila, carvão ativado de semente de goiaba (Vadivelan e Kumar, 2005).

A utilização de cinzas de carvão e zeólitas naturais e sintéticas como materiais adsorventes do azul de metileno em solução aquosa tem sido também investigada.

\subsubsection{Adsorventes de baixo custo}

As cinzas leves de carvão foram modificadas por tratamento hidrotérmico com $\mathrm{NaOH} 7 \mathrm{~mol} \mathrm{~L}^{-1}$ (Woolard et al. 2002). O produto obtido apresentou um aumento de oito vezes da área superficial em relação à cinza e, como conseqüência uma capacidade de adsorção do azul de metileno dez vezes maior foi alcançada. A hidroxisodalita foi identificada por difração por Raios-X como o componente cristalino primário do produto obtido no tratamento hidrotérmico. A eficiência de adsorção do azul de metileno sobre a zeólita de cinzas de carvão foi mais baixa do que com sílica amorfa e os autores consideraram que novos estudos deveriam ser realizados para obtenção de um tipo de zeólita que resultasse em remoção mais efetiva de corantes catiônicos.

A adsorção do azul de metileno em soluções aquosas sobre os adsorventes de baixo custo, tais como: cinza leve de carvão, cinza de esterco de vaca, lama de cana de açúcar carbonizada, cinza pesada do bagaço de cana de açúcar foi analisada por Kumar (2002). Os dados de equilíbrio de adsorção foram analisados pelos modelos de isotermas Freundlich, Langmuir e Redlich-Peterson. Entre todos os materiais usados, a cinza pesada do bagaço de cana de açúcar apresentou a máxima capacidade de adsorção de $142,5 \mathrm{mg} \mathrm{g}^{-1}$. Este estudo de equilíbrio confirmou que os vários materiais alternativos podem ser usados para substituir os adsorventes de alto custo.

Janos et al., (2003) testaram as cinzas leves de carvão marrom como um adsorvente de custo potencialmente baixo para a remoção de corantes sintéticos em água. Constatou-se que tanto os corantes básicos (catiônicos), como os corantes ácidos (aniônicos) podiam ser adsorvidos pelas cinzas leves. O processo obedeceu à isoterma de Langmuir apresentando capacidades de adsorção dentro da faixa de $10^{-1}$ a $10^{-3} \mathrm{mmol} \mathrm{g}^{-1}$, não havendo diferença significativa em relação à natureza do corante (básico ou ácido). A 
adsorção de cada corante foi afetada consideravelmente pela presença de surfactantes carregados com carga oposta a sua. Este é um efeito bastante complicado merecendo maiores investigações porque os surfactantes são constituintes comuns dos efluentes industriais.

A adsorção do azul de metileno em solução aquosa usando as cinzas leves de carvão como adsorvente foi estudada por Kumar et al. (2004). As variáveis operacionais, tais como, concentração inicial do corante, massa da cinza leve, $\mathrm{pH}$ e tempo de contato, foram consideradas. A eficiência máxima de adsorção foi observada no valor de $\mathrm{pH}$ 8. Os dados de equilílbrio obedeceram à equação de Langmuir mostrando uma capacidade de adsorção da monocamada de 5,718 $\mathrm{mg} \mathrm{g}^{-1}$.

As cinzas leves de carvão e a lama vermelha foram empregadas como adsorventes para a remoção do azul de metileno de soluções aquosas, usando-se tratamento térmico e químico com ácido nítrico como pré-tratamento das matérias-primas (Wang et al., 2005a). Os dados de adsorção foram analisados usando-se as isotermas de Langmuir, Freundlich e Redlich-Peterson, sendo que os resultados se ajustaram melhor á equação do último modelo. A cinza leve apresentou uma capacidade de adsorção maior do que a lama vermelha.

Um estudo comparativo da adsorção do corante azul de metileno por cinzas leves, zeólitas naturais e carvão não queimado foi realizado (Wang et al., 2005b). As influências da concentração inicial do corante, do tamanho da partícula do adsorvente, do pH inicial da solução e da temperatura de adsorção foram avaliadas. O carvão não queimado apresentou a maior eficiência de remoção do corante com capacidade de adsorção de $2,5 \times 10^{-4} \mathrm{~mol} \mathrm{~g}^{-1}$. O processo de adsorção seguiu o modelo cinético da equação de pseudo-segunda-ordem.

Wang et al., (2006) realizaram experimentos com a zeólita MCM-22 para remoção dos corantes básicos azul de metileno (AM), violeta cristal (VC) e rodamina $\mathrm{B}$ (RB) de solução aquosa. A capacidade de adsorção da zeólita seguiu a seguinte ordem decrescente: $\mathrm{AM}>\mathrm{VC} \sim \mathrm{RB}$. Os autores concluíram que o MCM-22 é um adsorvente efetivo na remoção dos corantes básicos provenientes de efluentes e que o processo de adsorção foi espontâneo e endotérmico.

A capacidade de diferentes tipos de zeólitas sintetizadas a partir de cinzas de carvão brasileiro na remoção de íons metálicos e azul de metileno de solução aquosa foi investigada (Fungaro et al., 2005). Os autores concluíram que a zeólita sintetizada a partir da cinza leve do filtro manga apresentou a melhor capacidade de adsorção dos compostos 
tóxicos. As capacidades máximas de adsorção encontradas foram 36,1, 76,3 e 3,99 mg g ${ }^{-1}$ para os íons de $\mathrm{Zn}^{2+}, \mathrm{Cd}^{2+}$ e o corante, respectivamente.

\subsection{Modelagem de adsorção}

\subsubsection{Modelos Cinéticos}

Estes estudos envolvem a relação da dependência da eficiência de adsorção com o tempo de agitação. A concentração do poluente que permanece em solução decresce com o tempo e, em certo ponto, alcança um valor constante além do qual não ocorre mais a remoção do poluente da solução. Neste ponto, a quantidade de poluente que está sendo adsorvida pelo adsorvente está em estado de equilíbrio dinâmico com a quantidade de poluente que está dessorvendo. O tempo requerido para atingir este estado é chamado de tempo de equilíbrio e a quantidade de poluente adsorvida neste tempo reflete a capacidade de adsorção máxima do poluente pelo adsorvente sob aquelas condições de operação particulares.

Os estudos cinéticos são importantes na determinação do tempo necessário para alcançar o equilíbrio, no exame das velocidades de adsorção que podem ser usadas para desenvolver modelos e no entendimento dos processos que influenciam a remoção dos solutos. A previsão das cinéticas do processo adsorção em leito móvel é necessária para o projeto de colunas.

No processo de adsorção sólido-líquido, a transferência do soluto é caracterizada por transferência de massa externa ou difusão intrapartícula ou ambos. A dinâmica de adsorção pode ser descrita por 3 etapas consecutivas:

1. Transporte do soluto do seio da solução através do filme líquido para a superfície exterior do adsorvente;

2. Difusão do soluto dentro do poro do adsorvente e mecanismo de difusão intrapartícula;

3. Adsorção do soluto nas superfícies interiores dos poros e espaços capilares do adsorvente.

A última etapa é considerada uma reação de equilíbrio e assume-se que a velocidade da reação é tão rápida que pode ser negligenciada (Crank, 1956). A velocidade final do processo de adsorção irá ser controlada pela etapa mais lenta, isto é, a etapa determinante da velocidade. A natureza da etapa determinante da velocidade no processo descontínuo pode ser determinada pelas propriedades do soluto com o adsorvente. As 
velocidades de adsorção são usualmente encontradas pelo estudo da mudança na concentração do adsorbato com o adsorvente em função do tempo.

Previamente vários pesquisadores usaram modelos cinéticos diferentes para predizer o mecanismo envolvido no processo de adsorção. Existem mais de 25 modelos matemáticos desenvolvidos e disponibilizados na literatura, cada um baseado em considerações teóricas e experimentais específicas e, portanto, com suas próprias limitações (Khraisheh et al, 2002). Destes modelos, as cinéticas de adsorção são usualmente descritas pelos modelos de pseudo primeira-ordem, de pseudo segunda-ordem e difusão intrapartícula para a maioria dos sistemas adsorvente-adsorbato. A aplicabilidade destes modelos é evidenciada quando os dados experimentais obedecem ao modelo utilizado.

\subsubsection{Modelo da pseudo-primeira-ordem de Lagergren}

A velocidade de adsorção pode ser determinada por uma expressão de velocidade de pseudo-primeira-ordem dada por Lagergren para a adsorção em sistema líquido/sólido baseada na capacidade do sólido (Lagergren, 1898). Ele assumiu que a velocidade de remoção do adsorbato com o tempo é diretamente proporcional à diferença na concentração de saturação e ao número de sítios ativos do sólido. A equação cinética de Lagergren é a mais usada para a adsorção de um adsorbato de uma solução aquosa (Ho e Mckay, 1998a).

A equação geral é expressa como:

$\log _{10}\left(q_{e}-q\right)=\log _{10} q_{e}-K_{1} t / 2,303$

onde $\mathrm{q}_{\mathrm{e}}$ e q são as quantidades de metal adsorvida $\left(\mathrm{mg} \mathrm{g}^{-1}\right)$ no equilíbrio e no tempo $\mathrm{t}$ (min), respectivamente; $\mathrm{K}_{1}$ é a constante de velocidade de adsorção $\left(\min ^{-1}\right)$. A constante $\mathrm{K}_{1}$ pode ser calculada a partir da inclinação da reta do gráfico $\log _{10}\left(\mathrm{q}_{\mathrm{e}}-\mathrm{q}\right)$ versus t.

$\mathrm{O}$ ajuste da equação aos dados experimentais exige que a capacidade de adsorção no equilíbrio, $\mathrm{q}_{\mathrm{e}}$, seja conhecida. Em muitos casos, $\mathrm{q}_{\mathrm{e}}$ é desconhecido e á medida que a adsorção tende a ficar imensuravelmente lenta, a quantidade adsorvida ainda é significativamente menor que a quantidade em equilíbrio. Além do mais, na maioria dos casos a equação de pseudo-primeira-ordem de Lagergren não se ajusta bem á faixa inteira do tempo de contato e é geralmente aplicável nos 20-30 minutos iniciais do processo de adsorção (Ho e McKay,1998b). 


\subsubsection{Modelo da pseudo-segunda-ordem de Ho}

Os dados cinéticos foram também analisados usando as cinéticas de pseudosegunda-ordem desenvolvidas por Ho e colaboradores (Ho et al, 1996), onde a velocidade da reação é dependente da quantidade do soluto adsorvido na superfície do adsorvente e da quantidade adsorvida no equilíbrio. O modelo linear de pseudo-segunda-ordem pode ser representado por:

$$
\frac{t}{q}=\frac{1}{K_{2} q_{e}^{2}}+\frac{1}{q_{e}} t
$$

onde $\mathrm{K}_{2}$ é a constante de velocidade de pseudo-segunda-ordem (g/mg min), $\mathrm{q}_{\mathrm{e}}$ e q são as quantidades de corante adsorvida $\left(\mathrm{mg} \mathrm{g}^{-1}\right)$ no equilíbrio e no tempo $\mathrm{t}(\mathrm{min})$.

A partir das retas do gráfico de t/q versus $\mathrm{t}$, os valores das constantes $\mathrm{K}_{2}$ (g/mg min) e $\mathrm{q}_{\mathrm{e}}\left(\mathrm{mg} \mathrm{g}^{-1}\right)$ podem ser calculados. Ao contrário do modelo cinético de primeira-ordem, não há necessidade do conhecimento de algum parâmetro prévio e este modelo prevê o comportamento sobre o período completo da adsorção e está de acordo com um mecanismo de adsorção responsável pela etapa controladora da velocidade (Ho e McKay, 1998).

A constante $\mathrm{K}_{2}$ é usada para calcular a velocidade de adsorção inicial $\mathrm{h}$ (mg /g min), para $\mathrm{t} \rightarrow 0$, como segue:

$\mathrm{h}=\mathrm{K}_{2} \mathrm{qe}^{2}$

\subsubsection{Modelo da difusão intrapartícula}

O mecanismo do processo de adsorção definitivo pode não ser obtido pelos modelos cinéticos descritos acima e, portanto, o modelo da difusão intrapartícula pode ser empregado. De acordo com Weber e Morris, 1963, se a difusão intrapartícula é o fator determinante da velocidade, a remoção do adsorbato varia com a raiz quadrada do tempo. Assim, o coeficiente de difusão intrapartícula $\left(\mathrm{K}_{\mathrm{i}}\right)$ pode ser definido como:

$K_{i}=q / t^{0,5}$

onde q é a quantidade de metal adsorvida e t é o tempo de agitação. 
$\mathrm{O}$ valor de $\mathrm{K}_{\mathrm{i}}\left(\mathrm{mg} / \mathrm{g} \mathrm{min}^{0,5}\right)$ pode ser obtido da inclinação da curva do gráfico $\mathrm{q}\left(\mathrm{mg} \mathrm{g}^{-1}\right)$ versus $\mathrm{t}^{0,5}\left(\min ^{0,5}\right)$. Estudos prévios mostraram que o gráfico pode apresentar uma multi-linearidade, a qual caracteriza os diferentes estágios na adsorção: transferência de massa externa seguida por difusão intrapartícula no macro, meso e microporo (Allen et al, 1989).

\subsubsection{Isotermas de adsorção}

A adsorção pode ser avaliada quantitativamente através das isotermas. As isotermas de adsorção mostram a relação de equilíbrio entre a concentração na fase fluida e a concentração nas partículas adsorventes em uma determinada temperatura. Embora algumas tentativas tenham sido feitas para estimar teoricamente os dados de equilíbrio de adsorção, a determinação experimental das isotermas é, ainda, um primeiro e fundamental passo em qualquer estudo para um novo sistema adsorbato/adsorvente.

O procedimento experimental é bastante simples: basta colocar em contato a solução contendo o componente a ser adsorvido em diferentes concentrações com o adsorvente até atingir o equilíbrio. Após a centrifugação, pode-se obter a concentração de

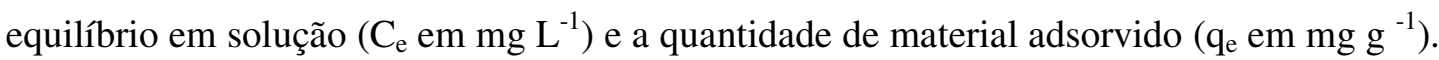
Os gráficos $\mathrm{q}_{\mathrm{e}}$ versus $\mathrm{C}_{\mathrm{e}}$ assim obtidos são as isotermas e podem apresentar-se de várias formas, fornecendo informações importantes sobre o mecanismo de adsorção. Algumas formas mais comuns estão apresentadas na FIG. 2. A isoterma linear passa pela origem e a quantidade adsorvida é proporcional à concentração do fluido. Isotermas convexas são favoráveis, pois grandes quantidades adsorvidas podem ser obtidas com baixas concentrações de soluto.

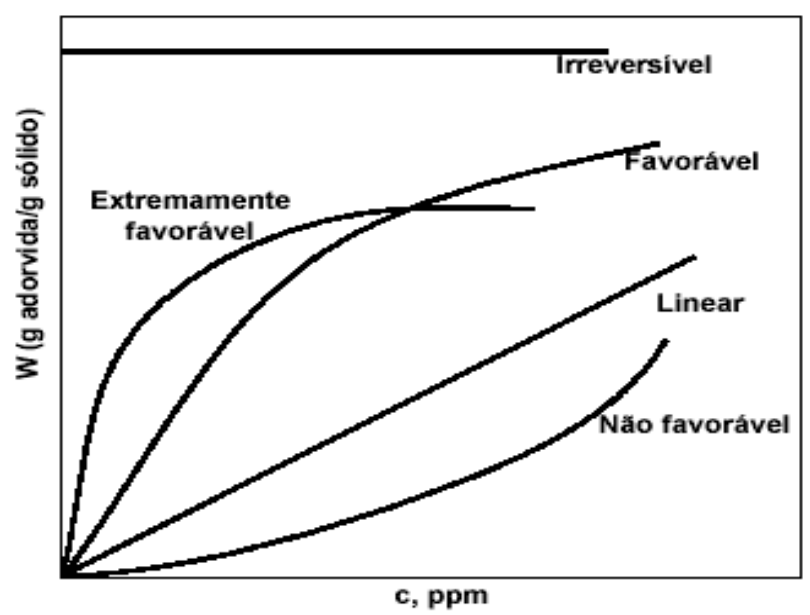

FIGURA 2 - Isotermas de Adsorção (McCabe et al., 1993) 
As isotermas de sistemas líquido/sólido podem ser classificadas de acordo com suas formas que são determinadas pelo mecanismo de adsorção e, portanto esta classificação pode ser usada para o diagnóstico da natureza da adsorção (Giles et al., 1960). Nesta classificação qualitativa, as isotermas foram divididas em quatro classes principais que por conveniência usam o termo S, L (Langmuir), H (alta afinidade) e C (partição constante). Cada uma das classes foi subdividida de acordo com a presença de patamares, pontos de inflexão de máximo ou mínimo (subgrupos 1, 2, 3, 4 ou max). Existem vários modelos publicados em literatura para descrever os dados experimentais das isotermas de adsorção. A análise dos dados da isoterma é importante para desenvolver uma equação que represente realmente os resultados e que possa ser usada para propósitos de dimensionamento de sistemas de remoção do adsorbato (equipamentos).

Os modelos de Langmuir e Freundlich são os mais freqüentemente usados para descrever isotermas para aplicações em tratamento de águas e efluentes (Perrich 1981; Faust e Aly 1987).

A isoterma de Langmuir assume uma cobertura de monocamada do adsorbato sobre a superfície homogênea do adsorvente contendo um número finito de sítios idênticos. O modelo assume energias uniformes de adsorção na superfície e que não há transmigração do adsorbato no plano da superfície. A equação de Langmuir é termodinamicamente consistente e segue a lei de Henry para concentrações baixas.

A equação semi-empírica de Langmuir é:

$$
\mathrm{q}_{\mathrm{e}}=\frac{Q_{o} b C_{e}}{1+C_{e}}
$$

A expressão 9 na forma linear é:

$$
\frac{C_{e}}{q_{e}}=\frac{1}{Q_{o} b}+\frac{C_{e}}{Q_{o}}
$$

onde $\mathrm{C}_{\mathrm{e}}$ é a concentração do adsorbato no equilíbrio $\left(\mathrm{mg} \mathrm{L}^{-1}\right), \mathrm{q}_{\mathrm{e}}$ é a quantidade adsorvida no equilíbrio $\left(\mathrm{mg} \mathrm{g}^{-1}\right), \mathrm{Q}_{o}\left(\mathrm{mg} \mathrm{g}^{-1}\right)$ e $\mathrm{b}\left(\mathrm{L} \mathrm{mg}^{-1}\right)$ são constantes relacionadas com a capacidade de adsorção máxima e a energia de adsorção, respectivamente. 
$\mathrm{O}$ gráfico linear de $\mathrm{C}_{\mathrm{e}} / \mathrm{q}_{\mathrm{e}}$ vs $\mathrm{C}_{\mathrm{e}}$ confirma a validade do modelo de Langmuir para o processo. A equação de reta obtida apresentará coeficiente angular correspondente a 1/Q $\mathrm{Q}_{\mathrm{o}} \mathrm{e}$ coeficiente linear correspondente a $1 / \mathrm{Q}_{\mathrm{o}} \mathrm{b}$.

A característica essencial da isoterma pode ser expressa pela constante adimensional " $\mathrm{R}_{\mathrm{L}}$ " chamada parâmetro de equilíbrio ou fator de separação, a qual é definida como (Hall et al., 1966):

$\mathrm{R}_{\mathrm{L}}=\frac{1}{1+b C_{o}}$

onde $\mathrm{C}_{\mathrm{o}}$ é a concentração inicial do adsorbato $\left(\mathrm{mg} \mathrm{L}^{-1}\right)$ e b é a constante de Langmuir. $\mathrm{O}$ valor de $\mathrm{R}_{\mathrm{L}}$ indica a forma da isoterma e se um sistema de adsorção é favorável ou desfavorável (Tabela 1).

TABELA 1 - Relação entre o valor de $R_{L}$ e o processo de adsorção

\begin{tabular}{|ll|}
\hline Valor de $\mathrm{R}_{\mathrm{L}}$ & Processo de adsorção \\
\hline$>1$ & Não favorável \\
$=1$ & Linear \\
$0<\mathrm{R}_{\mathrm{L}}<1$ & Favorável \\
$=0$ & Irreversível \\
\hline
\end{tabular}

A isoterma de Freundlich considera que a adsorção ocorre em multicamadas e é útil para descrever sistemas com superfícies heterogêneas. Em muitos casos, fornece uma representação do equilíbrio de adsorção de um único soluto melhor do que a isoterma de Langmuir, sendo que o calor de adsorção depende da concentração na fase sólida. A desvantagem desta isoterma empírica é que ela não se reduz à Lei de Henry em concentrações próximas a zero e sua aplicabilidade é restrita a um intervalo de concentração limitado.

A expressão de Freundlich é dada por:

$\mathrm{qe}=\mathrm{K}_{\mathrm{f}} \mathrm{C}_{\mathrm{e}}^{1 / \mathrm{n}}$ 
A forma linear da equação (12) de Freundlich é:

$\log \mathrm{q}_{\mathrm{e}}=\log \mathrm{K}_{\mathrm{f}}+\frac{1}{n} \log C_{e}$

onde $\mathrm{C}_{\mathrm{e}}$ é a concentração do adsorbato no equilíbrio $\left(\mathrm{mg} \mathrm{L}^{-1}\right), \mathrm{q}_{\mathrm{e}}$ é a quantidade adsorvida no equilíbrio $\left(\mathrm{mg} \mathrm{g}^{-1}\right), \mathrm{K}_{\mathrm{f}}\left[\left(\mathrm{mg} \mathrm{g}^{-1}\right)\left(\mathrm{L} \mathrm{mg}^{-1}\right)^{1 / n}\right]$ e $\mathrm{n}$ são constantes relacionadas com a capacidade de adsorção e a intensidade de adsorção, respectivamente. Os valores de $\mathrm{K}_{\mathrm{f}} \mathrm{e} n$ podem ser obtidos pela intersecção e inclinação do gráfico linear de $\log \mathrm{q}_{\mathrm{e}}$ versus $\log \mathrm{C}_{\mathrm{e}} \mathrm{O}$ valor de n entre 2 e 10 indica processo de adsorção favorável (Helby, 1952).

\subsubsection{Termodinâmica de adsorção}

A mudança no conteúdo de calor de um sistema no qual a adsorção ocorre, ou seja, o conteúdo total de calor envolvido na adsorção de uma quantidade definida de adsorbato em um adsorvente é chamado de calor de adsorção (Weber, 1972). Quando um processo espontâneo ocorre, há um decréscimo na energia livre de Gibbs e um decréscimo na entropia porque as moléculas perdem pelo menos um grau de liberdade quando adsorvida (Thomas e Crittenden, 1998). Em processos de adsorção, a energia livre de Gibbs e a entalpia devem ser determinadas para indicar se o processo irá ocorrer espontaneamente. Os valores dos parâmetros termodinâmicos são os reais indicadores para a aplicação prática do processo.

Geralmente, os estudos têm indicado que um aumento da temperatura é acompanhado por um decréscimo na reação de adsorção e o cálculo dos parâmetros termodinâmicos mostra que o processo é exotérmico. Este fato é verdadeiro para adsorbatos não-polares, porém é difícil antecipar o efeito da temperatura em sistemas que contenham moléculas polares.

É importante conduzir experimentos de adsorção em uma faixa de temperaturas devido ao impacto significativo que as mudanças causam na extensão e na velocidade dos processos de adsorção. A temperatura das águas naturais, sistemas solo e sedimentos podem variar bastante entre o inverno e verão. Em processos industriais, a temperatura da água que sai pode ser significativamente maior do que daquela captada.

Os parâmetros termodinâmicos do processo de adsorção, energia livre de Gibbs $\left(\Delta \mathrm{G}^{\mathrm{o}}\right)$, entalpia $\left(\Delta \mathrm{H}^{\mathrm{o}}\right)$ e entropia $\left(\Delta \mathrm{S}^{\mathrm{o}}\right)$, podem ser calculados pelas seguintes equações: 
$\mathrm{K}_{\mathrm{C}}=\frac{C_{A}}{C_{s}}$

$\Delta \mathrm{G}^{\mathrm{o}}=-2,303 \mathrm{RT} \log \mathrm{K}_{\mathrm{C}}\left(\mathrm{em} \mathrm{kJ} \mathrm{mol}{ }^{-1}\right)$

$\Delta \mathrm{H}^{\mathrm{o}}=2,303 \mathrm{R}\left(\frac{T_{1} T_{2}}{T_{2}-T_{1}}\right) \log \frac{K_{C_{2}}}{K c_{1}}\left(\mathrm{em} \mathrm{kJ} \mathrm{mol}^{-1}\right)$

$\Delta \mathrm{S}^{\mathrm{o}}=\frac{\Delta H^{o}-\Delta G^{o}}{T}\left(\mathrm{em} \mathrm{J} \mathrm{K}^{-1} \mathrm{~mol}^{-1}\right)$

Onde

$\mathrm{K}_{\mathrm{C}}$ é a constante de equilíbrio

$\mathrm{C}_{\mathrm{A}}$ é a concentração do corante adsorvido no adsorvente no equilíbrio

$\mathrm{C}_{\mathrm{s}}$ é a concentração do corante em solução no equilíbrio

$\mathrm{R}=$ constante dos gases $\left(8,314 \mathrm{~J} \mathrm{~mol}^{-1} \mathrm{~K}^{-1}\right)$

$\mathrm{T}, \mathrm{T}_{1}$ e $\mathrm{T}_{2}$ são as temperaturas em Kelvin

$\mathrm{K}_{\mathrm{C}}, \mathrm{K}_{\mathrm{C} 1}$ e $\mathrm{K}_{\mathrm{C} 2}$ são as constantes de equilíbrio nas temperaturas $\mathrm{T}, \mathrm{T}_{1}$ e $\mathrm{T}_{2}$, respectivamente.

A TAB. 2 mostra os valores dos parâmetros termodinâmicos característicos para processos de adsorção espontâneos e não espontâneos.

TABELA 2 - Valores característicos de variação de entalpia $\left(\Delta H^{0}\right)$, de entropia $\left(\Delta S^{0}\right)$ e de energia livre de Gibbs $\left(\Delta \mathrm{G}^{0}\right)$ para processos de adsorção espontâneos e não-espontâneos.

\begin{tabular}{|c|c|c|l|}
\hline$\Delta \mathrm{H}^{0}$ & $\Delta \mathrm{S}^{0}$ & $\Delta \mathrm{G}^{0}$ & Processo \\
\hline$<0$ & $>0$ & $<0$ & Espontâneo \\
\hline$>0$ & $<0$ & $>0$ & Não-espontâneo \\
\hline$<0$ & $<0$ & $<0$ a T baixa & Espontâneo \\
\hline$<0$ & $<0$ & $>0$ a T alta & Não - espontâneo \\
\hline$>0$ & $>0$ & $>0$ a T baixa & Não-espontâneo \\
\hline$>0$ & $>0$ & $<0$ a T alta & Espontâneo \\
\hline
\end{tabular}




\section{Materiais e Métodos}

\section{1. Área de Estudo}

A usina termelétrica de Figueira a base de carvão situa-se no município de Figueira, na região denominada Vale Rio do Peixe (Figura 3). O Município de Figueira localiza-se no Norte do Estado do Paraná, a $230^{\circ} 51^{\prime}$ 00" latitude sul e $500^{\circ} 24^{\prime} 00^{\prime \prime}$ longitude norte. Abrangendo uma área territorial de $115 \mathrm{Km}^{2}$, o município pertence a Microregião Geográfica de Ibaiti, que segundo a divisão adotada pelo IBGE (1991), é composta por 8 municípios: Conselheiro Mairinck, Curiúva, Figueira, Ibaiti, Jaboti, Japira, Pinhalão e Sapopema.

Nesta região está a principal bacia carbonífera do Estado. A usina tem uma capacidade atual de 125 MW consumindo carvão mineral procedente da Mina Cambuí, localizada a $5 \mathrm{~km}$ da usina. A usina já está em operação há aproximadamente 40 anos (de 1963 a 1998, sem filtros, e de 1998 aos dias atuais, com filtros). A área adjacente à usina é predominantemente agrícola e com baixa densidade populacional. A operação e a manutenção desta usina estão sendo executadas desde 1994 pela Companhia Carbonífera do Cambuí Ltda. 


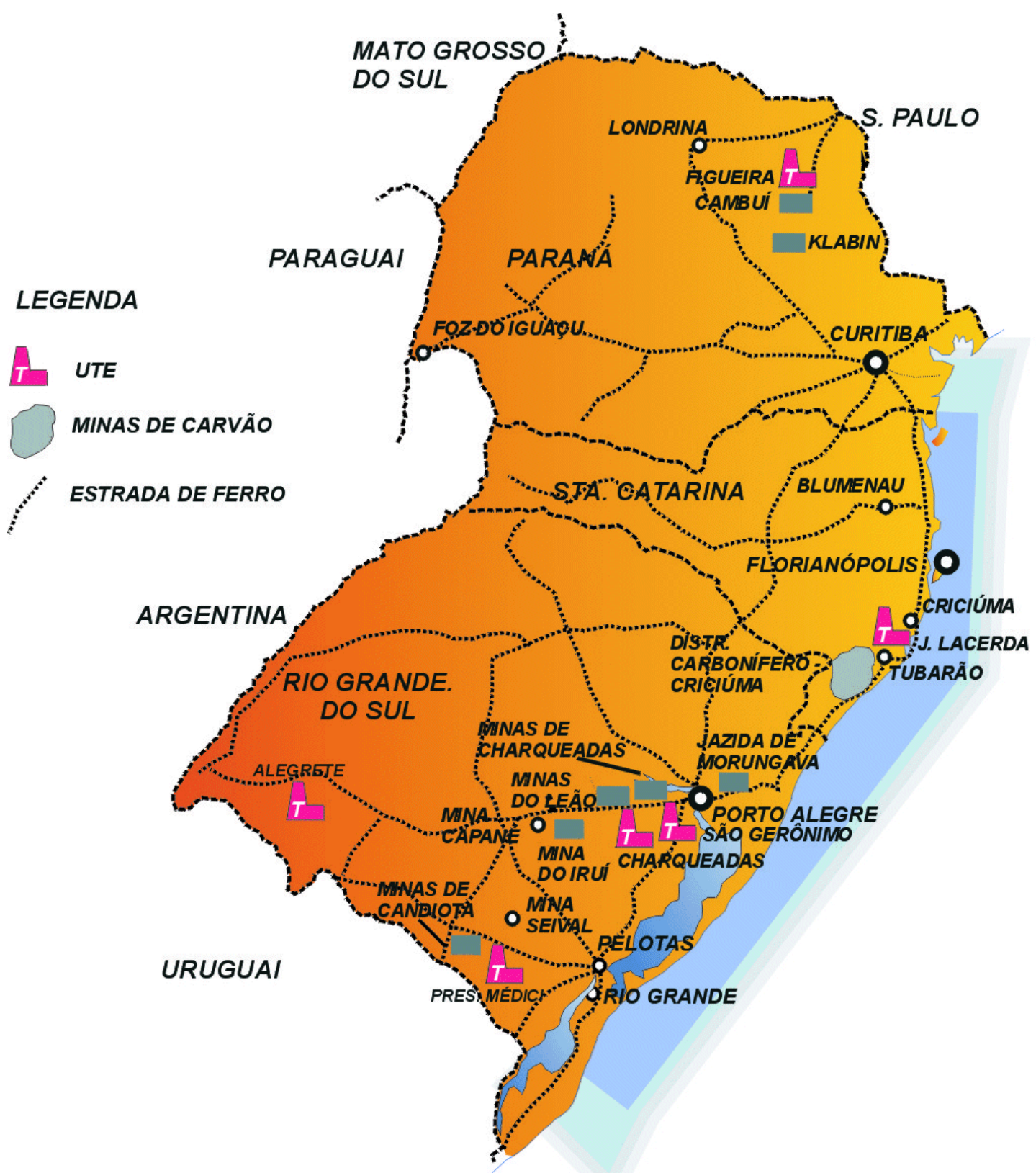

FIGURA 3 - Localização da Usina Termelétrica de Figueira - PR 


\subsection{Amostras de Cinzas de Carvão}

As cinzas leves, que provém do processo de combustão do carvão para geração de energia na usina termelétrica em estudo, foram coletadas em filtro do tipo manga que retêm as frações dos grãos das cinzas antes de serem liberados para a atmosfera pela chaminé.

As amostras foram coletadas num período de 10 meses (entre 2001 e 2002), em intervalos de 2 meses, totalizando 5 lotes. Em cada lote foram coletados aproximadamente $1 \mathrm{~kg}$ de cinzas de carvão. As cinzas do filtro manga (CM) com números de 1 a 5 referem-se ao material coletado nas 5 amostragens, respectivamente. A composição química das cinzas de carvão foi determinada por fluorescência de raios-X (XRFS RIX 300 - Rigaku).

\subsection{Reagentes e Soluções}

Todos os reagentes usados foram de grau analítico. As soluções do azul de metileno foram preparadas a partir da diluição de solução estoque com água ultrapura do sistema Millipore Milli-Q. Os $\mathrm{pH}$ das soluções do corante foram ajustados com $\mathrm{HNO}_{3}$ $0,1 \mathrm{~mol} \mathrm{~L}^{-1}$ e $\mathrm{NaOH} 0,5 \mathrm{~mol} \mathrm{~L}^{-1}$.

\subsection{Preparação das zeólitas por síntese hidrotérmica}

O procedimento de Henmi (1987) foi seguido no tratamento hidrotérmico: a amostra contendo $30 \mathrm{~g}$ de cinzas de carvão foi colocada com $240 \mathrm{~mL}$ de $\mathrm{NaOH} 3,5 \mathrm{~mol} \mathrm{~L}^{-1}$ (relação cinzas/solução 0,125 g. $\mathrm{mL}^{-1}$ ) e aquecida em estufa, à $100^{\circ} \mathrm{C}$, por $24 \mathrm{~h}$. A suspensão foi filtrada e o sólido foi repetidamente lavado com água deionizada até $\mathrm{pH} \sim 10$ e seco em estufa a $50^{\circ} \mathrm{C}$. Outros parâmetros de ativação das cinzas de carvão foram usados: $\mathrm{NaOH}$ 4,0 e 7,0 mol L-1; temperatura de $90{ }^{\circ} \mathrm{C}$; tempo de reação $21,48,72$ e $96 \mathrm{~h} \mathrm{e}$ relação cinzas/solução $0,1 \mathrm{~g} \mathrm{~mL}^{-1}$.

\subsection{Estudos sobre a remoção do corante}

A remoção do azul de metileno em solução aquosa pelas zeólitas foi realizada por processos descontínuos. Uma alíquota de $100 \mathrm{~mL}$ de solução do corante de concentração conhecida (faixa de 1,6 a $32 \mathrm{mg} \mathrm{L}^{-1}$ ) foi colocada em um béquer com $1 \mathrm{~g}$ de zeólita e agitada com agitador mecânico com temperatura controlada á 120 rpm. Após um 
tempo de contato desejado, o sobrenadante foi separado por centrifugação e a concentração final nesta solução foi determinada.

A concentração do corante azul de metileno foi determinada por espectrofotometria UV-visível (espectrofotômetro modelo Cary 1E da Varian), no comprimento de onda correspondente á absorbância máxima, $\lambda_{\max }=650 \mathrm{~nm}$, após ajuste do $\mathrm{pH}$ ótimo $(\mathrm{pH}=5)$. As curvas analíticas da absorbância versus a concentração do corante em solução foram obtidas. O desvio padrão relativo nas medições da absorbância em triplicata estava na faixa de 0,2 a $0,7 \%$. A capacidade de adsorção do adsorvente no equilíbrio $\left(\mathrm{q}_{\mathrm{e}} \mathrm{em} \mathrm{mg} \mathrm{g}^{-1}\right)$ foi calculada através de um balanço de massa, considerando que o corante que não se encontra na solução está adsorvido na fase sólida:

$$
\mathrm{q}_{\mathrm{e}}=\frac{V\left(C_{o}-C_{e}\right)}{M}
$$

Onde V (L) é o volume da solução inicial, $\mathrm{C}_{\mathrm{o}}\left(\mathrm{mg} \mathrm{L}^{-1}\right)$ é a concentração inicial da solução, $\mathrm{C}_{\mathrm{e}}\left(\mathrm{mg} \mathrm{L}^{-1}\right)$ é a concentração final da solução obtida no equilíbrio e $\mathrm{M}$ (g) é a massa de zeólita. O tempo de equilíbrio utilizado para obtenção das isotermas foi determinado a partir dos estudos cinéticos. 


\section{RESULTADOS E DISCUSSÃO}

\subsection{Caracterização Química das Cinzas de Carvão}

A TAB. 3 apresenta a composição química (em \% em massa) determinada por fluorescência de raios-X de todas as cinzas de carvão utilizadas no estudo.

TABELA 3 - Composição química das cinzas de carvão de diferentes amostragens

\begin{tabular}{cccccc}
\hline $\begin{array}{c}\text { Óxidos } \\
\text { (\%em massa) }\end{array}$ & $\mathbf{C M 1}$ & $\mathbf{C M 2}$ & $\begin{array}{c}\text { Cinzas de carvão } \\
\mathbf{C M 3}\end{array}$ & $\mathbf{C M 4}$ & CM5 \\
\hline $\mathrm{SiO}_{2}$ & 19,8 & 20,4 & 18,7 & 19,8 & 18,4 \\
$\mathrm{Al}_{2} \mathrm{O}_{3}$ & 17,5 & 15,9 & 15,3 & 17,3 & 18,8 \\
$\mathrm{Fe}_{2} \mathrm{O}_{3}$ & 6,38 & 6,99 & 6,73 & 6,59 & 5,78 \\
$\mathrm{Na}_{2} \mathrm{O}$ & 1,18 & 1,18 & 1,07 & 1,20 & 0,975 \\
$\mathrm{CaO}$ & 0,777 & 0,86 & 0,763 & 0,826 & 0,733 \\
$\mathrm{~K}_{2} \mathrm{O}$ & 2,82 & 2,94 & 2,4 & 2,71 & 2,51 \\
$\mathrm{TiO}_{2}$ & 0,520 & 0,471 & 0,448 & 0,549 & 0,55 \\
$\mathrm{SO}_{3}$ & 0,4 & 0,582 & 0,82 & 0,419 & 0,731 \\
$\mathrm{MgO}$ & 0,539 & 0,483 & 0,4 & 0,455 & 0,406 \\
$\mathrm{ZnO}^{\mathrm{As}} \mathrm{O}_{3}$ & 0,181 & 0,131 & 0,147 & 0,245 & 0,219 \\
$\mathrm{P}_{2} \mathrm{O}_{5}$ & 0,176 & & 0,189 & 0,207 & 0,25 \\
$\mathrm{SiO}_{2} / \mathrm{Al}_{2} \mathrm{O}_{3}$ & - & - & - & - & 0,14 \\
\hline
\end{tabular}

As cinzas de carvão apresentaram conteúdos de alumina e sílica muito similares $(15-21 \%)$, conteúdos baixos: de óxido férrico $(6-7 \%)$, de óxido de enxofre $(0,40-0,82 \%)$ e óxidos de cálcio $(0,73-0,86 \%)$. Encontraram-se os óxidos de sódio, potássio, titânio, magnésio e outros compostos em quantidades menores que $3 \%$.

As cinzas leves do filtro manga apresentaram uma relação $\mathrm{SiO}_{2} / \mathrm{Al}_{2} \mathrm{O}_{3}$ muito baixa comparada com a maioria das cinzas leves de carvão $(\sim 2 \mathrm{~m} / \mathrm{m})$ (Zeng et al., 2002). Esta característica em conjunto com o conteúdo relativamente baixo das impurezas de óxidos de $\mathrm{Fe}, \mathrm{Ca}$ e $\mathrm{S}$ confere um alto potencial para o uso destas amostras como matériaprima para a síntese de zeólitas com baixo teor de silício.

As concentrações dos elementos traço das cinzas de carvão têm importante implicação por causa do impacto ambiental potencial derivado da possível solubilização dos elementos tóxicos durante a síntese da zeólita. As concentrações dos elementos traço mostradas na TAB. 4 podem ser sumarizadas da seguinte forma: 
- O conteúdo de Mn (254-279 $\mu \mathrm{g} / \mathrm{g}) ; \mathrm{Pb}(258-627 \mu \mathrm{g} / \mathrm{g}) ; \mathrm{Sr}(201-394 \mu \mathrm{g} / \mathrm{g}) ; \mathrm{Cr}(135-181$ $\mu \mathrm{g} / \mathrm{g}) ; \mathrm{P}(438-691 \mu \mathrm{g} / \mathrm{g}) ; \mathrm{Cu}(50-68 \mu \mathrm{g} / \mathrm{g}) ; \mathrm{Ni}(63-92 \mu \mathrm{g} / \mathrm{g}) ; \mathrm{U}(192-355 \mu \mathrm{g} / \mathrm{g}) ; \mathrm{Y}(114-177$ $\mu \mathrm{g} / \mathrm{g}) ; \mathrm{Rb}(43-48 \mu \mathrm{g} / \mathrm{g}) ; \mathrm{Zr}(527-751 \mu \mathrm{g} / \mathrm{g})$ e $\mathrm{Ge}(45-73 \mu \mathrm{g} / \mathrm{g})$ não apresentaram variações significativas entre as cinzas de carvão.

- A cinza de carvão CM5 apresentou enriquecimento dos seguintes elementos quando comparada com as outras cinzas: $\mathrm{Pb}(627 \mu \mathrm{g} / \mathrm{g})$; Ge $(151 \mu \mathrm{g} / \mathrm{g})$ e $\mathrm{Zr}(900 \mu \mathrm{g} / \mathrm{g})$.

De modo geral, as cinzas têm grande aplicação na síntese de zeólitas já que apresentaram concentração baixa de Sr e ausência de Ba e Mo em relação aos elementos solúveis. Em relação aos elementos tóxicos apresentaram ausência de $\mathrm{Hg}, \mathrm{Cd}$ e $\mathrm{Se}$. No tratamento do efluente, após a zeolitização da cinza CM5 deve-se ter atenção apenas em relação ao $\mathrm{Pb}, \mathrm{U}$, As e $\mathrm{Zn}$.

TABELA 4 - Concentrações dos elementos traço das cinzas de carvão de diferentes amostragens

\begin{tabular}{cccccc}
\hline Elementos traço & \multicolumn{5}{c}{ Cinzas de Carvão } \\
$(\boldsymbol{\mu g} / \mathbf{g})$ & $\mathbf{C M 1}$ & $\mathbf{C M 2}$ & $\mathbf{C M 3}$ & $\mathbf{C M 4}$ & $\mathbf{C M 5}$ \\
\hline $\mathrm{Mn}$ & 278 & 267 & 254 & 279 & 219 \\
$\mathrm{~Pb}$ & 323 & 258 & 324 & 427 & 627 \\
$\mathrm{Sr}$ & 323 & 201 & 294 & 328 & 394 \\
$\mathrm{Cr}$ & 147 & 135 & 135 & 181 & 165 \\
$\mathrm{P}$ & 691 & 438 & 534 & 674 & \\
$\mathrm{Cu}$ & 66 & 50 & 53 & 68 & 88 \\
$\mathrm{Ni}$ & 89 & 67 & 63 & 66 & 92 \\
$\mathrm{U}$ & 308 & 192 & 294 & 355 & \\
$\mathrm{Y}$ & 114 & 114 & 132 & 131 & 177 \\
$\mathrm{As}$ & & 889 & & & \\
$\mathrm{Rb}$ & 49 & 48 & 43 & 49 & 48 \\
$\mathrm{Zr}$ & 751 & 527 & 726 & 710 & 900 \\
$\mathrm{~V}$ & & & 192 & 294 & 293 \\
$\mathrm{Ge}$ & 73 & 45 & 47 & 87 & 151 \\
$\mathrm{Ga}$ & 29 & & & 28 & 35 \\
\hline
\end{tabular}




\subsection{Estudo da influência das amostras de cinzas de carvão}

O tipo e a quantidade de zeólita que é sintetizada dependem de condições experimentais, sendo que as mais importantes são: composição da cinza, razão líquido/sólido, temperatura, tempo de reação e, concentração e tipo do agente de ativação.

As cinzas de carvão retidas no filtro manga de 5 amostragens diferentes foram submetidas às mesmas condições de tratamento hidrotérmico e as eficiências de adsorção de azul de metileno em água dos diferentes tipos de produtos zeolíticos foram comparadas.

Os parâmetros de ativação usados foram: concentração de $\mathrm{NaOH}$ de $3,5 \mathrm{~mol} \mathrm{~L}^{-1}$; tempo de reação de $24 \mathrm{~h}$; temperatura de $100{ }^{\circ} \mathrm{C}$ e relação sólido/líquido de $0,125 \mathrm{~g} \mathrm{~mL}^{-1}$. As zeólitas das cinzas do filtro manga (ZM) com números de 1 a 5 referem-se ás respectivas amostras de cinzas coletadas nas 5 amostragens.

\subsubsection{Efeito do tempo de contato}

O efeito do tempo de agitação e da concentração inicial na adsorção do azul de metileno pelas zeólitas ZM1 a ZM5 foram investigados (FIG. 4). O tempo de equilíbrio foi de 90 min para todos os adsorventes e a eficiência de adsorção estava entre 43 a $90 \%$. O aumento da concentração inicial causou uma maior competição das moléculas de azul de metileno pelos sítios ativos dos adsorventes e, como resultado, mais corante foi adsorvido por grama de zeólita. 

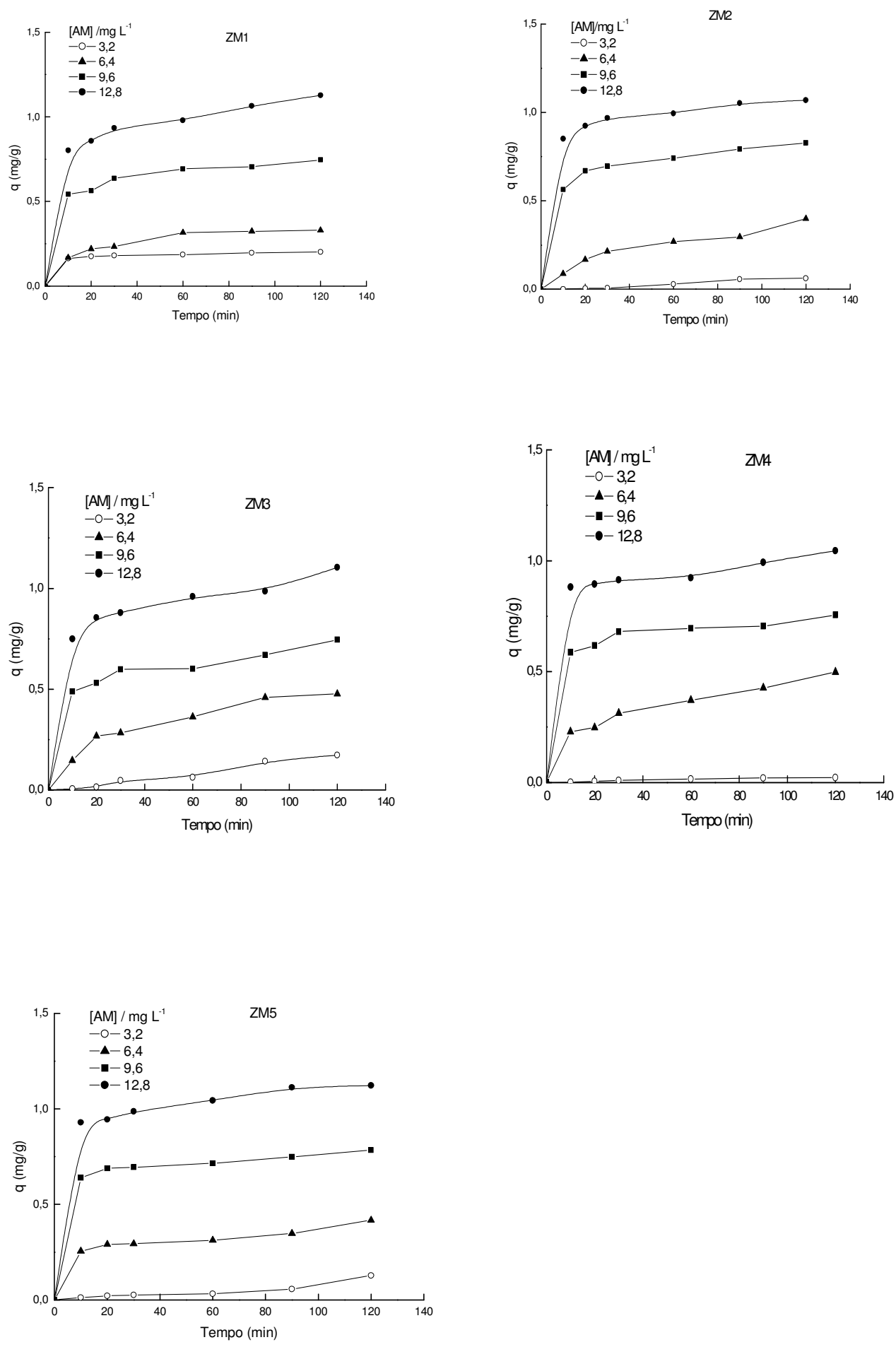

FIGURA 4 - Efeito do tempo de agitação e da concentração do azul de metileno sobre a capacidade de adsorção das zeólitas ZM1 a ZM5. 


\subsubsection{Modelos cinéticos de adsorção}

O comportamento transiente do processo de adsorção do azul de metileno pelos adsorventes foi analisado usando os modelos cinéticos de pseudo-primeira-ordem de Lagergren; pseudo segunda-ordem de Ho e McKay e modelo da difusão intrapartícula.

As FIG. 5, 6, 7, 8 e 9 mostram os ajustes dos resultados do processo de adsorção do azul de metileno sobre as zeólitas ZM1 a ZM5 aos vários modelos cinéticos e os parâmetros de todos os modelos encontram-se nas TAB. 5, 6, 7, 8 e 9.
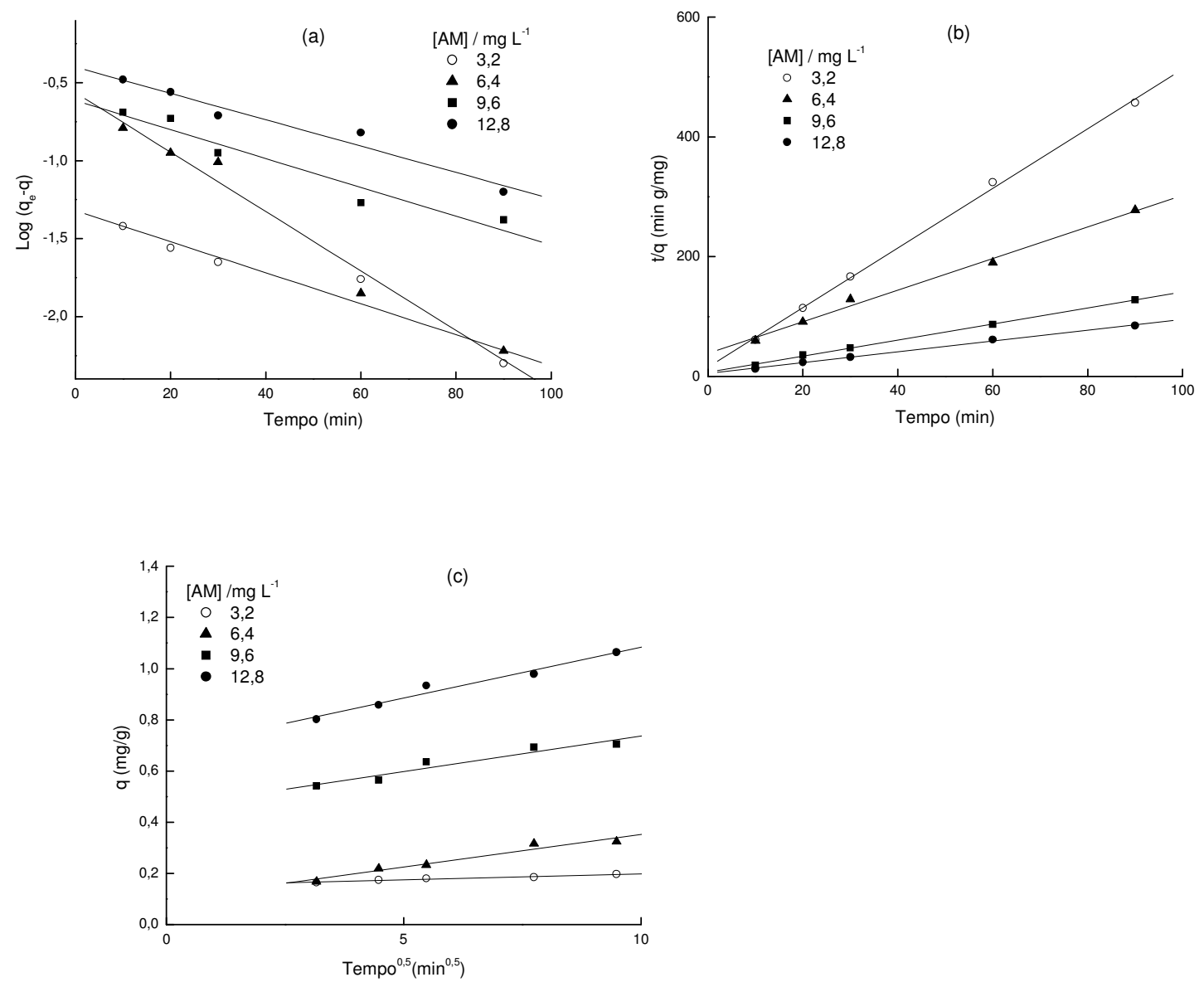

FIGURA 5 - Comparação dos modelos de adsorção do azul de metileno sobre ZM1 (a) cinética pseudo-primeria-ordem; (b) cinética de pseudo-segunda-ordem; (c) difusão intraparticula 

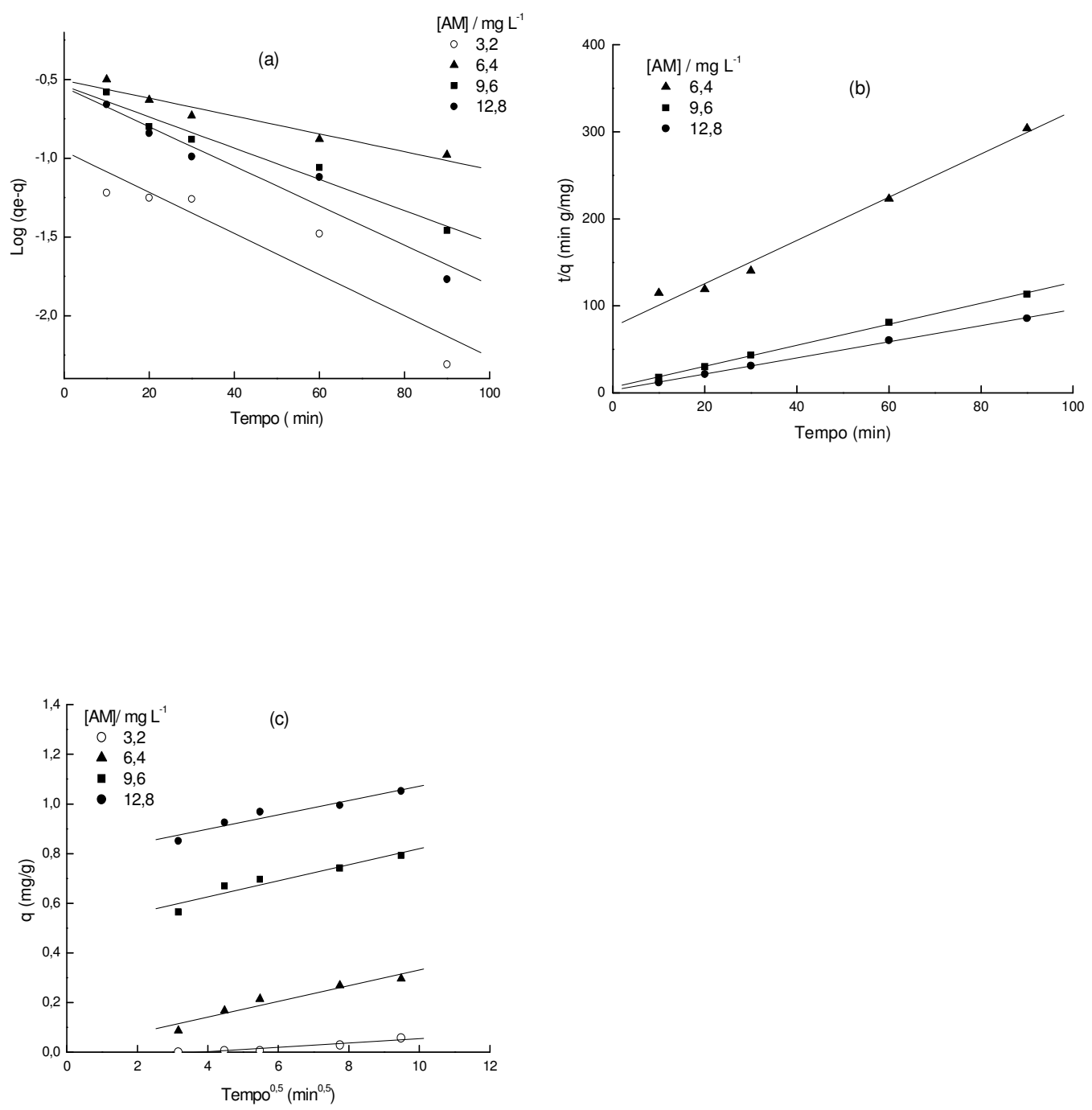

FIGURA 6 - Comparação dos modelos cinéticos da adsorção do azul de metileno sobre ZM2: (a) cinética de pseudo-primeira-ordem; (b) cinética de pseudo-segunda-ordem; (c) difusão intrapartícula. 

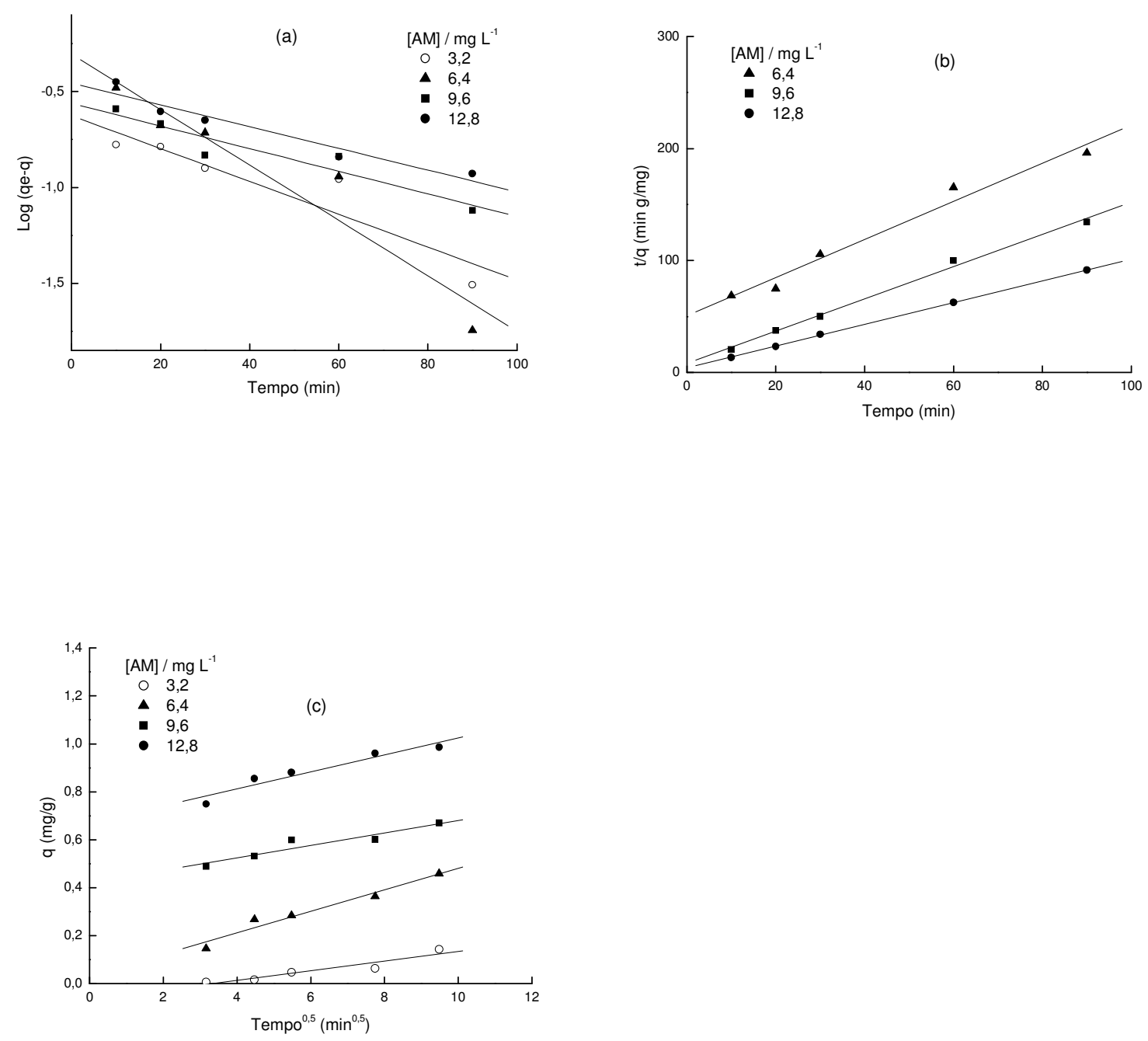

FIGURA 7 - Comparação dos modelos cinéticos da adsorção do azul de metileno sobre ZM3: (a) cinética de pseudo-primeira-ordem; (b) cinética de pseudo-segunda-ordem; (c) difusão intrapartícula. 

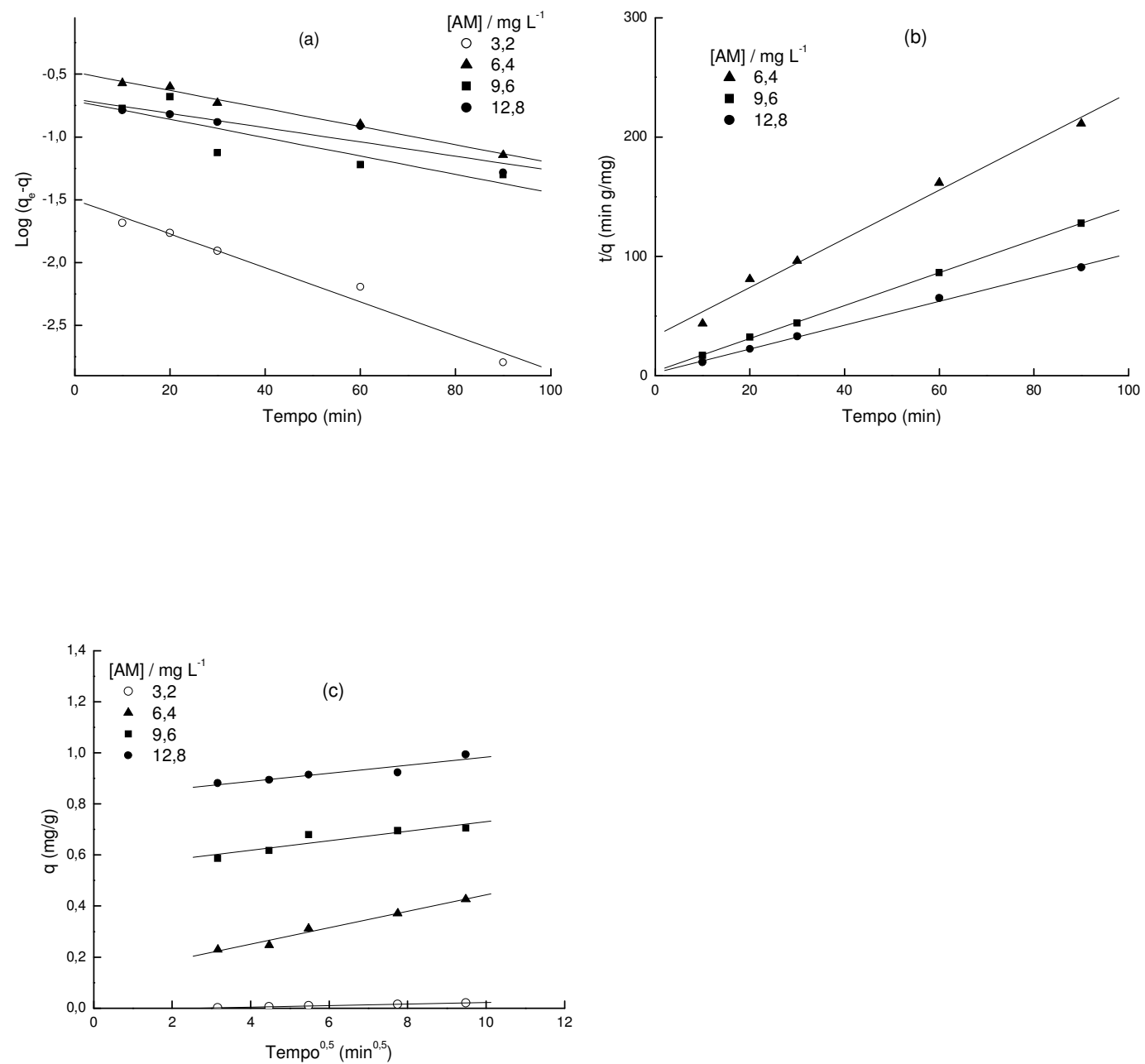

FIGURA 8 - Comparação dos modelos cinéticos da adsorção do azul de metileno sobre ZM4: (a) cinética de pseudo-primeira-ordem; (b) cinética de pseudo-segunda-ordem; (c) difusão intrapartícula. 

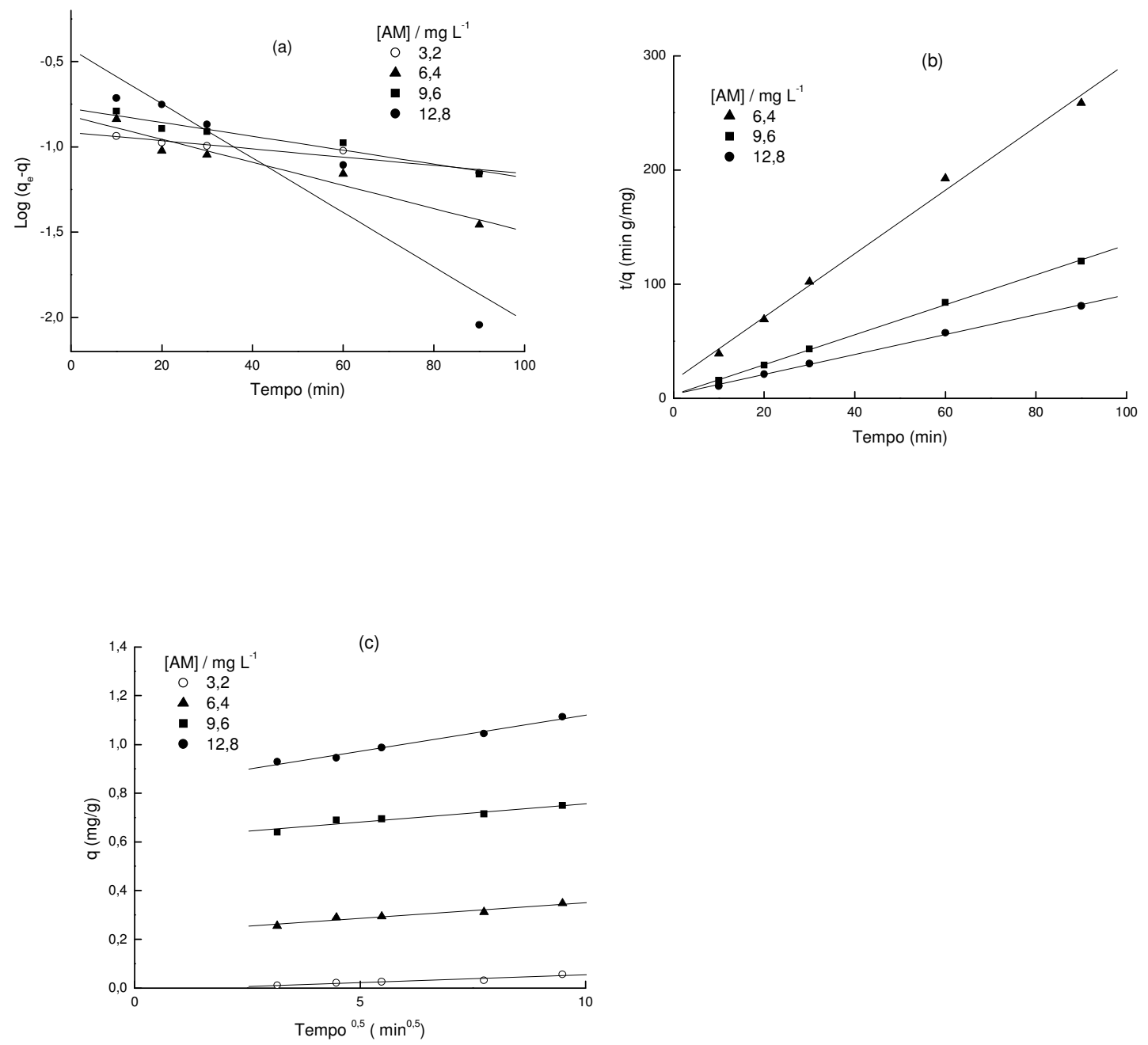

FIGURA 9 - Comparação dos modelos cinéticos da adsorção do azul de metileno sobre ZM5: (a) cinética de pseudo-primeira-ordem; (b) cinética de pseudo-segunda-ordem; (c) difusão intrapartícula. 
TABELA 5 - Parâmetros cinéticos para a remoção do azul de metileno pela zeólita ZM1

\begin{tabular}{|c|c|c|c|c|}
\hline [AM] & Pseudo- $1^{\mathrm{a}}$ or & & & \\
\hline$(\mathrm{mg} / \mathrm{L})$ & $\begin{array}{l}\mathrm{K}_{1} \times 10^{-2} \\
\left(\mathrm{~min}^{-1}\right)\end{array}$ & $\mathrm{R}_{1}^{2}$ & & \\
\hline 3,2 & 2,28 & 0,962 & & \\
\hline 6,4 & 4,39 & 0,987 & & \\
\hline 9,6 & 2,12 & 0,970 & & \\
\hline \multirow[t]{3}{*}{12,8} & 1,94 & 0,980 & & \\
\hline & \multicolumn{4}{|c|}{ Pseudo- $2^{\mathrm{a}}$ ordem } \\
\hline & $\begin{array}{l}\mathrm{K}_{2} \times 10^{-1} \\
(\mathrm{~g} / \mathrm{mg} \min )\end{array}$ & $\begin{array}{l}\mathrm{h} \times 10^{-2} \\
(\mathrm{mg} / \mathrm{g} \mathrm{min})\end{array}$ & $\begin{array}{l}\mathrm{q}_{\mathrm{e}} \times 10^{-1} \\
(\mathrm{mg} / \mathrm{g})\end{array}$ & $\mathrm{R}_{2}^{2}$ \\
\hline 3,2 & 15,9 & 6,41 & 2,00 & 0,999 \\
\hline 6,4 & 1,80 & 2,59 & 3,79 & 0,997 \\
\hline 9,6 & 2,72 & 15,1 & 7,44 & 0,999 \\
\hline \multirow[t]{3}{*}{12,8} & 1,68 & 20,6 & 11,1 & 0,999 \\
\hline & \multicolumn{4}{|c|}{ Difusão intrapartícula } \\
\hline & $\begin{array}{l}\mathrm{K}_{\mathrm{i}} \times 10^{-2} \\
\left(\mathrm{mg} / \mathrm{g} \min ^{0,5}\right)\end{array}$ & $\mathrm{R}_{\mathrm{i}}^{2}$ & & \\
\hline 3,2 & 0,468 & 0,976 & & \\
\hline 6,4 & 2,56 & 0,976 & & \\
\hline 9,6 & 2,79 & 0,961 & & \\
\hline 12,8 & 3,98 & 0,985 & & \\
\hline
\end{tabular}


TABELA 6 - Parâmetros cinéticos para a remoção do azul de metileno pela zeólita ZM2

\begin{tabular}{|c|c|c|c|c|}
\hline$[\mathrm{AM}]$ & Pseudo $-1^{\mathrm{a}}$ or & & & \\
\hline$(\mathrm{mg} / \mathrm{L})$ & $\begin{array}{l}\mathrm{K}_{1} \times 10^{-2} \\
\left(\mathrm{~min}^{-1}\right)\end{array}$ & $\mathrm{R}_{1}^{2}$ & & \\
\hline 3,2 & 3,01 & 0,923 & & \\
\hline 6,4 & 1,31 & 0,967 & & \\
\hline 9,6 & 2,29 & 0,982 & & \\
\hline \multirow[t]{3}{*}{12,8} & 2,89 & 0,966 & & \\
\hline & \multicolumn{4}{|c|}{ Pseudo- $2^{\mathrm{a}}$ ordem } \\
\hline & $\begin{array}{l}\mathrm{K}_{2} \times 10^{-1} \\
(\mathrm{~g} / \mathrm{mg} \min )\end{array}$ & $\begin{array}{l}\mathrm{h} \times 10^{-2} \\
(\mathrm{mg} / \mathrm{g} \mathrm{min})\end{array}$ & $\begin{array}{l}\mathrm{q}_{\mathrm{e}} \times 10^{-1} \\
(\mathrm{mg} / \mathrm{g})\end{array}$ & $\mathrm{R}_{2}^{2}$ \\
\hline 6,4 & 0,812 & 1,32 & 4,03 & 0,993 \\
\hline 9,6 & 2,29 & 15,7 & 8,29 & 0,999 \\
\hline \multirow[t]{3}{*}{12,8} & 2,77 & 32,2 & 10,8 & 0,999 \\
\hline & \multicolumn{4}{|c|}{ Difusão intrapartícula } \\
\hline & $\begin{array}{l}\mathrm{K}_{\mathrm{i}} \times 10^{-2} \\
\left(\mathrm{mg} / \mathrm{g} \min ^{0,5}\right)\end{array}$ & $\mathrm{R}_{\mathrm{i}}^{2}$ & & \\
\hline 3,2 & 0,880 & 0,954 & & \\
\hline 6,4 & 3,15 & 0,963 & & \\
\hline 9,6 & 3,22 & 0,955 & & \\
\hline 12,8 & 2,87 & 0,964 & & \\
\hline
\end{tabular}


TABELA 7 - Parâmetros cinéticos para a remoção do azul de metileno pela zeólita ZM3

\begin{tabular}{|c|c|c|c|c|}
\hline$[\mathrm{AM}]$ & Pseudo- $1^{\mathrm{a}}$ or & & & \\
\hline$(\mathrm{mg} / \mathrm{L})$ & $\begin{array}{l}\mathrm{K}_{1} \times 10^{-2} \\
\left(\min ^{-1}\right)\end{array}$ & $\mathrm{R}_{1}^{2}$ & & \\
\hline 3,2 & 1,97 & 0,929 & & \\
\hline 6,4 & 3,33 & 0,958 & & \\
\hline 9,6 & 1,36 & 0,949 & & \\
\hline \multirow[t]{3}{*}{12,8} & 1,31 & 0,968 & & \\
\hline & \multicolumn{4}{|c|}{ Pseudo- $2^{\mathrm{a}}$ ordem } \\
\hline & $\begin{array}{l}\mathrm{K}_{2} \times 10^{-1} \\
(\mathrm{~g} / \mathrm{mg} \min )\end{array}$ & $\begin{array}{l}\mathrm{h} \times 10^{-2} \\
(\mathrm{mg} / \mathrm{g} \mathrm{min})\end{array}$ & $\begin{array}{l}\mathrm{q}_{\mathrm{e}} \times 10^{-1} \\
(\mathrm{mg} / \mathrm{g})\end{array}$ & $\mathrm{R}_{2}^{2}$ \\
\hline 6,4 & 5,71 & 1,78 & 5,88 & 0,987 \\
\hline 9,6 & 2,58 & 12,5 & 6,95 & 0,997 \\
\hline \multirow[t]{3}{*}{12,8} & 2,27 & 24,1 & 10,3 & 0,999 \\
\hline & \multicolumn{4}{|c|}{ Difusão intrapartícula } \\
\hline & $\begin{array}{l}\mathrm{K}_{\mathrm{i}} \times 10^{-2} \\
\left(\mathrm{mg} / \mathrm{g} \min ^{0,5}\right)\end{array}$ & $\mathrm{R}_{\mathrm{i}}^{2}$ & & \\
\hline 3,2 & 2,02 & 0,947 & & \\
\hline 6,4 & 4,45 & 0,979 & & \\
\hline 9,6 & 2,61 & 0,948 & & \\
\hline 12,8 & 3,55 & 0,961 & & \\
\hline
\end{tabular}


TABELA 8 - Parâmetros cinéticos para a remoção do azul de metileno pela zeólita ZM4

\begin{tabular}{|c|c|c|c|c|}
\hline$[\mathrm{AM}]$ & Pseudo $-1^{\mathrm{a}}$ or & & & \\
\hline$(\mathrm{mg} / \mathrm{L})$ & $\begin{array}{l}\mathrm{K}_{1} \times 10^{-2} \\
\left(\min ^{-1}\right)\end{array}$ & $\mathrm{R}_{1}^{2}$ & & \\
\hline 3,2 & 3,13 & 0,986 & & \\
\hline 6,4 & 1,65 & 0,995 & & \\
\hline 9,6 & 1,68 & 0,862 & & \\
\hline \multirow[t]{3}{*}{12,8} & 1,31 & 0,927 & & \\
\hline & \multicolumn{3}{|c|}{ Pseudo $-2^{\mathrm{a}}$ ordem } & \\
\hline & $\begin{array}{l}\mathrm{K}_{2} \times 10^{-1} \\
(\mathrm{~g} / \mathrm{mg} \min )\end{array}$ & $\begin{array}{l}\mathrm{h} \times 10^{-2} \\
(\mathrm{mg} / \mathrm{g} \min )\end{array}$ & $\begin{array}{l}\mathrm{q}_{\mathrm{e}} \times 10^{-1} \\
(\mathrm{mg} / \mathrm{g})\end{array}$ & $\mathrm{R}_{2}{ }^{2}$ \\
\hline 6,4 & 1,25 & 3,01 & 4,91 & 0,994 \\
\hline 9,6 & 5,14 & 27,1 & 7,26 & 0,999 \\
\hline \multirow[t]{3}{*}{12,8} & 3,95 & 39,7 & 10,0 & 0,999 \\
\hline & \multicolumn{2}{|c|}{ Difusão intrapartícula } & & \\
\hline & $\begin{array}{l}\mathrm{K}_{\mathrm{i}} \times 10^{-2} \\
\left(\mathrm{mg} / \mathrm{g} \min ^{0,5}\right)\end{array}$ & $\mathrm{R}_{\mathrm{i}}^{2}$ & & \\
\hline 3,2 & 0,305 & 0,996 & & \\
\hline 6,4 & 3,23 & 0,989 & & \\
\hline 9,6 & 1,87 & 0,912 & & \\
\hline 12,8 & 1,16 & 0,934 & & \\
\hline
\end{tabular}


TABELA 9 - Parâmetros cinéticos para a remoção do azul de metileno pela zeólita ZM5

[AM] Pseudo- $1^{\text {a }}$ ordem

\begin{tabular}{lll}
$(\mathrm{mg} / \mathrm{L})$ & $\begin{array}{l}\mathrm{K}_{1} \times 10^{-2} \\
\left(\mathrm{~min}^{-1}\right)\end{array}$ & $\mathrm{R}_{1}{ }^{2}$ \\
\hline 3,2 & 0,557 & 0,960 \\
\hline 6,4 & 1,56 & 0,968 \\
\hline 9,6 & 0,935 & 0,970 \\
\hline 12,8 & 3,67 & 0,946
\end{tabular}

Pseudo $-2^{\mathrm{a}}$ ordem

\begin{tabular}{lllll} 
& $\begin{array}{l}\mathrm{K}_{2} \times 10^{-1} \\
(\mathrm{~g} / \mathrm{mg} \min )\end{array}$ & $\begin{array}{l}\mathrm{h} \times 10^{-2} \\
(\mathrm{mg} / \mathrm{g} \min )\end{array}$ & $\begin{array}{l}\mathrm{q}_{\mathrm{e}} \times 10^{-1} \\
(\mathrm{mg} / \mathrm{g})\end{array}$ & \\
\hline 6,4 & 4,93 & 6,39 & 3,60 & 0,997 \\
9,6 & 5,31 & 30,8 & 7,62 & 0,999 \\
12,8 & 2,23 & 29,2 & 11,4 & 0,999 \\
\hline
\end{tabular}

Difusão intrapartícula

\begin{tabular}{lll} 
& $\mathrm{K}_{\mathrm{i}} \times 10^{-2}$ & $\mathrm{R}_{\mathrm{i}}^{2}$ \\
& $\left(\mathrm{mg} / \mathrm{g} \mathrm{\operatorname {min } ^ { 0 , 5 } )}\right.$ \\
\hline 3,2 & 0,635 & 0,955 \\
6,4 & 1,29 & 0,969 \\
9,6 & 1,51 & 0,955 \\
12,8 & 2,95 & 0,991 \\
\hline
\end{tabular}

A avaliação quantitativa dos modelos requer que os coeficientes de correlação sejam comparados $\left(\mathrm{R}^{2}\right)$. Comparando-se os dados das TAB. 5, 6, 7, 8 e 9, observou-se que os valores dos coeficientes de correlação calculados para os modelos cinéticos de pseudo-primeira-ordem de Lagergren e pseudo-segunda-ordem de Ho, eram maiores que 0,9 mostrando a aplicabilidade de ambos os modelos cinéticos. As capacidades de adsorção das zeólitas ZM2 a ZM3 apresentaram valores muito baixos com a concentração do azul metileno de 3,2 $\mathrm{mg} \mathrm{L}^{-1}$ e conseqüentemente, estes dados não se ajustaram á equação de pseudo-segunda-ordem de Ho.

A linearidade dos gráficos das FIGS. 5c, 6c, 7c, 8c e 9c mostra a presença da difusão intrapartícula e como as linhas não passam pela origem, esta etapa não é a determinante da velocidade indicando um mecanismo complexo consistindo de adsorção 
superficial e transferência intrapartícula (Weber e Morris, 1963). Os valores de $\mathrm{R}_{2}^{2}$ foram maiores que aqueles de $\mathrm{R}_{1}{ }^{2}$ e $\mathrm{R}_{\mathrm{i}}{ }^{2}$ confirmando que o processo de adsorção se ajusta melhor ao mecanismo de pseudo-segunda-ordem e nos sistemas corante/zeólita deve estar envolvido um mecanismo de adsorção ativado ou quimissorção (Ho e McKay, 1998). A adsorção ativada é um tipo de adsorção de caráter intermediário entre a adsorção física e a química.

Alguns estudos cinéticos sobre a adsorção de azul de metileno em zeólita mostraram resultados similares aos reportados nesta investigação, ou seja, que o processo seguiu a expressão de velocidade de pseudo-segunda-ordem. Estes estudos utilizaram zeólita sintética MCM-22 e zeólita natural clinoptilolita como materiais adsorventes (Wang et al, 2005; 2006 a; 2006 c).

\subsubsection{Isotermas de adsorção}

Neste item serão discutidos os resultados dos ensaios das isotermas de adsorção dos sistemas azul de metileno/zeolitas.

As isotermas de sistemas líquido-sólido, conforme foi descrito em capítulo introdutório, podem ser classificadas qualitativamente de acordo com suas formas que são determinadas pelo mecanismo de adsorção e, portanto refletem a natureza do processo. Neste item serão discutidos os resultados dos ensaios das isotermas de adsorção dos sistemas azul de metileno/zeólitas.

A FIG. 10 mostra as isotermas de adsorção do azul de metileno para as zeólitas ZM1 a ZM5 obtidas após 90 min de agitação, onde $\mathrm{C}_{\mathrm{e}}\left(\mathrm{mg} \mathrm{L}^{-1}\right)$ corresponde á concentração de equilíbrio do corante na fase líquida e $\mathrm{q}_{\mathrm{e}}\left(\mathrm{mg}^{-1}\right)$ é a capacidade de adsorção do adsorvente. As isotermas de equilíbrio das zeólitas ZM1 a ZM5 apresentaram curvas na forma sigmoidal com comportamento corresponde á isoterma Tipo L3, indicando a formação indicando rápida de uma segunda camada de adsorção (Giles et al., 1960). 

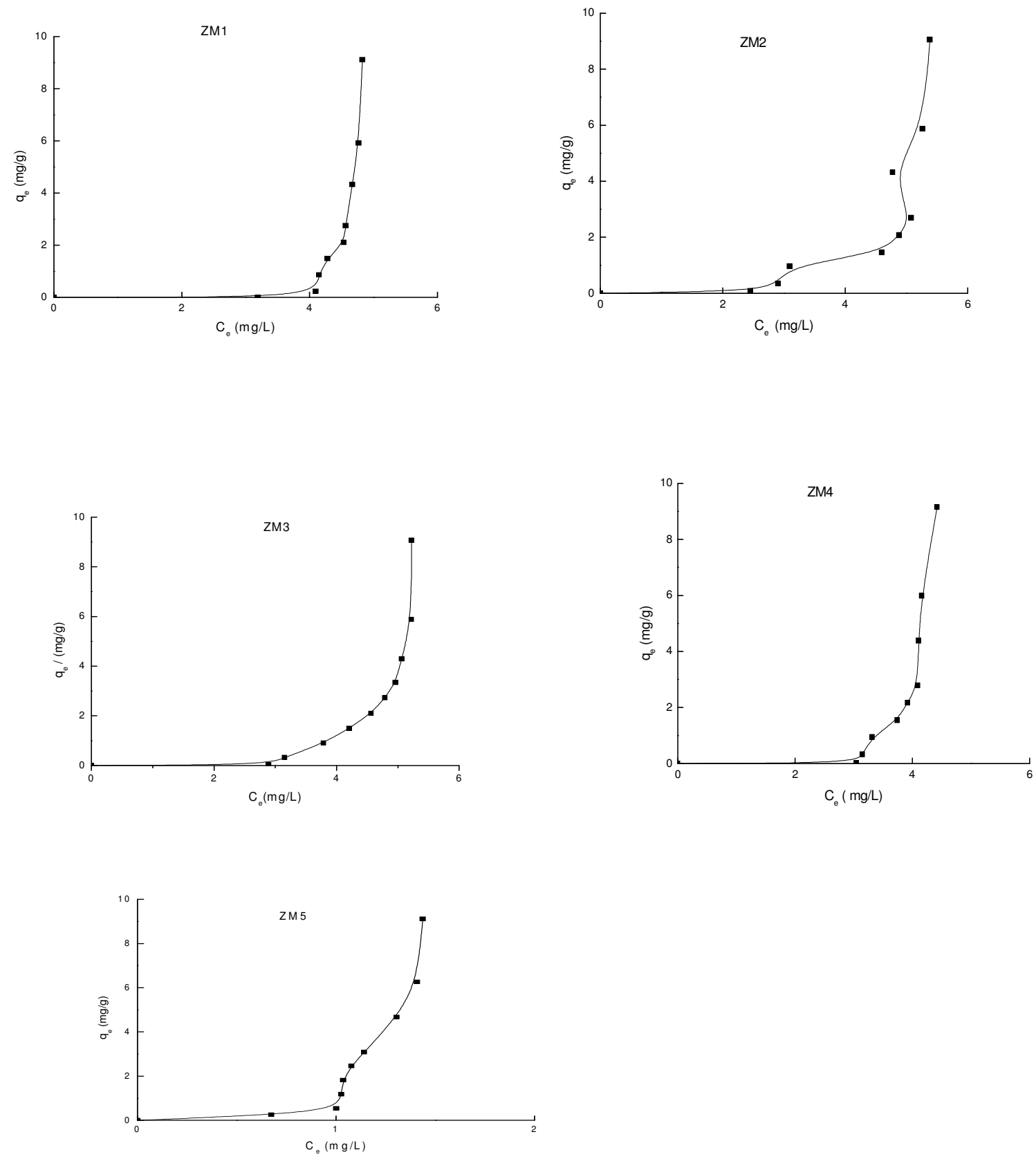

FIGURA 10 - Isotermas de adsorção do azul de metileno com diferentes zeólitas. 
Os dados de equilíbrio foram analisados usando-se os modelos das isotermas de adsorção de Langmuir e Freundlich. Os dados não se ajustaram ao modelo de adsorção de Langmuir apresentando valores das constantes negativos (intersecção e inclinação da curva). Este fato sugere que o sistema não segue as proposições nas quais o modelo Langmuir é baseado e que a heterogeneidade na superfície ou nos poros das zeólitas de cinzas de carvão influencia a adsorçao

As curvas linearizadas de Freundlich encontram-se na FIG. 11 e as respectivas constantes foram determinadas por regressão linear e estão listadas na TAB. 10. 

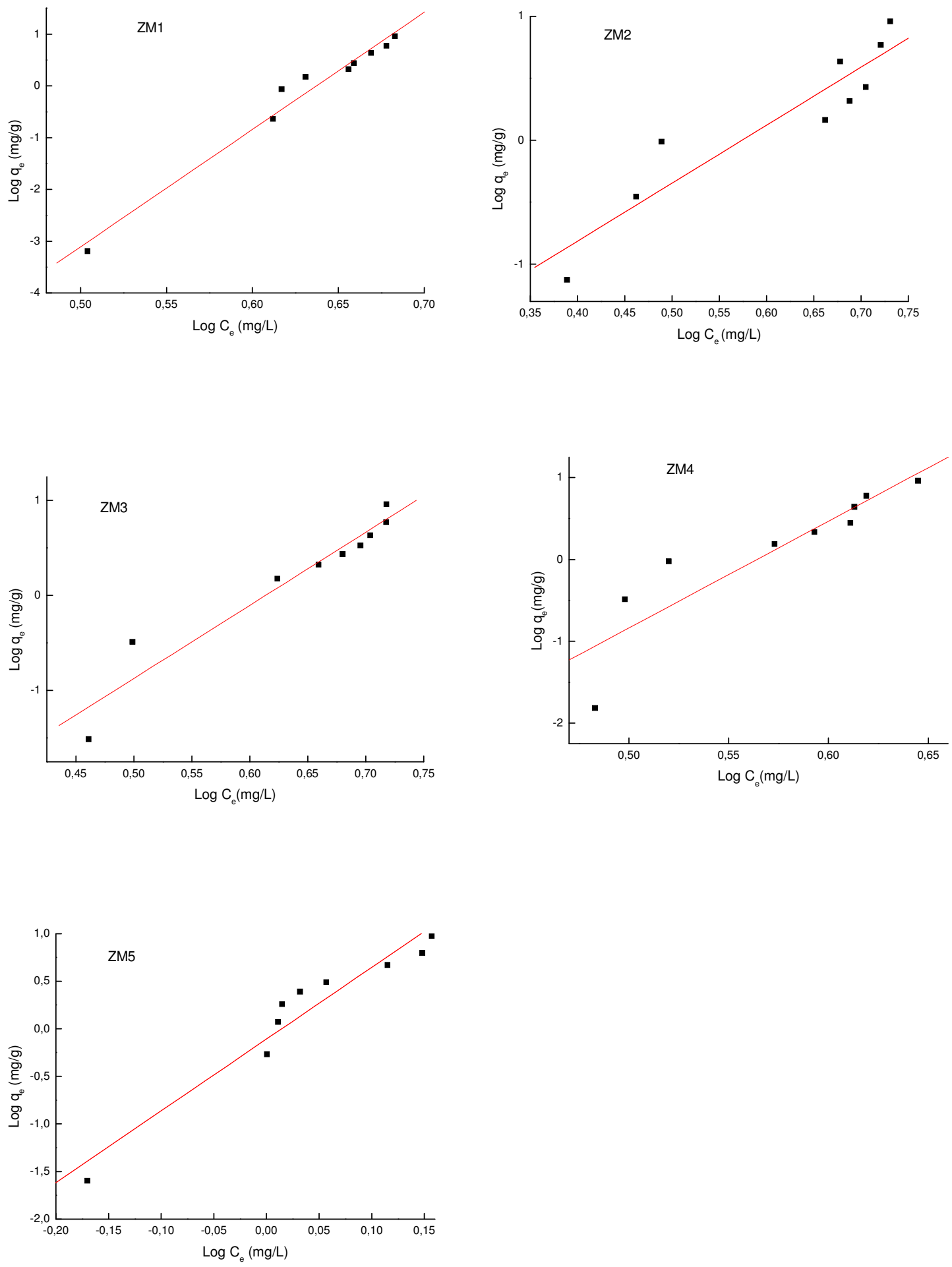

FIGURA 11 - Isotermas de Freundlich para adsorção do azul de metileno com diferentes zeólitas. 
TABELA 10 - Parâmetros dos modelos de Freundlich para azul de metileno com as zeólitas

Adsorvente

\begin{tabular}{llll} 
& $\mathrm{K}_{\mathrm{f}}^{*}$ & $\mathrm{n}$ & $\mathrm{R}^{2}$ \\
\hline ZM1 & $3,8 \times 10^{-15}$ & 0,044 & 0,987 \\
ZM2 & $2,1 \times 10^{-3}$ & 0,21 & 0,933 \\
ZM3 & $1,9 \times 10^{-5}$ & 0,13 & 0,964 \\
ZM4 & $4,4 \times 10^{-8}$ & 0,077 & 0,902 \\
ZM5 & $1,3 \times 10^{-1}$ & 0,78 & 0,968 \\
\hline
\end{tabular}

\section{Freundlich}

$(*)\left(\mathrm{mg} \mathrm{g}^{-1}\right)\left(\mathrm{L} \mathrm{mg}^{-1}\right)^{1 / 1}$

O valor alto do coeficiente de correlação $\left(\mathrm{R}^{2}>0,90\right)$ mostrou que os dados experimentais se ajustaram ao modelo da isoterma de Freundlich para as zeólitas ZM1 a ZM5. O valor da constante $\mathrm{n}$ menor que 1 indicou processo de adsorção cooperativa em sítios com energias diferentes de ligação (Atkins, 1970; Singh, et al., 2000).

A capacidade de adsorção das zeólitas decresceu na seguinte ordem:

ZM5 > ZM2 > ZM3 > ZM4 > ZM1

Esta eficiência de adsorção está relacionada com a composição química da cinza M5 que apresenta menor relação $\mathrm{SiO}_{2} / \mathrm{Al}_{2} \mathrm{O}_{3}$ (TAB. 3 - do ITEM 5.1) e conseqüentemente, maior capacidade de troca iônica da zeólita formada (Breck, 1984). Os outros fatores que também contribuem são: (a) maior conteúdo de vidro da cinza que resulta em maior rendimento da síntese hidrotérmica (Querol et al., 1997); (b) o tipo de zeólita formada na reação hidrotérmica que depende da composição química e mineralógica da cinza.

\subsection{Estudo da influência dos parâmetros de ativação na síntese das zeólitas}

Como foi descrito em capítulos anteriores, o tipo e a quantidade de zeólita que é sintetizada a partir das cinzas de carvão dependem de condições experimentais do processo hidrotérmico, sendo que as mais importantes são: composição da cinza, razão líquido/sólido, temperatura, tempo de reação e, concentração e tipo do agente de ativação.

Em uma primeira etapa do estudo, as cinzas leves de carvão retidas no filtro manga amostradas na usina termelétrica, em intervalos de tempos diferentes, foram submetidas às mesmas condições de tratamento hidrotérmico e as eficiências de adsorção dos diferentes tipos de materiais zeolíticos foram comparadas. 
Na segunda etapa do trabalho, uma mesma cinza de carvão foi submetida às condições diferentes de tratamento hidrotérmico e as capacidades de adsorção dos produtos zeolíticos obtidos foram avaliadas para o azul de metileno. A cinza selecionada foi a cinza de carvão CM5 (amostragem número 5) porque apresentou a maior capacidade de adsorção da zeólita formada (ZM5) conforme estudos relatados no item 5.2.

As condições de ativação da cinza de carvão foram variadas visando maximizar a capacidade de adsorção do azul de metileno pelos produtos zeolíticos obtidos.

As amostras de cinzas de carvão foram submetidas às seguintes variáveis no tratamento hidrotérmico: temperatura: 90 - $100{ }^{\circ} \mathrm{C}$; tempo de reação: 21 - 96 h; concentração da base: $3,5-7,0 \mathrm{~mol} \mathrm{~L} \mathrm{~L}^{-1}$; relação cinza/solução: $0,1-0,125 \mathrm{~g} \mathrm{~mL}^{-1}$ (TAB. 11).

A remoção do azul de metileno $6,4 \mathrm{mg} \mathrm{L}^{-1}$ em solução aquosa pelas zeólitas foi realizada por processos descontínuos usando-se tempo de equilíbrio de 90 min para todos os adsorventes. As capacidades de adsorção $\left(\mathrm{q}_{\mathrm{e}}\right)$ dos produtos zeolíticos foram comparadas juntamente com os valores obtidos com zeólitas comerciais (TAB. 12)

TABELA 11 - Condições experimentais para a síntese dos produtos zeolíticos a partir da cinza de carvão

\begin{tabular}{lcccc}
\hline \multicolumn{1}{c}{ Zeólita } & {$[\mathrm{NaOH}]\left(\mathrm{mol} \mathrm{L}^{-1}\right)$} & $\mathrm{t}(\mathrm{h})$ & $\mathrm{T}\left({ }^{\circ} \mathrm{C}\right)$ & $\mathrm{M}_{\text {cinza }}: \mathrm{V}_{\text {sol }}\left(\mathrm{g} \mathrm{mL}^{-1}\right)$ \\
\hline Z1 & 4,0 & 21 & 90 & 0,1 \\
$\mathrm{Z} 2$ & 4,0 & 48 & 90 & 0,1 \\
$\mathrm{Z3}$ & 4,0 & 72 & 90 & 0,1 \\
$\mathrm{Z} 4$ & 4,0 & 96 & 90 & 0,1 \\
Z5 & 7,0 & 21 & 90 & 0,1 \\
ZM5 & 3,5 & 24 & 100 & 0,125 \\
\hline
\end{tabular}


TABELA 12 - Capacidades de adsorção do azul de metileno com as zeólitas obtidas com diferentes condições de tratamento hidrotérmico.

\begin{tabular}{|c|c|c|}
\hline Zeólita & $q\left(\mathrm{mg} \mathrm{g}^{-1}\right)$ & Adsorção (\%) \\
\hline $\mathrm{Z1}$ & 0,580 & 90,8 \\
\hline $\mathrm{Z} 2$ & 0,487 & 76,1 \\
\hline $\mathrm{Z3}$ & 0,431 & 67,4 \\
\hline $\mathrm{Z4}$ & 0,415 & 65 \\
\hline $\mathrm{Z5}$ & 0,531 & 83,0 \\
\hline ZM5 & 0,348 & 54,4 \\
\hline $4 A^{*}$ & 0,534 & 83,5 \\
\hline $5 A^{*}$ & 0,547 & 85,5 \\
\hline
\end{tabular}

(*) zeólitas comerciais

A capacidade de adsorção das zeólitas decresceu na seguinte ordem:

$\mathrm{Z} 1>\mathrm{Z} 5>\mathrm{Z} 2>\mathrm{Z} 3>\mathrm{Z} 4>\mathrm{ZM} 5$

A zeólita Z5 apresentou uma eficiência de adsorção similar ao valor obtido com as zeólitas comerciais 4A e 5A, enquanto a zeólita Z1 mostrou uma capacidade de adsorção superior a todos os adsorventes estudados.

A capacidade de adsorção é influenciada pelas diferentes estruturas (canais e cavidades) das zeólitas obtidas nas reações de ativação. Estudos anteriores mostraram que geralmente, nas condições experimentais utilizadas na TAB. 11 houve a formação das zeólitas NaP1, hidroxisodalita, X e A (Scott et al., 2002; Woolard et al., 2002). Pode-se formar somente uma fase zeolítica preferencialmente ou a mistura de 2 ou 3 fases zeóliticas.

A formação da zeólita do tipo hidroxisodalita é indesejável porque tem estrutura com canais estreitos que dificultam o acesso do azul de metileno (Woolard et al., 2002). Por outro lado, as zeólitas do tipo X e A apresentam diâmetros de canais largos que facilitariam a adsorção da molécula do corante.

Na condição usada para obtenção da zeólita ZM5 identificou-se por difração de Raios-X a formação da zeólita do tipo NaP1 com traços de hidroxisodalita, quartzo e mulita (Fungaro et al., 2004; Fungaro e Izidoro, 2006 a; 2006b). A zeólita NaP1 apresenta alta capacidade de troca iônica, área superficial específica e tamanho de poro maiores que 
os da hidroxisodalita,sendo portanto, adequada para a adsorção do azul de metileno. A diminuição da temperatura e do tempo da reação em relação ao processo da ZM5 causa uma diminuição na obtenção de hidroxisodalita. As concentrações de $\mathrm{NaOH}$ entre 4 e 6 mol L $\mathrm{L}^{-1}$ proporcionam a formação das zeólitas do tipo X e A em conjunto com a zeólita NaP1 (Ferret, 2004; Wang et al., 2001).

As condições ótimas da síntese do produto zeolítico a partir da cinza de carvão para a sua utilização como material adsorvente do azul de metileno foram observadas na obtenção da zeólita Z1. A zeólita Z1 foi selecionada para os demais estudos que influenciam a adsorção do azul de metileno em solução aquosa.

Os efeitos dos parâmetros de ativação na zeolitização das cinzas de carvão foram estudados por diversos autores.

Em relação ao efeito do $\mathrm{NaOH}$ constatou-se que o processo hidrotérmico em concentração menor que $0,5 \mathrm{~mol} \mathrm{~L}^{-1}$ foi incapaz de ativar significantemente a cinza de carvão porque o conteúdo de $\mathrm{OH}^{-}$é muito baixo para induzir a cristalização da zeólita. A diminuição da capacidade de adsorção observada em concentrações mais altas de $\mathrm{NaOH}$ (> $5 \mathrm{~mol} \mathrm{~L}^{-1}$ ) foi atribuída á presença de excesso de íons $\mathrm{Na}^{+}$presentes na estrutura da zeólita impedindo o processo de troca catiônica (Lin e Hsi, 1995; Amrhein et al., 1996).

O efeito do tempo de reação na formação da zeólita pode ser explicado pela variação do conteúdo de Si. Durante o tratamento hidrotérmico da cinza, o conteúdo de $\mathrm{SiO}_{2}$ (quartzo) se dissolve com o tempo até atingir um valor constante, enquanto a mulita se mantém constante durante todo o processo (Singer e Berkgaut, 1995; Lin e Hsi, 1995; Murayama et al., 2002). O tempo de reação para a formação de um tipo de zeólita pode ser mais curto se concentrações maiores de $\mathrm{NaOH}$ forem usadas (Wang et al., 2003).

Geralmente, os estudos de síntese hidrotérmica de zeólitas de cinzas de carvão utilizam relação massa de cinza/volume da solução de $\mathrm{NaOH}$ variando de 0,1 a $2,5 \mathrm{~g} \mathrm{~mL}^{-1}$. Wang et al. 2003, verificaram que quando a concentração de $\mathrm{NaOH}$ está acima de 2 molL ${ }^{1}$ a relação cinza/solução tem pouco efeito na velocidade de conversão da cinza leve em zeólita.

As zeólitas são termodinamicamente metaestáveis e a temperatura da reação de ativação tem considerável efeito na sua estrutura e estabilidade. Geralmente, somente um tipo de zeólita com velocidade de conversão baixa é obtido sob condições normais de temperatura, enquanto altas temperaturas podem resultar em diferentes tipos de zeólitas com velocidades de conversão mais altas. As temperaturas excessivamente altas podem 
levar a um heteromorfismo. A importância da temperatura pode ser explicada pelo valor da energia de ativação necessário para a reação de espécies de silicato simples ou amorfo formar polímeros de silicato. Mouhtaris et al., 2003 concluíram que a temperatura é um fator mais importante no processo de zeolitização que a concentração de $\mathrm{NaOH}$ e o tempo de reação.

\subsubsection{Efeito do tempo de contato}

A FIG.12 mostra o gráfico da quantidade de corante adsorvida $\left(\mathrm{mg} \mathrm{g}^{-1}\right) \mathrm{em}$ função do tempo de contato para concentrações iniciais diferentes do azul de metileno. $\mathrm{O}$ tempo de equilíbrio foi rapidamente atingido em 10 min para toda a faixa de concentração estudada. Estas observações mostraram que a concentração inicial do corante não afetou o tempo de equilíbrio. Grandes frações $(\sim 70-92 \%$ da quantidade total de cor adsorvida) do corante foram removidas dentro da primeira fase rápida de remoção, isto é, os primeiros 10 min. Isto ocorreu devido ao decréscimo do fluxo (gradiente de concentração) da transferência do soluto para a fase sólida com o tempo. A rápida remoção das partículas do corante nos primeiros 10 min é devido somente á interações adsorbato - adsorvente com interferência negligenciável das interações adsorbato - adsorbato (Varshney et al., 1996).

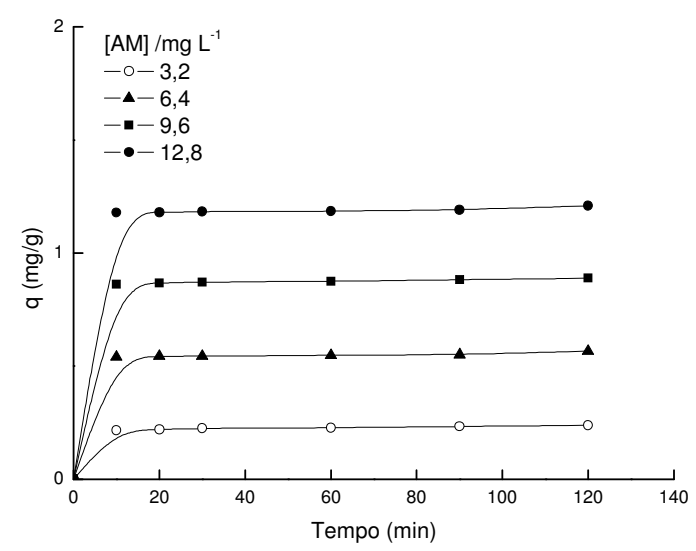

FIGURA 12 - Efeito do tempo de agitação e da concentração do azul de metileno sobre a capacidade de adsorção da zeólita Z1 


\subsubsection{Modelos cinéticos de adsorção}

A FIG. 13 mostra os ajustes dos resultados do processo de adsorção do azul de metileno sobre a zeólita $\mathrm{Z} 1$ aos vários modelos cinéticos e os parâmetros de todos os modelos encontram-se na TAB. 13
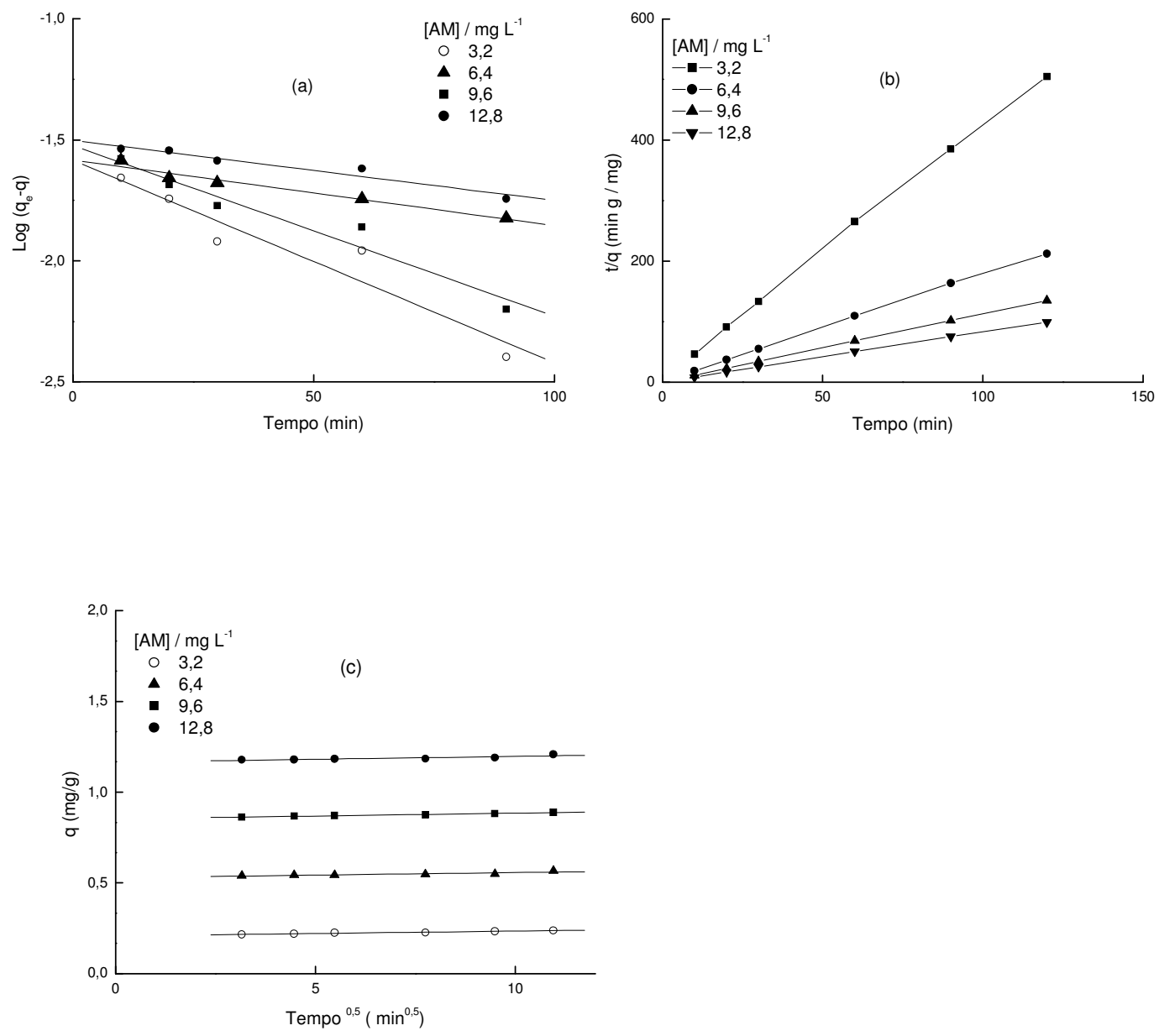

FIGURA 13 - Comparação dos modelos cinéticos da adsorção do azul de metileno sobre ZM1: (a) cinética de pseudo-primeira-ordem; (b) cinética de pseudo-segunda-ordem; (c) difusão intrapartícula 
TABELA 13 - Parâmetros cinéticos para a remoção do azul de metileno pela zeólita Z1

\begin{tabular}{lll}
\hline$[\mathrm{AM}]$ & \multicolumn{2}{l}{ Pseudo $-1^{\mathrm{a}}$ ordem } \\
$(\mathrm{mg} / \mathrm{L})$ & $\begin{array}{l}\mathrm{K}_{1} \times 10^{-2} \\
\left(\mathrm{~min}^{-1}\right)\end{array}$ & $\mathrm{R}_{1}{ }^{2}$ \\
\hline 3,2 & 1,93 & 0,957 \\
6,4 & 0,624 & 0,981 \\
9,6 & 1,63 & 0,974 \\
12,8 & 0,573 & 0,971 \\
\hline
\end{tabular}

Pseudo - $2^{\mathrm{a}}$ ordem

\begin{tabular}{lllll} 
& $\begin{array}{l}\mathrm{K}_{2} \\
(\mathrm{~g} / \mathrm{mg} \min )\end{array}$ & $\begin{array}{l}\mathrm{h} \times 10^{-1} \\
(\mathrm{mg} / \mathrm{g} \min )\end{array}$ & $\begin{array}{l}\mathrm{q}_{\mathrm{e}} \times 10^{-1} \\
(\mathrm{mg} / \mathrm{g})\end{array}$ & $\mathrm{R}_{2}{ }^{2}$ \\
\hline 3,2 & 2,01 & 1,16 & 2,40 & 0,999 \\
6,4 & 1,64 & 5,24 & 5,65 & 0,999 \\
9,6 & 1,88 & 14,9 & 8,9 & 0,999 \\
12,8 & 1,36 & 19,8 & 12,1 & 0,999 \\
\hline
\end{tabular}

Difusão intrapartícula

\begin{tabular}{lll} 
& $\begin{array}{l}\mathrm{K}_{\mathrm{i}} \times 10^{-3} \\
\left(\mathrm{mg} / \mathrm{g} \mathrm{min}^{0,5}\right)\end{array}$ & $\mathrm{R}_{\mathrm{i}}^{2}$ \\
\hline 3,2 & 2,72 & 0,981 \\
6,4 & 2,81 & 0,904 \\
9,6 & 3,14 & 0,987 \\
12,8 & 3,23 & 0,877 \\
\hline
\end{tabular}

Os valores das constantes de velocidade de adsorção estavam na faixa de 0,6 a $1,9 \times 10^{-2} \mathrm{~min}^{-1}$ (pseudo-primeira ordem) e 1,36 a 2,01 $\mathrm{g} / \mathrm{mg}$ min (pseudo-segunda-ordem) e coeficiente de difusão intrapartícula entre $2,7 \times 10^{-3}$ a $3,2 \mathrm{mg} / \mathrm{g} \mathrm{min}{ }^{0,5}$ (TAB. 13 ).

Os coeficientes de correlação $\left(\mathrm{R}^{2}\right)$ calculados foram maiores que 0,9 mostrando a aplicabilidade dos modelos cinéticos. Os valores de $\mathrm{R}_{2}{ }^{2}$ foram maiores que aqueles de $\mathrm{R}_{1}^{2}$ e $\mathrm{R}_{\mathrm{i}}^{2}$ confirmando que o processo de adsorção se ajusta melhor ao mecanismo de pseudo-segunda-ordem e nos sistemas corante/zeólita Z1 deve estar envolvido um mecanismo de adsorção ativado ou quimissorção (Ho e McKay, 1998). A linearidade do gráfico q vs $\mathrm{t}^{0,5}$ e o desvio das linhas da origem (FIG. 13c) apontaram a presença da 
difusão intrapartícula como uma etapa não determinante da velocidade do processo de adsorção do sistema azul de metileno - zeólita Z1 (Weber e Morris, 1963).

\subsubsection{Isotermas de adsorção}

A FIG. 15 mostra a isoterma de adsorção do azul de metileno com a zeólita Z1 obtida após 10 min de agitação. A isoterma de equilíbrio apresentou uma curva com comportamento correspondente á isoterma Tipo L3 indicando a formação rápida de uma segunda camada de adsorção (Giles et al., 1960). Os dados não se ajustaram ao modelo de adsorção de Langmuir. As constantes de Freundlich foram determinadas por regressão linear dos dados apresentados na FIG. 14 e estão listadas na TAB. 14. Os dados das zeólitas sintéticas comerciais Baylith 4A e 5A (Bayer) foram obtidos nas mesmas condições experimentais para comparação.

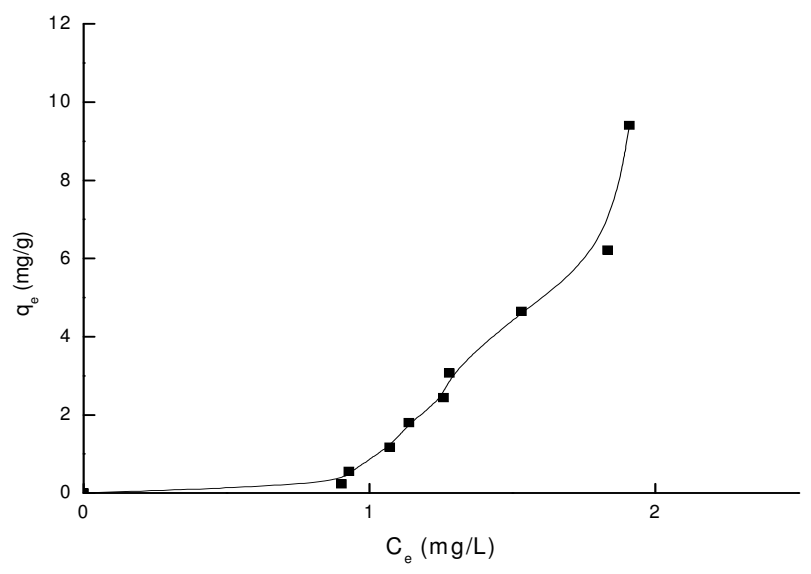

FIGURA 14 - Isoterma de adsorção da zeólita Z1 para o azul de metileno 


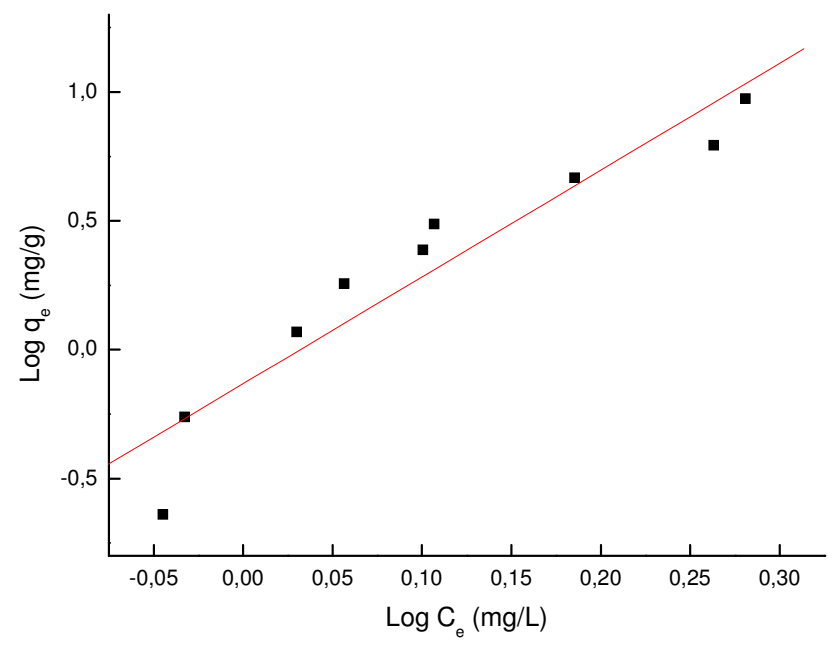

FIGURA 15 - Isoterma de Freundlich para adsorção do azul de metileno com zeólita Z1.

TABELA 14 - Parâmetros dos modelos de Freundlich para azul de metileno com a zeólita $\mathrm{Z1}$.

\begin{tabular}{llll}
\hline Adsorvente & \multicolumn{3}{c}{ Freundlich } \\
& $\mathrm{K}_{\mathrm{f}}^{*}$ & $\mathrm{n}$ & $\mathrm{R}^{2}$ \\
\hline $\mathrm{Z1}$ & 0,738 & 0,241 & 0,950 \\
4 A & 1,28 & 1,01 & 0,765 \\
$5 \mathrm{~A}$ & 1,36 & 1,01 & 0,763 \\
\hline
\end{tabular}

$(*)\left(\mathrm{mg} \mathrm{g}^{-1}\right)\left(\mathrm{L} \mathrm{mg}^{-1}\right)^{1 / \mathrm{n}}$

$\mathrm{O}$ valor alto do coeficiente de correlação $\left(\mathrm{R}^{2}>0,9\right)$ mostrou que os dados experimentais se ajustaram ao modelo da isoterma de Freundlich para a adsorção do azul de metileno na zeólita Z1. A adsorção ocorreu por um processo cooperativo em sítios com energias diferentes de ligação conforme assinalou o valor da constante $n$ menor que 1 (Atkins, 1970; Singh et al, 2000). A capacidade de adsorção da zeólita Z1 foi cerca de 80\% maior do que aquela obtida com a zeólita ZM5 (TAB. 10 - ITEM 5.2.3). Os dados de adsorção para as zeólitas comerciais não se ajustaram ao modelo de adsorção de Langmuir e o comportamento foi razoavelmente explicado pela equação de Freundlich $\left(\mathrm{R}^{2} \sim 0,8\right)$. As zeólitas de cinzas de carvão podem ser uma alternativa ao uso das zeólitas comerciais que 
são comercializadas com preços elevados. Uma comparação de custos mostrou que a substituição da resina de troca iônica comercial pela zeólita sintetizada com cinza de carvão pode representar uma economia de cerca de $42 \%$ no tratamento de efluentes industriais (Fungaro, 2004).O desempenho da adsorção do azul de metileno sobre a cinza leve de carvão original (amostra C5), matéria-prima da zeólita Z1, também foi estudado para comparação. O tempo de equilíbrio foi atingido em $60 \mathrm{~min}$ para a faixa de concentração do azul de metileno de 3,2 a $12,8 \mathrm{mg} \mathrm{L}^{-1}$. Os dados da isoterma de equilíbrio não se ajustaram ao modelo de adsorção de Langmuir, nem ao modelo de Freundlich. A cinza leve removeu menos azul de metileno da solução aquosa do que a sua respectiva zeólita Z1 (concentração inicial máxima de $26 \mathrm{mg} \mathrm{L}^{-1}$ ).

A TAB. 15 compara as capacidades de adsorção do azul de metileno sobre cinzas leve de carvão e zeólitas encontradas neste estudo e por outros pesquisadores. Algumas condições experimentais estão também relatadas para uma melhor avaliação. Pode ser visto que a zeólita Z1 apresentou capacidade de adsorção próxima ao estudo realizado por Wang et al, 2006. No entanto um tempo de agitação bem menor foi necessário para alcançar o equilíbrio de adsorção. 
TABELA 15 - Comparação da capacidade de adsorção (segundo Freundlich) do azul de metileno em vários adsorventes.

\begin{tabular}{|c|c|c|}
\hline Adsorvente & $\begin{array}{l}\text { Capacidade de Adsorção } \\
\mathrm{K}_{\mathrm{f}}(\mathrm{mg} / \mathrm{g})(\mathrm{L} / \mathrm{mg})^{1 / \mathrm{n}}\end{array}$ & Referências \\
\hline Zeólita Z1 & $7,38 \times 10^{-1}$ & $\begin{array}{l}\text { Este estudo } \\
\mathrm{t} \text { agit }=10 \mathrm{~min} \\
{[\mathrm{AM}]=3,2-96 \mathrm{mg} / \mathrm{L}}\end{array}$ \\
\hline Zeólita sintética MCM 22 & $9,95 \times 10^{-2}$ & $\begin{array}{l}\text { Wang et al., } 2006 \\
\mathrm{t} \text { agit }=10 \text { dias } \\
{[\mathrm{AM}]=0,32-3,2 \mathrm{mg} / \mathrm{L}} \\
\mathrm{T}=30^{\circ} \mathrm{C}\end{array}$ \\
\hline Cinza leve & $1,85 \times 10^{-3}$ & Wang et al., 2006 \\
\hline $\begin{array}{l}\text { Zeólita de cinza de carvão } \\
\left(100^{\circ} \mathrm{C}\right)^{\mathrm{a}}\end{array}$ & 1,22 & \\
\hline $\begin{array}{l}\text { Zeólita de cinza de carvão } \\
\left(140^{\circ} \mathrm{C}\right)^{\mathrm{a}}\end{array}$ & 1,65 & $\begin{array}{l}\mathrm{t} \text { agit }=72 \mathrm{~h} \\
{[\mathrm{AM}]=1-20 \mathrm{mg} / \mathrm{L}}\end{array}$ \\
\hline Zeólita natural & $5,37 \times 10^{-2}$ & $\begin{array}{l}\text { Li et al., } 2006 \\
t \text { agit }=5 \text { dias[ } \\
\text { AM }]=0,32-3,2 \mathrm{mg} / \mathrm{L} \\
\mathrm{T}=30{ }^{\circ} \mathrm{C}\end{array}$ \\
\hline Cinza leve & $3,54 \times 10^{-1}$ & $\begin{array}{l}\text { Kumar, } 2002 \\
\mathrm{t} \text { agit }=3 \mathrm{~h} \\
{[\mathrm{AM}]=1-20 \mathrm{mg} / \mathrm{L}}\end{array}$ \\
\hline Cinza leve tratada com $\mathrm{HNO}_{3}$ & $11,9 \times 10^{-3}$ & $\begin{array}{l}\text { Wang et al., } 2005 \\
\mathrm{t} \text { agit }=80 \mathrm{~h} \\
{[\mathrm{AM}]=0,032-9,6 \mathrm{mg} / \mathrm{L}}\end{array}$ \\
\hline Cinza leve & $4,38 \times 10^{-3}$ & $\begin{array}{l}\text { Kumar, et al., } 2004 \\
\mathrm{t} \text { agit }=2 \mathrm{~h} \\
{[\mathrm{AM}]=20-100 \mathrm{mg} / \mathrm{L}}\end{array}$ \\
\hline
\end{tabular}

(a) temperatura do tratamento hidrotérmico; t agit = tempo de agitação 


\subsubsection{Influência do pH inicial}

$\mathrm{O}$ pH inicial da solução aquosa do corante é um parâmetro controlador importante no processo de adsorção e particularmente na capacidade de adsorção do material adsorvente. $\mathrm{O}$ pH afeta a estrutura química das moléculas do corante e a superfície do adsorvente. Os corantes iônicos se dissociam produzindo moléculas coloridas aniônicas ou catiônicas em solução aquosa. O azul de metileno é um corante básico e em água produz íons catiônicos $\left(\mathrm{C}^{+}\right)$e reduzidos $\left(\mathrm{CH}^{+}\right)$. A adsorção destes grupos carregados sobre a superfície do adsorvente é primeiramente influenciada pela carga superficial do mesmo, a qual por sua vez, é influenciada pelo pH da solução.

$\mathrm{O}$ efeito do $\mathrm{pH}$ inicial na remoção de azul de metileno foi determinado para uma concentração fixa de $6,4 \mathrm{mg} \mathrm{L}^{-1}$, dose do adsorvente de $1 \mathrm{~g}$ e tempo de agitação de 10 min sobre uma faixa de $\mathrm{pH}$ de 2 a 11 (FIG.16). A eficiência de adsorção permaneceu praticamente inalterada com a mudança de $\mathrm{pH}$ inicial da solução. Este fato pode ser explicado por um mecanismo de interação eletrostática fraca entre as moléculas do corante e os sítios ativos do adsorvente (Sharma e Bhattacharyya, 2005).

Uma tendência similar da não influência do pH no processo de adsorção foi observada na adsorção do azul de metileno sobre: resíduo de biogás na faixa de 4 a 10,5 (Namasivayan e Yamuna, 1994) ; cinza leve de carvão na faixa de 2 a 10 (Wang et al.,2005); biomassa de coqueiro na faixa de 2 a 11 (Kavitha e Namasivayam, 2007).

Esta não influência do pH no processo de adsorção do azul de metileno sobre a zeólita de cinzas de carvão Z1 é muito importante sob o ponto de vista prático já que efluentes ácidos ou alcalinos podem resultar de processos de coloração diversos da indústria têxtil. 


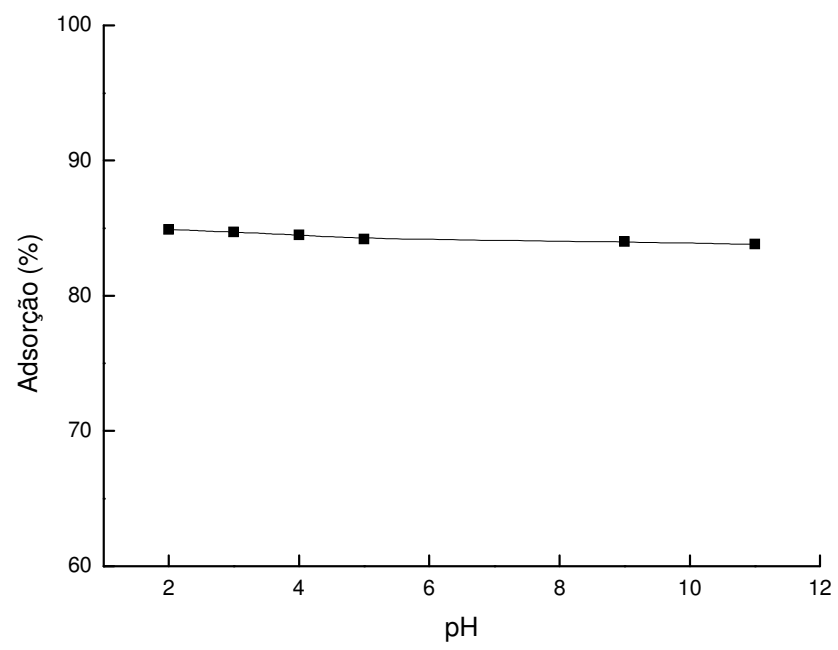

FIGURA 16 - Influência do pH na adsorção do azul de metileno na zeólita Z1.

\subsubsection{Influência da dose de zeólita}

Uma determinada massa fixa de adsorvente pode somente adsorver certa quantidade de corante. Quanto maior a dose de adsorvente (relação massa de adsorvente / volume da solução de corante), mais rápida é a adsorção superficial causando uma diminuição da concentração do soluto em solução e maior será o volume de efluente que poderá ser purificado. $\mathrm{O}$ aumento na porcentagem de adsorção com o crescimento da dose de adsorvente é devido ao aumento da área superficial e da disponibilidade de sítios de adsorção.

A FIG.17 mostra o efeito da dose de zeólita Z1 na eficiência de remoção do azul de metileno $6,4 \mathrm{mg} \mathrm{L}^{-1}$ e tempo de agitação de $10 \mathrm{~min}$. A eficiência de remoção de cor aumentou de 71 a $82 \%$ com o crescimento da dose de zeólita de 2,5 a 5,0 g L L $^{-1}$ e após permaneceu aproximadamente constante. A adsorção superficial do azul de metileno sobre as partículas de zeólita foi muito rápida.

A eficiência de remoção aumentou tendendo a entrar em patamar enquanto a capacidade de adsorção ( $\mathrm{q}$ em $\mathrm{mg} \mathrm{g}^{-1}$ ) diminuiu com o aumento da dose de adsorvente (FIG. 17). A queda na capacidade de adsorção é principalmente devida aos sítios que permanecem insaturados durante a reação de adsorção (Shukla et al., 2002; Yu et al., 2003). Outra razão pode ser a interação inter-partícula, tal como agregação, resultado da alta dose do adsorvente. Tal agregação poderia levar a um decréscimo na área superficial total do adsorvente e um aumento no comprimento do caminho difusional (Shukla et al., 2002). 


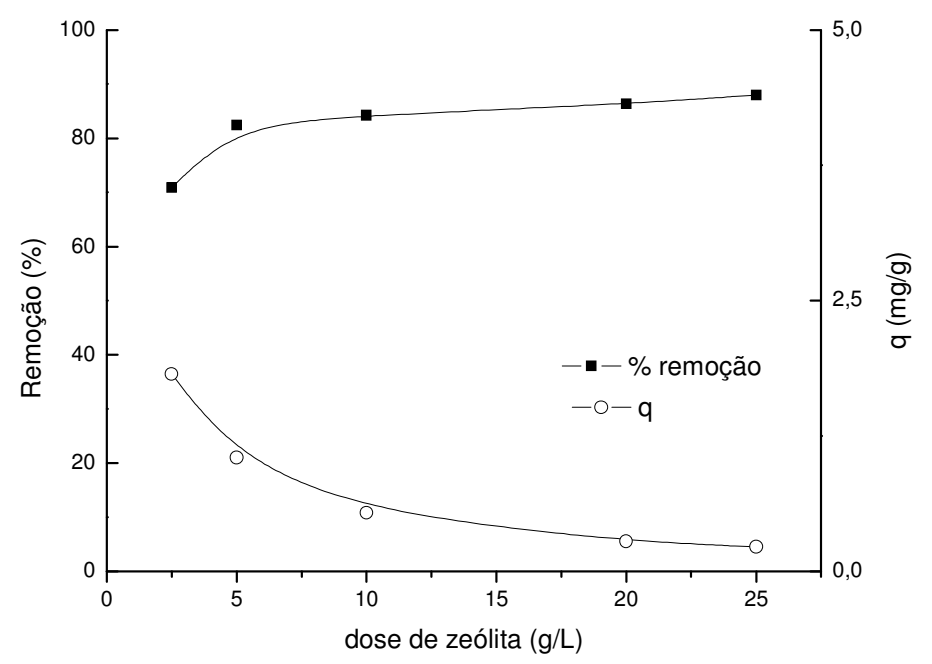

FIGURA 17 - Influência da dose de zeólita Z1 na adsorção do azul de metileno.

\subsubsection{Influência da temperatura}

Na FIG.18 apresentam-se as dinâmicas de adsorção do azul de metileno sobre a zeólita Z1 em várias temperaturas. Uma concentração inicial do corante de $6,4 \mathrm{mg} \mathrm{L}^{-1}$, dose do adsorvente de $10 \mathrm{~g} \mathrm{~L}^{-1}$ e tempos de agitação na faixa de $10 \mathrm{~min}$ a $120 \mathrm{~min}$ foram mantidos fixos no experimento. As capacidades de adsorção da zeólita nas diferentes temperaturas apresentaram valores muito próximos sugerindo que a temperatura não desempenha um papel significativo no processo de adsorção. 


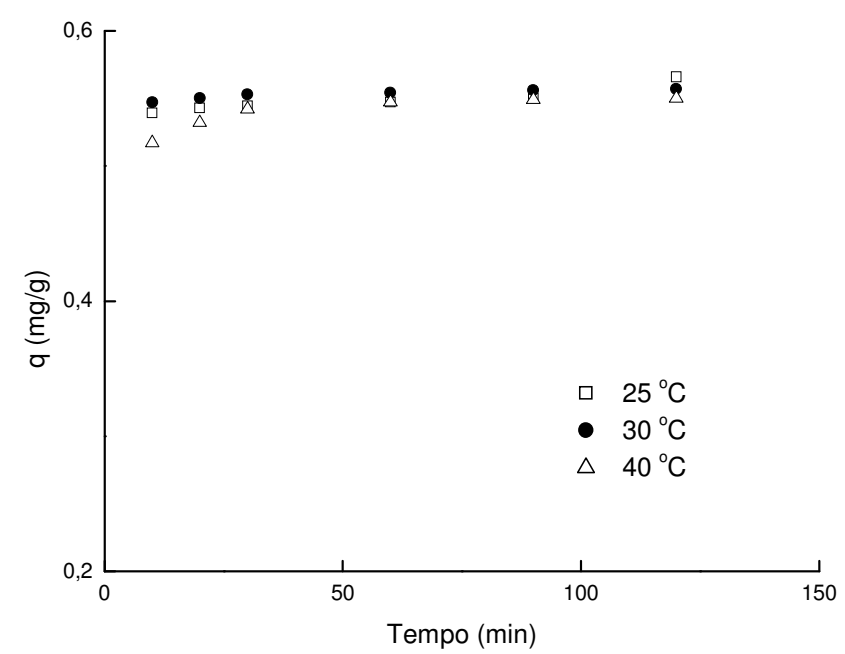

Figura 18 - Efeito da temperatura na dinâmica de adsorção do azul de metileno sobre zeólita Z1

Como foi discutido no Item 5.3.2., a dinâmica de adsorção do azul de metileno sobre a zeólita Z1 segue o modelo cinético de pseudo-segunda-ordem de Ho e os parâmetros deste modelo em diferentes temperaturas foram comparados (TAB. 16). A capacidade de adsorção calculada $\left(\mathrm{q}_{\mathrm{e}}\right)$ é similar nas três temperaturas e o valor da constante de velocidade á $30{ }^{\circ} \mathrm{C}$ foi maior do que o valor das constantes nas outras temperaturas.

TABELA 16 - Parâmetros cinéticos da adsorção do azul de metileno sobre a zeólita Z1 em diferentes temperaturas.

\begin{tabular}{|c|c|c|c|c|}
\hline \multirow[t]{2}{*}{$\mathrm{T}\left({ }^{\circ} \mathrm{C}\right)$} & \multicolumn{4}{|c|}{ Modelo de pseudo-segunda-ordem } \\
\hline & $\mathrm{K}_{2}\left(\mathrm{~g} . \mathrm{mg}^{-1} \mathrm{~min}^{-1}\right)$ & $\mathrm{h}\left(\mathrm{mg} \cdot \mathrm{g}^{-1} \mathrm{~min}^{-1}\right)$ & $\mathrm{q}_{\mathrm{e}}\left(\mathrm{mg} \mathrm{g}^{-1}\right)$ & $\mathrm{R}_{2}^{2}$ \\
\hline 25 & 1,64 & 0,524 & 0,565 & 0,999 \\
\hline 30 & 6,48 & 2,02 & 0,558 & 0,999 \\
\hline 40 & 2,55 & 0,780 & 0,553 & 0,999 \\
\hline
\end{tabular}

A variação da extensão da adsorção em relação á temperatura foi também avaliada com base nos parâmetros termodinâmicos, isto é, energia livre de Gibbs $\left(\Delta \mathrm{G}^{\mathrm{o}}\right)$, entalpia $\left(\Delta \mathrm{H}^{\mathrm{o}}\right)$ e entropia $\left(\Delta \mathrm{S}^{\mathrm{o}}\right)$. Estes parâmetros foram calculados seguindo as equações (Equações 14, 15, 16 e 17 do ITEM 3.6.3) e estão apresentados na TAB.17. 
TABELA 17 - Parâmetros termodinâmicos para a adsorção do azul de metileno sobre a zeólita Z1 em diferentes temperaturas.

\begin{tabular}{clll}
\hline $\mathrm{T}\left({ }^{\mathrm{o}} \mathrm{C}\right)$ & $\Delta \mathrm{G}^{\mathrm{o}}\left(\mathrm{kJ} \mathrm{mol}^{-1)}\right.$ & $\Delta \mathrm{H}^{\mathrm{o}}\left(\mathrm{kJ} \mathrm{mol}^{-1}\right)$ & $\Delta \mathrm{S}^{\mathrm{o}}\left(\mathrm{J} \mathrm{K}^{-1} \mathrm{~mol}^{-1}\right)$ \\
\hline 25 & $-5,05$ & $-19,7$ & $-49,1$ \\
30 & $-2,08$ & $-6,49$ & $-14,5$ \\
40 & $-2,06$ & & \\
\hline
\end{tabular}

Os valores negativos de $\Delta \mathrm{G}^{\mathrm{o}}$ em dIferentes temperaturas indicaram que a natureza do processo de adsorção do azul de metileno sobre a zeólita Z1 é espontânea. Os valores negativos de $\Delta \mathrm{H}^{\mathrm{o}}$ confirmaram a natureza exotérmica da adsorção, fato já observado no estudo da dinâmica de adsorção (TAB. 16), onde a eficiência de adsorção apresentou uma pequena tendência de diminuição com o aumento de temperatura. Os valores negativos de $\Delta S^{o}$ sugeriram a diminuição da desordem na interface sólido/solução durante a adsorção do corante sobre a zeólita sintetizada a partir de cinzas de carvão.

Um comportamento termodinâmico similar foi reportado para a adsorção do azul de metileno sobre cinza de bagaço de cana-de-açúcar (Gupta et al., 2000) e sobre fibra de algodão.

\subsubsection{Análise espectrofotométrica da degradação do azul de metileno comparada a um padrão permitido}

A eficiência da remoção da cor por um determinado processo pode ser avaliada pela comparação com um padrão espectrofotometricamente permitido definido pela literatura (Cooper, 1993). O padrão de qualidade define o grau máximo de coloração permitido em um efluente para descarte em rios e foi estabelecido no Reino Unido pela Autoridade Nacional de rios (NRA do inglês). De acordo com este método, as absorbâncias na faixa de 400 a $650 \mathrm{~nm}$ são medidas e comparadas com o padrão permitido.

No Brasil, pela legislação do Conselho Nacional do Meio Ambiente - a antiga Resolução CONAMA №20/86 e a sua sucessora №. 357/05 (Ministério do Meio Ambiente, 2007) - não fixam limites de cor para lançamento de efluentes. Entretanto, se fizermos uma análise mais criteriosa da referida Resolução, observaremos que a mesma fixa limites para a cor como parâmetro de qualidade para classificação das águas, determinando inclusive que nenhum efluente lançado num corpo receptor poderá alterar suas características de qualidade. A Resolução estabelece que em águas doces e salinas os corantes sintéticos devem estar ausentes. 
A FIG.19 mostra a descoloração do azul de metileno obtida após o tratamento com a zeólita Z1 comparada com o padrão permitido. Os dados mostraram que com 10 minutos de agitação, a coloração da solução de azul de metileno $1,28 \mathrm{mg} \mathrm{L}^{-1}$, medida em vários comprimentos de ondas, encontrava-se abaixo dos padrões exigidos para descarte.

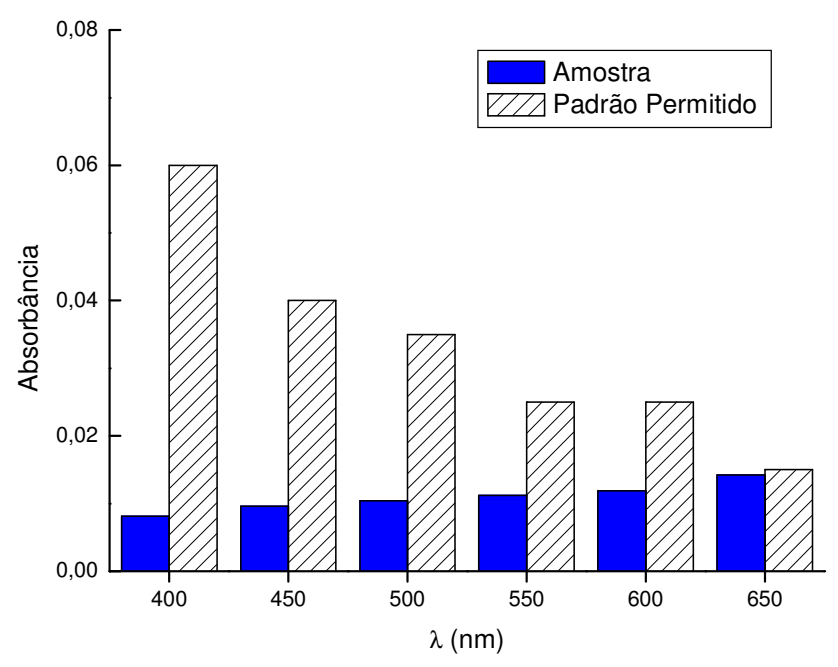

FIGURA 19 - Análise espectrofotométrica da degradação do azul de metileno após tratamento com zeólita Z1 comparada a um padrão definido.

Este resultado é importante porque mostra que o processo de adsorção usando adsorvente de baixo custo foi capaz de atingi níveis de remoção de cor compatíveis com os padrões estabelecidos.

A concentração inicial da solução de azul de metileno usada no presente estudo apresentava intensidade de coloração igual aquela do efluente simulado na indústria têxtil (solução do corante azul QR) usado em trabalho relatado em literatura. A descoloração do corante azul QR foi eficiente a partir de $50 \mathrm{~min}$ de tratamento fotoeletroquímico (Bertazzoli e Pelegrini, 2002). 


\section{CONCLUSÕES}

A zeólita sintetizada a partir de cinzas de carvão mostrou-se eficiente como material adsorvente de baixo custo na remoção do azul de metileno em solução aquosa. A mitigação dos impactos ambientais e dos prejuízos à saúde humana causados pela atividade de complexos carboelétricos com a transformação de um rejeito poluidor em matéria-prima de um produto aplicável no tratamento de efluentes industriais é a grande contribuição do presente estudo.

A análise da composição química por fluorescência de raios-X mostrou que as cinzas de carvão de cinco amostragens utilizadas neste estudo têm grande aplicação na síntese de zeólitas. De modo geral, as cinzas apresentaram uma relação $\mathrm{SiO}_{2} / \mathrm{Al}_{2} \mathrm{O}_{3}$ baixa $(\leq 1,3 \mathrm{~m} / \mathrm{m})$, conteúdo relativamente baixo das impurezas de óxidos de $\mathrm{Fe}, \mathrm{Ca}$ e $\mathrm{S}$; concentração baixa de $\mathrm{Sr}$ e ausência de $\mathrm{Ba}$ e Mo em relação aos elementos solúveis e ausência dos principais elementos tóxicos. As amostras de cinzas de carvão de cinco amostragens submetidas ao mesmo tratamento hidrotérmico apresentaram as seguintes características no processo de adsorção do sistema azul de metileno/zeólita:

- $\quad$ O tempo de equilíbrio foi de 90 min para todos os adsorventes e a eficiência de adsorção estava entre 43 a $90 \%$.

- $\quad$ O processo de adsorção se ajustou ao modelo cinético de pseudo-segunda-ordem.

- As isotermas de equilíbrio das zeólitas apresentaram curvas na forma sigmoidal com comportamento corresponde á isoterma Tipo L3. Os dados não se ajustaram ao modelo de isoterma de adsorção de Langmuir indicando heterogeneidade na superfície ou nos poros das zeólitas de cinzas de carvão e a formação de uma segunda camada de adsorção.

Uma mesma cinza de carvão submetida a diferentes parâmetros de ativação produziu materiais zeolíticos de características diferentes. As eficiências de adsorção do azul de metileno sobre as zeólitas indicaram que as melhores condições de tratamento hidrotérmico foram alcançadas com a zeólita $\mathrm{Z} 1$ : $\mathrm{NaOH} 4 \mathrm{~mol} \mathrm{~L}{ }^{-1}$; tempo de reação de $21 \mathrm{~h}$; temperatura de $90{ }^{\circ} \mathrm{C}$ e relação cinza de carvão:solução de $\mathrm{NaOH}$ igual a $0,1 \mathrm{~g} \mathrm{~mL}^{-1}$.

A velocidade de adsorção do azul de metileno sobre a zeólita $\mathrm{Z} 1$ foi rápida, atingindo o equilíbrio em cerca de $10 \mathrm{~min}$, com remoção de cor na faixa de 70 a $92 \%$. O processo de adsorção se ajustou ao modelo cinético de pseudo-segunda-ordem. 
A isoterma de equilíbrio do azul de metileno sobre a zeólita Z1 apresentou uma curva com comportamento corresponde á isoterma Tipo L3, a qual os dados experimentais se ajustaram apenas modelo da isoterma de Freundlich.

A zeólita Z1 apresentou uma capacidade de adsorção 42 - 46\% menor do que as zeólitas comercias $4 \mathrm{~A}$ e $5 \mathrm{~A}$, porém a análise de custos demonstrou que o uso deste material alternativo abundante compensa a menor eficiência.

A cinza leve de carvão, matéria-prima da zeólita Z1, foi hábil em remover menos azul de metileno da solução aquosa do que a sua respectiva zeólita e um tempo de contato maior foi necessário para atingir o equilíbrio de adsorção. Os dados da isoterma de equilíbrio não se ajustaram ao modelo de adsorção de Langmuir, nem ao modelo de Freundlich.

A eficiência de adsorção do azul de metileno sobre a zeólita Z1 permaneceu praticamente inalterada com a mudança de $\mathrm{pH}$ inicial da solução sobre uma faixa de $\mathrm{pH}$ de 2 a 11. A máxima porcentagem de remoção de cor foi alcançada com 0,5 g de material adsorvente e novas adições de zeólita não afetaram o processo de adsorção.

A descoloração do azul de metileno obtida após o tratamento com a zeólita Z1 foi comparada com um padrão permitido e demonstrou que a solução aquosa final poderia ser descartada em corpos d'água. Os estudos termodinâmicos indicaram que o processo de adsorção do azul de metileno sobre a zeólita Z1 é de natureza espontânea, exotérmica e apresenta uma diminuição da desordem na interface sólido/solução. 
APÊNDICES 


\section{$A P \hat{E} N D I C E A$ - Massa Específica e Área Superficial Específica das Zeólitas} sintetizadas a partir de cinzas de carvão

\begin{tabular}{lll}
\hline Zeólitas & $\begin{array}{l}\text { Massa Específica } \\
\left(\mathrm{g} / \mathrm{cm}^{3}\right)\end{array}$ & $\begin{array}{l}\text { Área Superficial } \\
\left(\mathrm{m}^{2} / \mathrm{g}\right)\end{array}$ \\
\hline ZM1 & 2,51 & 69,3 \\
ZM2 & 2,54 & 53,4 \\
ZM3 & 2,44 & 86,4 \\
ZM4 & 2,41 & 81,2 \\
ZM5 & 2,42 & 90,7 \\
Z1 & 2,36 & 131,5 \\
\hline
\end{tabular}


APÊEDICE B - Capacidade de Troca Catiônica (CTC) das Zeólitas sintetizadas a partir de cinzas de carvão

\begin{tabular}{ll}
\hline Zeólita & $\begin{array}{l}\text { CTC } \\
(\mathrm{meq} / 100 \mathrm{~g})\end{array}$ \\
\hline ZM5 & 156,0 \\
Z1 & 152,2 \\
\hline
\end{tabular}


APÊEDICE C - Microfotografias das Zeólitas sintetizadas a partir de cinzas de carvão por Microscopia Eletrônica de Varredura:

(a) ZM5; (b) Z1.

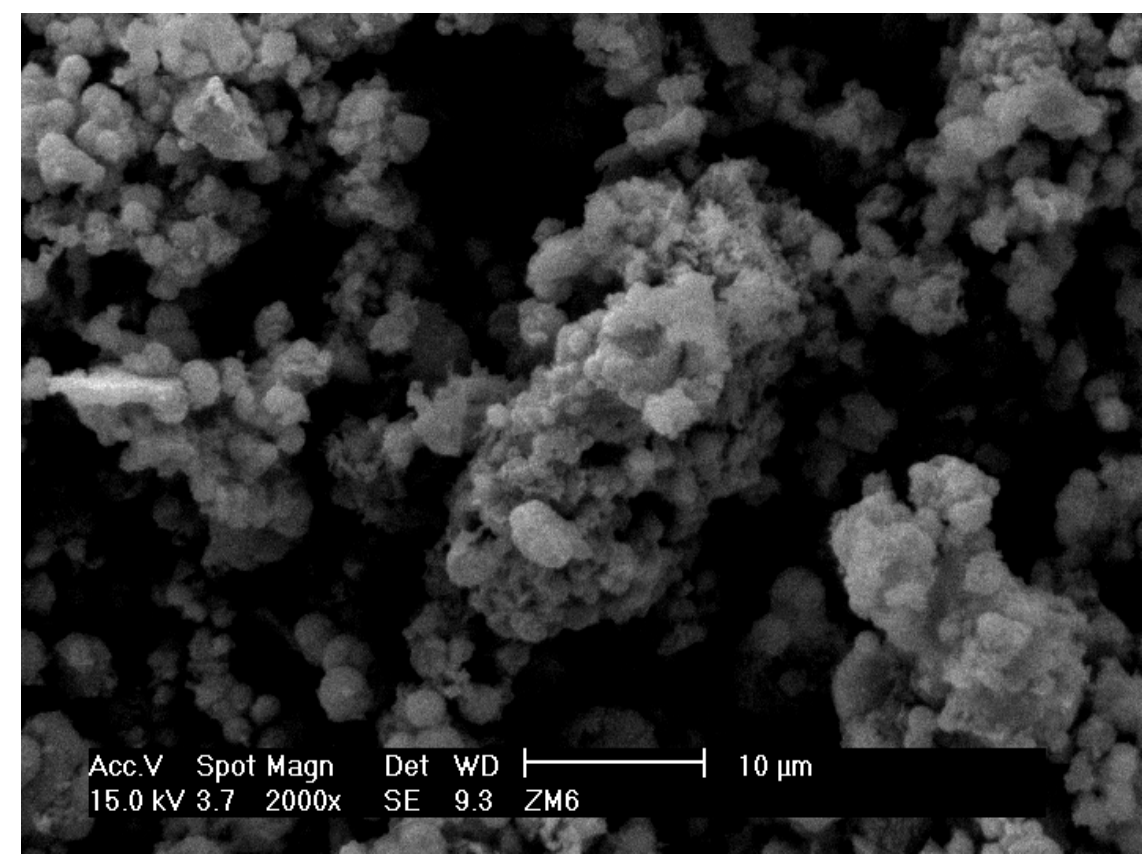

(a)

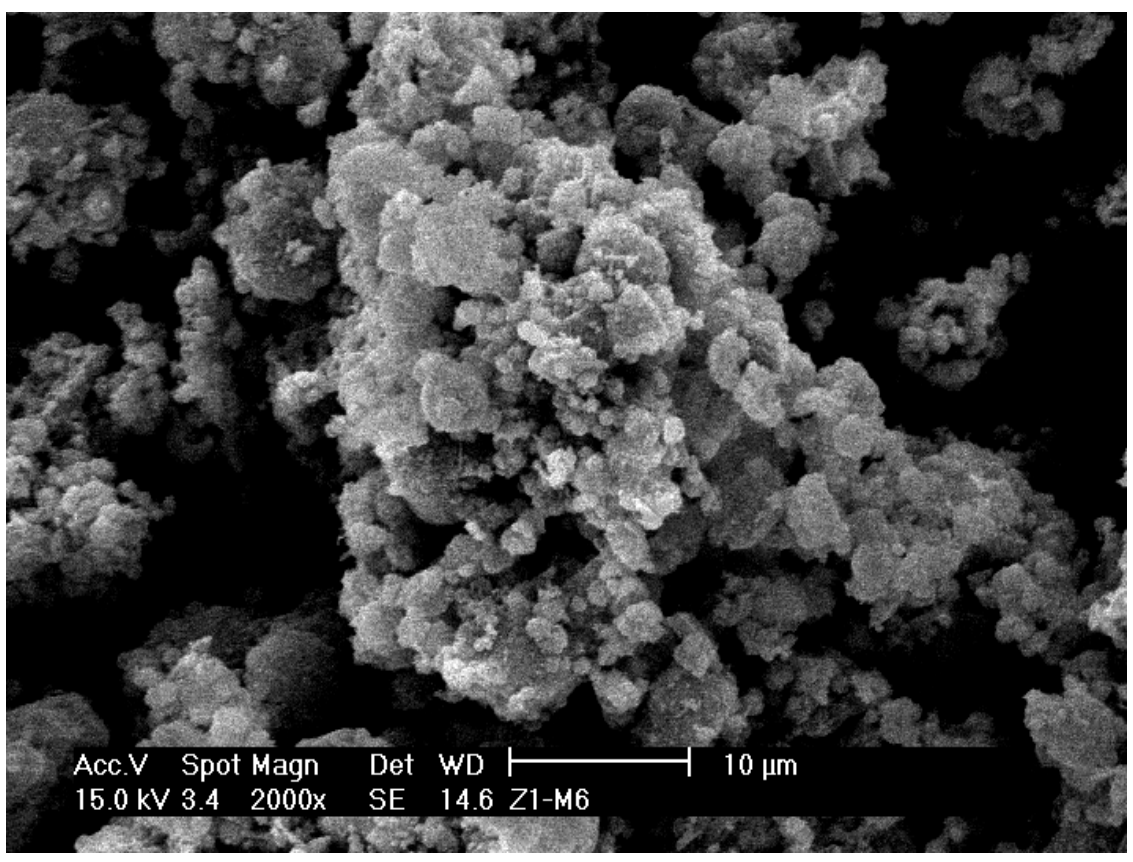

(b) 
APÊEDICE D - Difratogramas das Zeólitas sintetizadas a partir de cinzas de carvão:

(a) ZM5; (b) Z1. Q = Quartzo; $M$ = Mulita; $\mathbf{H}=$ hidroxisodalita; $\mathbf{P}=$ Na-P1.

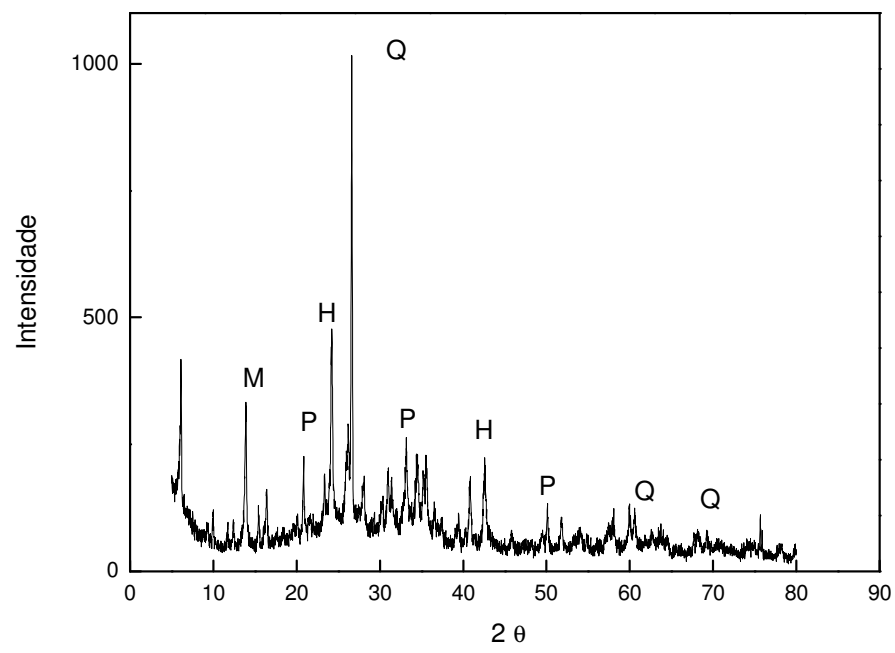

(a)

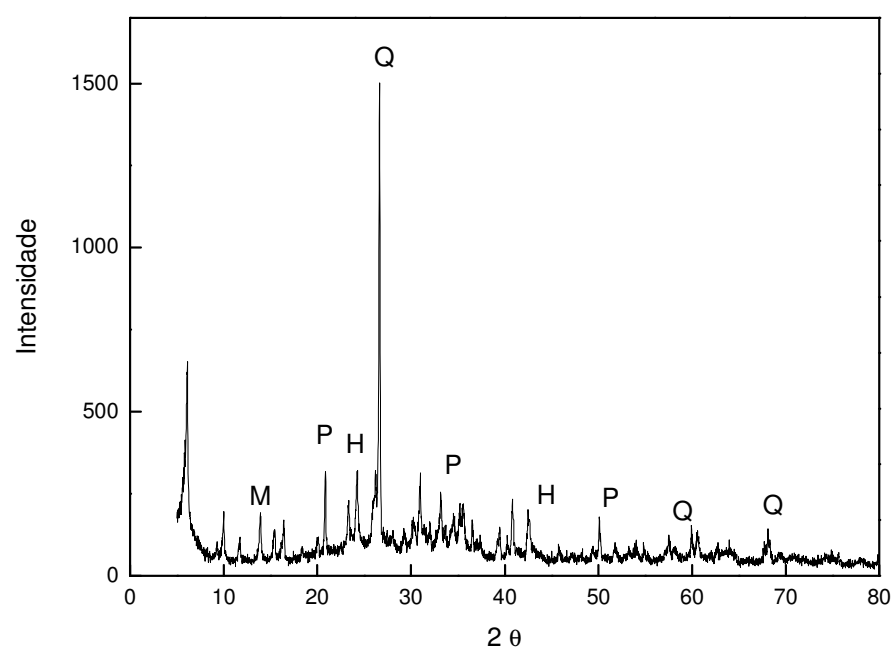

(b) 


\section{REFERÊNCIAS BIBLIOGRÁFICAS}

ACÂNTORA, M.R.; DALTIN, D. A química do processo têxtil. Química Nova, v. 19, n.3, p. 320-330, 1996.

ADRIANO, D.C.; PAGE, A.L.; ELSEEWI, A.A.; CHANG, A.C.; STRAUGHAN, I. Utilization and disposal of fly ash and other coal residues in terrestrial ecosystems: a review. J. Environm. Qual., v. 9, n. 3, p. 333 - 334, 1980.

ALLEN, S.J.; MCKAY, G.; KHADER, K.Y.H. Intraparticle diffusion of a basic dye during adsorption onto sphagnum peat. Environ. Pollut., v.56, p. 39-50, 1989.

AMRHEIN, C.; HAGHNIA, G.H.; KIM, T.S.; MOSHER, P.A.; GAGAJENA, R.C.; AMANIOS, T.; TORRE, L. Synthesis and properties of zeolites from coal fly ash. Environm. Sci. Technol., v. 30, n. 3, p. 735 - 742, 1996.

ATKINS, P. Physical Chemistry, Oxford University Press, Oxford UK, 1970.

AYGUN, A.; YENISOY-KARAKAS, S.; DUMAN, I. Production of granular activated carbon from fruit stones and nutshells and evaluation of their physical, chemical and adsorption properties. Microp. Mesop. Mater., v. 66, p. 189-195, 2003.

BANAT, M.I; NIGAM, P.; SINGH, D.; MARCHANT, R. Microbial decolorization of textile-dye-containing effluents: a review. Bioresour. Technol., n. 58, p. 217-227, 1996.

BANG-SUP, S.; SUNG-HO, L.; NAM-PYO, K. Preparation of zeolitic adsorbent from waste coal fly ash. J. Chem. Eng., v. 12, p. 352 - 356. 1995.

BARRER, R.M. Hydrotermal Chemistry of Zeolites. London: Academic Press, p. 260, 1982.

BERTAZZOLI, R.; PELEGRINI, R. Descoloração e degradação de poluentes orgânicos em soluções aquosas através do processo fotoeletroquímico. Quim. Nova, v. 25, n. 3 p. 477- 482, 2002.

BRECK, D.W. Zeolite Molecular Sieve; JOHN WILEY \& SONS: New York, 1984.

CALARGE, L.M.; SILVA, N.I.W.; CHIES, F.; ZWOSNOK, O. Desenvolvimento de tijolos maciços a partir de cinzas pesadas e cal hidratada. I- Caracterização da cinza pesada. In: FRANKENBERG, C.L.C., RAYA-RODRIGUES, M.T., CANTELLI, M. (Org.). Gerenciamento de Resíduos Sólidos e Certificação Ambiental. Porto Alegre, EDIPUCRS, v. 1, p. 130 - 139, Porto Alegre, 2000. 
CARNEIRO, P.A.; OSUGI, M.E.; SENE, J.J.; ANDERSON, M.A.; ZANONI, M.V.B. Evaluation of color removal and degradation of reactive textile azo dye on nanoporous $\mathrm{TiO}_{2}$ thin-film electrodes. Eletrochim. Acta, v. 49, p. 3807-3820, 2004.

CHIES, F.; SILVA, N.I.W.; ZWONOK, O. Desenvolvimento de blocos e tijolos a partir de cinzas de fundo de carvão - CIPECAL. Inl; ROCHA, J.C.; JOHN, U.M. Utilização de Resíduos na Construção Habitacional, p. 218 - 239, Porto Alegre, 2003. (Coleção Habitare, v.4).

CONCHON, J.A. Tratamento de efluentes na indústria têxtil. Base Têxtil, v. 1233, p. 1, 1999.

COOPER, P. Removing colour from dyehouse wastewaters - A critcal review of technology available. J. Soc. Dyers Col., MPG Information Division, v. 109, p. 97 - 100, 1993.

CRANK, J. The mathematics of diffusion. Clarendon, Oxford, 1956.

CZURDA, K.A.; HAUS, R. Reactive barriers with fly ash zeolites for in situ groundwater remediation. Appl. Clav. Sci.,v. 21, p. 13 - 20, 2002.

D. KAVITHA; C. NAMASIVAYAM. Experimental and kinetic studies on methylene blue adsorption by coir pith carbon. Biores. Technol., v. 98, p. 14-21, 2007.

DALLAGO, R.M.; SMANIOTTO, A. Resíduos Sólidos de curtumes como adsorventes para remoção de corantes em meio aquoso. Quím. Nova, v. 28/3, p. 433-437, 2005.

DAVIS, G.M.; KOON, J.H.; ADAMS, C.E. Treatment of two textile dye house wastewaters. Proc. $37^{\text {th }}$. Industrial Waste Conference. Purdue University, West afayette, Ind., p. 981-997, 1982.

DEER, W.A.; HOWIE, R.A.; ZUSMAN, J. Minerais constituintes das rochas: uma introdução, Fundação Calouste Gulbenkian: Lisboa, 1966.

DEJOHN, P.B.; HUTCHINS, R.A. Treatment of dye wastes with granular activated carbon. AATCC Book of Paper. National Technical Conference, p. 327, 1975.

EL-MOGAZI, D.; LISK, D.J.; WEINSTEIN, L.H. A review of physical, chemical and biological properties of fly ash and effects on agricultural ecosystems. The Sci. Total Environ., v. 74, p. 1 - 37, 1998.

FAUST, S.D.; ALY, O.M. Adsorption Process for Water Treatment, Butterworths, Boston, London, Wellington, p.16-18, 1987.

FERRET, L.S. Zeólitas de Cinzas de Carvão Síntese e Uso. F. 138. Tese para obtenção do título de Doutor em Engenharia. Programa de Pós-Graduação em Engenharia de Minas, Metalúrgica e de Materiais. Universidade Federal do Rio Grande do Sul, Porto Alegre, 2004. 
FUNGARO, D.A. Aplicação de material zeolítico preparado com cinzas de carvão no tratamento de águas contaminadas. Meio Filtrante, ano III - n. 9, p. 12 -13, Abril/Maio/Junho, 2004.

FUNGARO, D.A. Tratamento de drenagem ácida de mina usando zeólitas sintetizadas a partir de cinzas de carvão. Meio Filtrante, ano IV - n. 18, p. 5 - 19, Janeiro/Fevereiro, 2006.

Disponível em: < http://www.meiofiltrante.com.br $>$

FUNGARO, D.A.; FLUES, M.S.M.; CELEBRONI, A.P. Estabilização de solo contaminado com zinco usando zeólitas sintetizadas a partir de cinzas de carvão. Quím. Nova, v. 27, p. $582-585,2004$.

FUNGARO, D.A.; IZIDORO, J.C.; ALMEIDA, R.S. Remoção de compostos tóxicos de solução aquosa por adsorção com zeólita sintetizada a partir de cinzas de carvão. $\boldsymbol{E} \boldsymbol{c l}$. Quím, v. 30, p. 1-8, 2005.

FUNGARO, D.A.; IZIDORO, J.C. Estudo da remoção de íons metálicos em água tilizando zeólitas sintetizadas com cinzas de carvão. Tchê Quím., v.3, p. 21 - 30, 2006.

FUNGARO, D.A; IZIDORO, J.C. Remediação de drenagem ácida de mina usando zeólitas sintetizadas a partir de cinzas leves de carvão. Quím. Nova, v.29, p. 735-740, 2006.

FUNGARO, D.A., SILVA, M.G. Utilização de zeólita preparada a partir de cinza residuária de carvão como adsorvedor de metais em água. Quím. Nova, v. 25, p. 1081 1085, 2002.

GHOSK, D.; BHATTACHARYYA, K.G. Adsorption of methylene blue on kaolinite. Appl. Clay Sci., v. 20, p. 295-300, 2002.

GIANNETO, G. Zeólitas, características, propriedades y aplicaciones industriales. EdiT Ediciones Innovación Tecnológica: Caracas. 1990.

GILES, C.H.; MACEWAN, T.H.; NAKHUA, S.N.; SMITH, D. Studies in adsorption,11. A system of classification of solution adsorption isotherms, and its use in diagnosis of adsorption mechanisms and in measumrement of specific surface areas of solids. J. Chem. Soc. London, p. 3973-3993, 1960.

GRAU, P. Textile industry wastewaters treatment. Water Sci.Technol., v. 24, p. 97-103, 1991.

GUARATINI, C.C.I.; ZANONI, M.V. Corantes têxteis. Quím. Nova, v. 23, p. 71-78, São Paulo, 2000.

GUPTA, V.K.; MOHAN, D.; SHARMA, S.; SHARMA, M. Removal of basic dyes (rhodamine B and methylene blue) from aqueous solutions using bagasse fly ash. Sep. Sci. Technol. v. 35, p. 2097-2113, 2000. 
HALL, K.R.; EAGLETON, L.C.; ACRIVOS, A.; VERMEULEN, T. Pore and soliddiffusion kinetics in fixed-bed adsorption under constant-pattern. Ind. Eng. Chem

Fundam., v. 5, p. 212-219, 1966.

HALL, M.; LIVINGSTON, W.R. Fly ash: quality, past, present and future and the effect of ash on the development of novel products. J. Chem. Technol. Biotechnol., v. 77, p. 234 $239,2002$.

HANG, H.L.; SHIH, W.H. HAConversion of fly ash to zeolites for waste treatment. Ceram. Trans., v. 61, p. $81-88,1995$.

HELBY, W.A. Adsorption isotherm studies. Chem. Eng., v. 59, p. 153-158, 1952. HENMI, T. Synthesis of hydroxi-sodalite ("zeolite") from waste coal ash. Soil Sci. Plant Nutr., v. 33, p. $517-521,1987$.

HO, Y.S.; MCKAY, G. The kinetics of sorption of basic dyes from aqueous solution by sphagnum moss peat. Can. J. Chem. Eng., v. 76, n.4, p. 827,1998a.

HO, Y.S.; MCKAY, G. A comparision of chemissorption kinetic models applied to pollutant removal on various sorbents. Trans IChemE, v. 76, p. 332-340, 1998 b.

HO, Y.S.; MCKAY, G. Sorption of dye from aqueous solution by peat. Chem. Eng. J., v 70, p. 115-124, 1998c.

HO, Y.S.; MCKAY, G. Pseudo second-order model for sorption process. Process Biochemical, v. 34, p. 451-465, 1999.

HO, Y.S; WASE, D.A.J.; FORSTER, C.F. Kinetic studies of competitive heavy metal adsorption by sphagnum moss peat. Environm.Technol., v. 17, p.71-77,1996.

HÖHN, W. Nuevos desarrolos para la depuración / decoloración del água residual. Revista Têxtil, São Paulo: R. da Silva Haydu e Cia. Ltda., v. 5, p. 107-109, 1997.

HOLLER, H.; WIRCHING, G.U. Zeolite formation from fly ash. Fortschr. Mineral, v. 63, p. $21-43.1985$.

HOUK, V.S. The genotoxicity of industrial-wastes and effluents. Mutation Research, v. 277, n. 2 p.91-138, 1992.

JANOS, P.; BUCHTOVÁ, H.; RÝZNAROVÁ, M. Sorption of dyes from aqueous solutions onto fly ash. Water Res., v.37, p. 4938-4944, 2003.

JIDA, H.; ENDO, M. Clarification of wastewater containing dyes. III Preciptation of direct dyes and acid dyes by iron salts. J. Appl. Polymer Chem. Abstr., p. 333, 1968.

KAMEL, M.M.; MAGDA, M.K.; YOUSEEF, B.M.; WALY, A. Adsorption for direct dyes by cellulose derivates. American Dyestuff Reporter, v. 80, p. 34-48, 1991. 
KHAN A. R.; TAHIR, H.; UDDIN, F.; HAMMEED, U. Adsorption of methylene blue from aqueous solutions on the surface of wool fiber and cotton fiber. J. Appl. Sci. Environ. Mgt., v. 9, p. 29-35, 2005.

KAPDAN, I.K.; KARGI, F.; MCMULLANN, G.; MARCHANT, R. The biological decolorization of textile dyestuff by coriolus versicolor in a packed column react. nviron. Technol., v. 21, n.2, p.231- 236, 2000.

KARACA, S.; GÜRSCS, A.; BAYRAK, R. Effect of some pre-treatments on the adsorption of methylene blue by Balkaya lignite. Energy Convers. Manag., v.. 45, p. 1693-1704, 2004.

KHRAISHEH, M.A.M.; AL-DEGS, Y.S.; ALLEN, S.J.; AHMAD, M.N. Elucidation of controlling steps of reactive dye adsorption on actived carbon. Ind. Eng. Chem. Res., v. 41, p. 1651 - 1657, 1996.

KLANCNIK, M.; GORENSEK, M. Kinetics of hydrolysis of monofunctional and bifunctional Monochloro-s-triazine reactive dyes. Dyes Pigm., v. 33, p. 337-350, 1997.

KNAPP, J.S.; ZHANG, F.M.; TAPLEY, K.N. Decolourisation of orange II by a woodrotting fungus. J. Chem. Technol. Biotechnol., v.69, n.3, p. 289-296, 1997.

KOLOUSEK, D.; SEIDL, V.; PROCHAZKOVA, E.; OBSASNIKOVA, J.; KUBELKOVA, L.; SVETLIK, I. Ecological utilization of power-plant fly ashes by heir alteration to phillipsite: htdrotermal alteration, application. Acta Univ. Carol. Geol., v. 37, p. $167-178,1993$.

KHRAISHEH, M.A.M.; AL-DEGS, Y.S.; ALLEN, S.J.; AHMAD, M.N. Elucidation of controlling steps of reactive dye adsorption on actived carbon. Ind. Eng. Chem. Res., v. 41, p. $1651-1657,1996$.

KUMAR, K.V. Adsorption isotherms for basic dye onto low cost adsorbents. Res. $\boldsymbol{J}$. Chem. Environ., v. 6(4), p. 61-65, 2002.

KUMAR, K.V.; RAMARMURTHI, V.; SIVANESAN, S. Modeling the mechanism involved during the sorption of methylene blue onto fly ash. J. Colloid Interf. Sci, v. 284, p. 14-21, 2004.

KUNZ, A.; PERALTA-ZAMORA, P.; MORAES, S.G.; DURÄN, N. Novas tendências no tratamento de efluentes. Química Nova, v.25, n.1, pg. 78-82, São Paulo, 2002.

LAGERGREN, S. Zur theorie dersogenannten adsorption geloster stoffe. Kungl. Svenska Vetenskapsakad. Handl.,vol 24, p 1-39, 1898.

LI, L.; WANG, S.; ZHU, Z.H. Geopolymeric adsorbents from fly ash for dye removal from aqueous solution. J. Colloid Interface Sci., v. 300, p. 52-59, 2006.

LIN, C.F.; HSI, H.C. Resource recovery of waste fly ash:synthesis of zeolite-like materials. Environ. Sci. Technol., v.29, p. 1109-1117, 1995. 
LIN, S.H.; CHEN, A.L. Treatment of textile wastewater by chemical methods for reuse. Water Res., v. 31, P. 868-876, 1997.

LUZ, A.B. Zeólitas: propriedades e usos industriais. Rio de Janeiro: CETEM; CNPq, 1994, p. 37, il. (Tecnologia Mineral, 68).

MAGHAMI, G.G.; ROBERTS. G.A.F. Studies on the adsorption of anionic dyes on chitosan. Makrom. Chem., v. 189, p. 2239-2243, 1998.

MATTIGOD, S.V.; RAI, D.; EARY, L.E.; AINSWORTH, C.C. Geochemical factors controlling the mobilization of inorganic constituents from fossil fuel combustion residues I. Review of the major elements. J. Environ. Qual., v. 19, p. 188 - 201, 1990.

MCCABE, W.L.; SMITH, J.C.; HARRIOT, P. Units operations of chemical engineering. Editora McGraw Hill, 5a. ed., p. 810-821, 1993.

MCKAY, G.; ALEXANDER, F. Kinetics of the removal of basic dyes from effluent using sílica. The Chem. Engin., v. 15, p. 243 - 244, 1977.

MCKAY, G.; OTTERBURN, M.S.; SWEENEY, A.G. The removal of colour from effluent using various adsorbents - IV silica equilibria and column studies. Water Res., v. 14, p. 21-26, 1980.

MINISTÉRIO DO MEIO AMBIENTE. Conselho Nacional do Meio Ambiente, Resolução CONAMA N 357 de 17 de Março de 2005, artigo 34, <http://www.mma.gov.br/port/conama/res/res05/res35705.pdf>. Acesso em: 16 jan. 2007.

MISHIRA, G.; TRIPATHY, M.A. Critical rew of the treatments for decolourization of textile effluent. Colourage, p. 35-38, 1993.

MONDRAGON. F.; RINCON, F.;SIERRA, L.; ESCOBARA, J.; RAMIREZ J.;

FERNANDEZ, J. New perspectives for coal ash utilization: system of zeolitic materials. Fuel, v. 69, p. 263 - 266, 1990.

MORAN, C. Reducing the toxicity of textile effluent. J. Soc. Dyers Color., Information Division MPG, v. 114, p. 117-118, 1998, April.

MORAES, S.G.; FREIRE, R.S.; DURAN, N. Degradation and toxicity reduction of textile efflent by combined photocatalytic and ozonation processes. Chemosphere, v.40, p.369$373,2000$.

MORENO, N.; QUEROL, X.; AYORA, C.; FERNÁNDEZ-PEREIRA, C.; JANSSENJURKOVICOVÁ, M. Utilization of zeolites synthetized from coal fly ash for the purification of acid mine waters. Environ. Sci. Technol., v. 35a, p. 3526 - 3534, 2001.

MORENO, N.; QUEROL, X.; AYORA, C.; ALASTUEY, A.; FERNÁNDEZ-PEREIRA, C.; JANSSEN-JURTOKICOVÁ,M. Potential environmental application of pure zeolitic material synthetized from fly ash. J.Environ. Technol., v. 127, p. $994-1002$, 2001 b. 
MOUHTARIS, T.H.; CHARISTOS, D.; KINTIRANIS, N.; FILIPPIDS, A.; KASSOLIFOURNARAKI, A.; TSIRAMBIDIS, A.; Gys-type zeolite form Greek lignite sulphocalcic fly ashes promoted by $\mathrm{NaOH}$ solutions. Microp. Mes. Mat., v. 61, p. 57, 2003.

MURAYAMA, N.; YAMAMOTO, H.; SHIBATA, J. Mechanism of zeolite from coal fly ash by alkali hydrotermal reaction. Int. J. Miner. Process, v. 64, p. 1 -17, 2002.

NAM, S.; RENGANATHAN, V.; TRATNYEK, P.G. Substituent effects on azo dye oxidation by the Fe III-EDTA- $\mathrm{H}_{2} \mathrm{O}_{2}$. Chemosphere, v. 45, p. 59-65, 2001.

NAMASIVAYAN C; YAMUNA, R.T. Utilizing biogas residual slurry for dye adsorption. Am. Dyestuff Rep., v. 83, p. 22-28, 1994.

NAMASIVAYAM, C.; MUNIASAMI, N.; GAYATRI, K.; RANI, M.;

RANGANNATHAN, K. Removal of dyes from aqueous-solutions by cellulosic waste orange peel. Bioresour. Technol., v. 57, p. 37-43, 1996.

NASSAR, M.M.; EL-GUENDI, M. Comparative cost of colour removal from textile effluents using natural adsorbents. J. Chem. Technol. Biotechnol., v. 41A, p. 50, 1991.

NUNES, J.A. Processos unitários de tratamento físico-químico. In: Tratamento físicoquímico de efluentes industriais. Gráfica Editora J. Andrade, Aracajú, 1993.

PAGE, A.L.; ELSEEWI, A.A.; STRAUGHAN, I.R. Physical and chemical properties of fly ash from coal-fired power plants with reference to environmental impacts. Res. Rev., v. 71, p. 83-120, 1979.

PAGGA, U.; BROWN, D. The degradation of dyestuffs. Part II Behavior of dyestuffs in aerobic biodegradation test. Chemosphere, v.15, p. 479-491, 1986.

PAGE, A.L.; ELSEEWI, A.A.; STRAUGHAN, I.R. Physical and chemical properties of fly ash from coal-fired power plants with reference to environmental impacts. RES. Rev.; v. 71, p. 82-120, 1979.

PARK, M.; CHOL, J. Synthesis of philipsite from fly ash. Clay Sci., v. 9, p. 219 - 229, 1995.

PERKINS, W.S. Making textiles a little "greener". American Textiles International, Atlanta: Billian Publishing. Inc. 27(4), p. 62-64, 1998.

PERRICH, J.R. Actived carbon adsorption for waste water Treatment. CRC Press, Boca Raton, FL, 1981.

POOTS, V.J.P.; MCKAY, G.; HEAL, J.J. The removal of acid dye form effluent using natural adsorbents. Water Res., v. 10, p. 1061-1066, 1976.

PORTER, J.J.; SNIDER, E.I. Long-term biodegradability if textile chemicals. J. Water Poll. Control Fed., v. 48, p. 2198-2210, 1976. 
QUERALT, X.; QUEROL, X.; LÓPEZ-SOLER ; PLANA, F.; Use of coal fly ash Use of coal fly ash for ceramics: a case study for a large Spanish power station. Fuel, v. 76, p. $787-791,1997$.

QUEROL, X. UMAÑA, J.C.; PLANA, F.; ALASTUEY, A.; LÓPEZ-SOLER, A.; MEDINACELI, A.; VALERO, A.; DOMINGO, M.J.; GARCIA-ROJO, E. Synthesis of zeolites from fly ash at pilot plant scale. Examples of potential applications. Fuel, v. 80, p. $857-865,2001$.

ROBINSON, T.; MCMULLAN, G.; MARCHANT, R.; NIGAM, P. Remediation of dyes in textile effluent: a critical review on current treatment technologies with a proposed alternative. Biores. Technol., v. 77, p. 247-255, 2001.

ROCK, S.L.; STEVENS, B.W. Polymeric adsorption-ion exchange process for decolourization dye waste streams. Textile Chemist and Colorist, v. 9, p. 169-171, 1975.

RORRER, G.L.; HSIEN, T.Y. Synthesis of porous=magnetic chitosan beads for removal of cadmium ions from wastewater. American Chemical Science - Ind. Engin.Chem. Resid., v. 32, p. 2170 - 2178, 1993.SANGHI, R.; BHATTACHARYA, B. Review on decolorization of aqueous dye solutions by low cost adsorbents. Color Technol., v. 116, p. 256, 2002.

SCOTT, J.; GUANG, D.; NAERAMITMARNSUK, K.,THABUOT, M. Zeolite synthesis from coal fly ash for the removal of lead ions from aqueous solution. J. Chem. Technol. Biotechnol., v.77, p. 63-69, 2001.

SHARMA, A.; BHATTACHARYYA, K.G.; Utilization of biosorbent based on Azadirachta indica (Neem) leaves for removal of water-soluble dyes. Indian J. Chem. Technol., v. 12, p.285-295, 2005.

SHAW, D.J. Introdução à química dos colóides e de superfície. Ed. Edgard Blücher, p. 200, 1975.

SHIGEMOTO, N.; SHIRAKAMI, K.; HIRANO, S.; HAYASHI, H. Preparation and characterization of zeolites from coal ash. Nippon Kagaku Kaishi, v. 5, p. 484 - 492, 1992.

SHIGEMOTO, N.; HAYASHI, H.; MIYUARA, K. Selective formation of Na-X zeolita from coal fly ash by fusion with hydroxide prior to hydrothermal reaction. J. Mater. Sci., p. $4781-4786,1993$.

SHIGEMOTO, N.; SUGIYAMA, S.; HAYASHI, H. Characterization of Na-X, Na-A and coal fly ash zeolites and their amorphous precursors by IR, MAS NMR and XPS. J. Mater. Sci., v. 30, p. $5777-5783,1995$.

SHUKLA, A.; ZHANG, Y.H.; DUBEY, P.; MARGRAVE, J.L.; SHUKLA, S.S. The Role of Saw Dusti in the Removal of Unwanted Materials from Water. J. Hazard. Mater., v. B 95, p.137-152, 2002. 
SILVA, N.I.W.; CALARGE, L.M.; CHIES, F.; MALLMAN, J.E.; ZWONOK, O. Caracterização de cinzas volantes para aproveitamento cerâmico. Cerâmica., v. 45, p. 184 - 187, 1999.

SINGER, A.; BERKGAUT, V. Cation exchange properties of hydrotermally treated coal fly ash. Environ. Sci. Technol., v. 29, p. 1748 - 1753, 1995.

SINGER, P.C.; LITTLE, L.W. Characterization and treatment of textile dyeing wastewaters. J. Water Pollut. Control. Fed, v. 47, p. 10, 1975.

SINGH, B.; ALLOWAY, B.J.; BOCHERAU, J.M. Cadmium sorption behavior of natural and synthetic zeolites.Commun Soil Sci. Plant Anal. v. 31, p. 2775.

SMITH, B.; KOONCE, T.; HUDSON, S. Decolorizing dye wastewater using chitosan. American Dyest Report, v. 82/10, p. 18-36, 1003.

SUN, G.; XIANGJING, X.U. Sunflower stalks as adsorbents for color removal from textile wastewater. Ind. Eng. Res., v. 36, p. 808-812, 1997.

THOMAS, W.J.; CRITTENDEN, B. Adsorption technology and design. Reed Educational and Professional Publishing. Oxford, p. 27, 32 e 68, 1998.

TROTMAN, E.R. Dyeing and chemical technology of textile fibres. Charles Friffin \& Company Ltda., 5 ed., 1975.

TÜNAY, O.; KABDASLI, I.; EREMAKTAR, G.; ORHON, D. Colour removal from textile wastewaters. Water Sc. Technol., v. 34, p. 9-16, 1996.

UMAÑA, J.C.P. Síntesis de zeolitas a partir de cenizas volantes de centrales termoelétricas de carbón. Tese (Doutorado) Universitat Politécnica de Catalunya. Catalunha, 2002.

VADIVELAN, V.; KUMAR, K. V. Equilibrium, kinetics, mechanism and process design for the sorption of methylene blue onto rice husk. J. Colloid Interface Sci., v. 286, p. 90$100,2005$.

VARSHNEY, K.G.; KHAN, A.A.; GUPTA, U.; MAHESHWARI, S.M. Kinetics of adsorption of phosphamidon on antimony (V) phosphate cation exchanger: evaluation of the order of reaction and some physical parameters. Colloids and Surfaces: A

Physicochem. Engin. Aspects, v. 133, n. 1-2, p. 19, 1996.

VASSILEV, S.V.; MENENDEZ, R.; ALVAREZ, D.; BORREGO, A.G.. Multicomponent utilization of fly ash: dream or reality. In: INTERNATIONAL ASH UTILIZATION SYMPOSIUM, 4, Lexington, Kentucky, USA, 2001. Proceedings . University of Kentucky, p. 216 - 234, 2001.

WANG, H.; HANG, Q.; SONG, C.; LIU, F. Synthesis of zeolites by alkaline activation of fly ash. J. University Sci. Technol. Beijing, vol. 8, p.161-163, 2001.

WANG, S.; BOYJOO, Y.; CHOUEIB, A.; ZHU, Z.H. Removal of dyes from aqueous solution using fly ash and red mud. Water Res., v. 39, p. 129-138, 2005. 
WANG, S.; LI, H.; XIE, S.; LIU, S.; XU, L. Physical and chemical regeneration of zeolite adsorbents for dye removal in wastewater treatmnent. Chemosphere, v. 65, p. 82 -87, 2006b.

WANG, S.; LIN, L.; WU, H.; ZHU, Z.ZH. Unburned carbon as a low-cost adsorbent for treatment of methylene blue-containing wastewater. J. Col. Interf. Sci., v. 292, p. 336-343, 2005 .

WANG, S.; LI, H.; XU, L. Application of zeolite MCM-22 for basic dye removal from wastewater. J. Colloid Interf. Sci., v. 295, p. 71-78, 2006.

WANG, S.; SOUDI, M.; LI, L.; ZHU, Z.H. Coal ash conversion into effective adsorbents for removal of heavy metals and dyes from wastewater. J. Hazard Mater., v. B133, p. 243$251,2006$.

WANG, Y.; GUO, Y.; YANG, Z.; CAI, H.; QUEROL, X. Synthesis of zeolites using fly ash and their application in removing heavy metals from waters. Sci. in China, vol. 46, p. 967-976, 2003.

WEBER, E.J.; STICKNEY, V.C. Hydrolisis kinetics of reactive blue 19-vinyl sulfone. Water Res., v. 27, p. 63-67, 1993.

WEBER, W.J. Physiochemical process for water quality control. 2a. ed. Wiley, New York, 1972.

WEBER, W.J.; MORRIS, J.C. Kinetics of adsorption carbon from solutions. J. Sanit. Eng. Div. AM. Soc. Civ. Eng., v. 89, p. 31 - 60, 1963.

WOOLARD, C.D.; STRONG, J.; ERASMUS, C.R. Evaluation of the use of modified coal ash as a potential sorbent for organic waste streams. Appl. Geochem., v. 17, p. 1159-1164, 2002 .

YENISOY-KARAKAS; S. AYGUN, A.; GÜNES, M. TAHTASAKAL, E. Physical and chemical characteristics of polymer-based spherical activated carbon and its ability to adsorb organics. Carbon, v. 42, p. 477-484, 2004.

YU, L.J.; SHUKLA, S.S.; DORRIS, K.L.; SHUKLA, A.; MARGRAVE, J.L. Adsorption of Chromium from Aqueous Solutions by Maple Sawdust. J. Hazard. Mater., v. B100, p.3-63, 2003.

ZANONI, M.V.; CARNEIRO, P.A. O descarte dos corantes têxteis. Ciênc. Hoje, v. 29, p. 61-64, 2001.

ZENG, R.; UMANA. J.C.; QUEROL, X.; LOPEZ-SOLER, A.; PLANA, F.; ZHUANG, X. Zeolite synthesis from a high Si-Al fly ash from East China. J. Chem. Technol. Biotechnol, vol. 77, p. 267-273, 2002.

ZOOLINGER, H. Color Chemistry: Syntheses, properties and applications of organic dyes and pigments. VHC Publishers, 2. ed., Inc., New York, 1991. 